\title{
Novel Analgesics with Peripheral Targets
}

\author{
Cosmin I. Ciotu ${ }^{1} \cdot$ Michael J. M. Fischer ${ }^{1}$ (D) \\ Accepted: 27 September 2020 / Published online: 15 October 2020 \\ (C) The Author(s) 2020
}

\begin{abstract}
A limited number of peripheral targets generate pain. Inflammatory mediators can sensitize these. The review addresses targets acting exclusively or predominantly on sensory neurons, mediators involved in inflammation targeting sensory neurons, and mediators involved in a more general inflammatory process, of which an analgesic effect secondary to an anti-inflammatory effect can be expected. Different approaches to address these systems are discussed, including scavenging proinflammatory mediators, applying anti-inflammatory mediators, and inhibiting proinflammatory or facilitating anti-inflammatory receptors. New approaches are contrasted to established ones; the current stage of progress is mentioned, in particular considering whether there is data from a molecular and cellular level, from animals, or from human trials, including an early stage after a market release. An overview of publication activity is presented, considering a IuPhar/BPS-curated list of targets with restriction to painrelated publications, which was also used to identify topics.
\end{abstract}

Key Words Inflammation · cytokine $\cdot$ pain $\cdot$ receptor $\cdot$ sensory neuron.

\section{Introduction}

Analgesia is a medically important issue, with a large body of primary and review literature. Therefore, this review starts with an outline of the aim and the approach to the topic. The scope is to discuss novel analgesic approaches [1-3], including all stages of preclinical evidence and, in particular, approaches in the clinical trial phase. Established pain medications are mentioned, where they serve to discuss concepts or serve as a benchmark for novel approaches. A concept figure illustrates a general view on peripheral nociception and analgesic approaches (Fig. 1). Within this framework, the review discusses bottom-up direct effects predominantly or exclusively on the neuron, then inflammatory mediators with at least partial action on sensory neurons. We accept that this

Invited review, issue theme: Aligning New Approaches to Accelerate the Development of Analgesic Therapies

Electronic supplementary material The online version of this article (https://doi.org/10.1007/s13311-020-00937-z.) contains supplementary material, which is available to authorized users.

Michael J. M. Fischer

michael.jm.fischer@meduniwien.ac.at

1 Center of Physiology and Pharmacology, Medical University of Vienna, Schwarzspanierstrasse 17, 1090 Vienna, Austria structure also has disadvantages. We have tried to avoid a splitting of ligands from their targets where possible, and also refer to other approaches to structure the topic $[4,5]$. For mechanisms which are in summary anti-inflammatory, analgesia can be expected as a collateral effect. The other targets include resident and migrating cells. Resident cells include mast cells, macrophages, neutrophils, and Schwann cells. For this more general immunomodulation and systemic anti-inflammation, the reader is referred to the respective literature [6, 7]. Within neuronal targets, there might be some imprecision due to findings from afferent ganglia, which contain other cell types than neurons and a more detailed allocation to the cell type is unknown. Antipruritic approaches have a considerable overlap with analgesia; therefore, a conceptually similar view can be found in the respective literature [8].

This review focuses on recently published approaches, but ways to identify new targets should also be mentioned [9]. For identifying published topics, Pubmed was queried utilizing the NCBI E-Utilities [10]. As search terms, "pain" and the potential targets in inverted commas were entered. For the latter, the "targets and family" list of the IuPhar/BPS database [11] was used. As a caveat, searches by human gene nomenclature (HGNC) name, rat genome database (RGD) name, or the respective short forms provide a different rate of false positives and negatives, so 


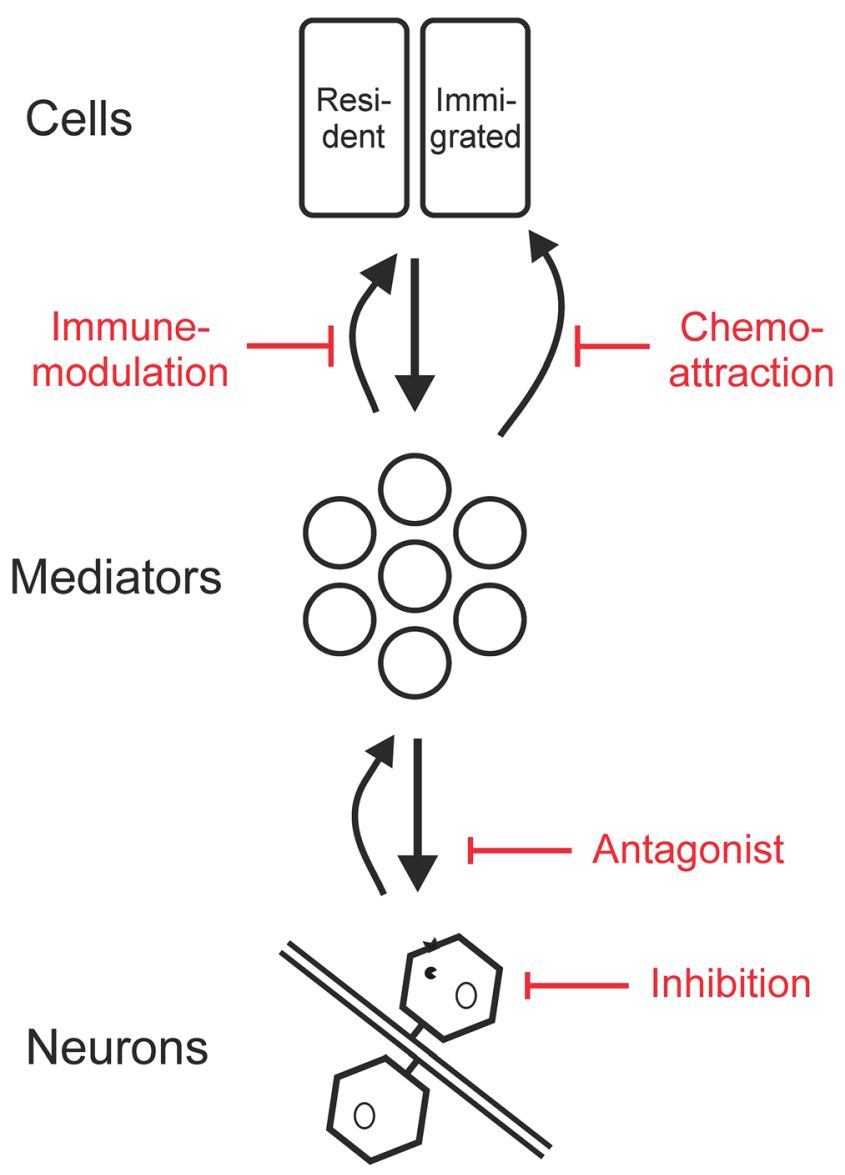

Fig. 1 Pathophysiological concept, also serving as outline for the review. Neuronal and non-neuronal cells were separated to provide a schematic for therapeutic approaches. These are discussed in the review, first considering direct inhibition of the neurons and then antagonizing mediators acting on neurons. For modulation of the immune response, separated in local modulation and chemoattraction as well as addressing systemic inflammation, the reader is referred to the reviews of the respective topic. In the neuron, a receptor and an enzyme are visualized as targets

the respective search term list required manual optimization. How to identify trends in these data? This can be addressed by complex strategies [12]; nevertheless, an easily comprehensible approach, considering rising publications per time, was preferred here. As suggested [13], a 3 -year interval was chosen. The search was conducted in April 2020. A comparison of the last 3 years in contrast to the prior 3 years provides a trend of a respective topic. Three indicators for the targets are presented (Fig. 2): a) Already "Large topics," assessed by the total number of publications, b) "Rising topics," calculated as publications within the last 3 years minus the 3 years before, and c) "Novel topics," considering only targets which have more than 10 publications within the last 3 years but no more than 10 publications in the 3 years before. The overall content is organized as outlined by Fig. 1, within this structure sorted by target type, e.g., GPCRs, ion channels, enzymes. Figure 2 was also used to pick topics.

\section{Effects Predominantly or Exclusively on Sensory Neurons}

\section{GPCRs in Sensory Neurons}

GPCRs form the largest receptor superfamily, with 1265 sequenced members in humans [14]. They play crucial roles in inflammation, with abundant expression in immune cells (regulating migration, accumulation at the inflammation site and phagocytosis), endothelial cells (regulating permeability), and nervous tissue, to name a few. As a brief reference to the above-mentioned inflammatory mediators and their GPCR targets, PAR1-4, S1P1, LPAR1-6, prostaglandin receptors, bradykinin receptors, and NK1 are among the most relevant families for inflammatory hyperalgesia. Ligands binding to these GPCRs modulate the three main signaling pathways of the G-alpha subunits Gi, Gs, and Gq, which have typical effects. For G-beta/gamma targets, the reader is referred to a review [15]. Gi couples inhibiting, Gs stimulating to adenylate cyclase, and prostaglandin and opioid receptor effects discussed below might be seen pro toto. Protein kinase A downstream of Gs has been shown to sensitize a variety of ion channels involved in nociception, similar to protein kinase C via Gq and Phospholipase C (PLC) [16]. Downstream of PLC, the intracellular signaling cascades diverge, and include protein kinase C (PKC) and calcium admission. Most of the inflammation pathways (leading to short-term hyperalgesia, in any case) converge onto these mechanisms.

\section{Opioid Receptors}

Opioids are an essential pillar of analgesic therapy. This will not change any time soon, opioid crisis or not, and a top spot in publications reflects that importance. Opioid analgesia in inflammation is the result of combined central and peripheral mechanisms $[17,18]$, and following the scope of this review, we briefly expand on the latter. Peripheral sensory neurons express the $\mu-, \delta-$, and $\mathrm{K}$-opioid receptors $[19,20]$. The opioid receptors are Gi-coupled and the downstream mechanisms apply to other Gi-coupled GRCRs on sensory neurons. Endogenous agonists met- and leu-enkephalin are broken down by neutral endopeptidase and aminopeptidase N. Single inhibition of these enzymes was not analgesic in humans [21]. On the other hand, inhibition of both enzymes has been successfully tested in animals [22], but only with intrathecal application in humans [23]. Progression of enkephalin inhibitors has been discussed [24], and there is sparse but ongoing development for analgesia [25]. Pharmacological intervention with opioids leads to analgesia via a reduction in neuronal excitability [26]. Thereby, opioid receptor activation also reduces neurogenic inflammation, e.g., by limiting calcitonin gene-related peptide (CGRP) and substance P release. In inflammatory conditions, opioid receptors are upregulated in 


$\begin{array}{lccc}\text { a } & \text { Total } & \text { Last 3y } & 3 \text { y earlier } \\ \text { TRPV1 } & 2695 & 612 & 564 \\ \text { COX-2 } & 2469 & 418 & 339 \\ \text { Mu opioid receptor } & 2022 & 391 & 371 \\ \text { Cysteine aminotransferase } & 1852 & 279 & 252 \\ \text { Mitogen-activated protein kinase } & 1418 & 240 & 345 \\ \text { CD4 } & 1286 & 238 & 212 \\ \text { Plasminogen } & 1183 & 87 & 88 \\ \text { Peptide transporter 4 } & 1112 & 149 & 230 \\ \text { Angiotensin-converting enzyme } & 1046 & 94 & 99 \\ \text { TRPA1 } & 999 & 299 & 260 \\ \text { Hydroxymethylglutaryl-CoA reductase } & 934 & 123 & 225 \\ \text { Kappa opioid receptor } & 724 & 105 & 109 \\ \text { COX-1 } & 678 & 77 & 75 \\ \text { Nav1.7 } & 669 & 218 & 184 \\ \text { Delta opioid receptor } & 634 & 95 & 86 \\ \text { Myeloperoxidase } & 597 & 114 & 146 \\ \text { P2X3 } & 488 & 88 & 92 \\ \text { Caspase 3 } & 479 & 158 & 130 \\ \text { Tyrosine kinase non receptor 1 } & 461 & 72 & 92 \\ \text { Nav1.8 } & 452 & 100 & 107 \\ \text { Tyrosine kinase non receptor 2 } & 415 & 70 & 84 \\ \text { TLR4 } & 414 & 167 & 119 \\ \text { Fatty acid amide hydrolase } & 383 & 76 & 75 \\ \text { TRPM8 } & 382 & 91 & 96 \\ \text { Renin } & 380 & 46 & 48 \\ \text { CYP2D6 } & 366 & 78 & 63 \\ \text { CB1 receptor } & 347 & 75 & 67 \\ \text { catalase } & 334 & 101 & 77 \\ \text { Protein kinase A } & 320 & 51 & 57 \\ \text { Catechol-O-methyltransferase } & 307 & 60 & 68 \\ & & & \end{array}$

b
COX-2
TRPV1
TLR4
TRPA1
NLRP3
Programmed cell death 1
Nav1.7
CGRP receptor
Caspase 3
MMP13
CD4
Caspase 1
Catalase
Mu opioid receptor
Fas
Acetylcholinesterase
Guanylyl cyclase-F
CYP2D6
Epidermal growth factor receptor
MMP3
TAO kinase 2
ADAMTS5
D1 receptor
Stat3
Solute carrier family 5 member 5
P2X4
CCR2
MMP9
Asparaginase
Aquaporin 4

\begin{tabular}{cccl} 
Total & Last 3y & 3y earlier & C \\
2469 & 418 & 339 & Programmed cell death 1 \\
2695 & 612 & 564 & TAO kinase 2 \\
414 & 167 & 119 & D1 receptor \\
999 & 299 & 260 & Asparaginase \\
148 & 75 & 38 & Cav3.1 \\
46 & 40 & 5 & PAC1 receptor \\
669 & 218 & 184 & ADAMTS13 \\
215 & 58 & 28 & ADAMTS4 \\
479 & 158 & 130 & SHP \\
97 & 51 & 24 & 5-HT1F receptor \\
1286 & 238 & 212 & CCR7 \\
98 & 45 & 19 & Nav1.1 \\
334 & 101 & 77 & Guanylyl cyclase-C \\
2022 & 391 & 371 & GlyT2 \\
223 & 56 & 36 & ABCG2 \\
228 & 50 & 32 & NRAS \\
150 & 35 & 19 & Leptin receptor \\
366 & 78 & 63 & TRPC6 \\
245 & 72 & 58 & Aryl hydrocarbon receptor \\
90 & 37 & 23 & Janus kinase 1 \\
44 & 19 & 5 & Piezo1 \\
54 & 26 & 13 & CD38 \\
55 & 20 & 8 & GluN1 \\
50 & 25 & 13 & RIO kinase 1 \\
16 & 7 & -4 & Cyclin dependent kinase 4 \\
211 & 58 & 47 & Cathepsin S \\
166 & 47 & 36 & Nav1.2 \\
115 & 45 & 34 & Kv1.2 \\
79 & 20 & 9 & Cav3.3 \\
65 & 29 & 16 & Tao kinase 3 \\
& & & \\
\hline 5
\end{tabular}

$\begin{array}{ccc}\text { Total } & \text { Last 3y } & 3 y \text { earlier } \\ 46 & 40 & 5 \\ 44 & 19 & 5 \\ 55 & 20 & 8 \\ 79 & 20 & 9 \\ 37 & 19 & 8 \\ 27 & 16 & 5 \\ 46 & 17 & 7 \\ 49 & 19 & 10 \\ 51 & 17 & 9 \\ 21 & 11 & 3 \\ 17 & 11 & 3 \\ 47 & 18 & 10 \\ 12 & 10 & 2 \\ 43 & 15 & 8 \\ 27 & 10 & 3 \\ 14 & 10 & 3 \\ 39 & 13 & 7 \\ 24 & 11 & 5 \\ 22 & 11 & 5 \\ 21 & 11 & 5 \\ 20 & 12 & 6 \\ 43 & 10 & 4 \\ 38 & 16 & 10 \\ 24 & 10 & 4 \\ 17 & 10 & 4 \\ 42 & 13 & 8 \\ 49 & 13 & 9 \\ 41 & 12 & 9 \\ 24 & 10 & 7 \\ 36 & 11 & 8\end{array}$

Enzyme

\begin{tabular}{l|l|l|l|l|}
\hline VGIC & GPCR TALTO \\
\hline
\end{tabular}

Enzyme

\begin{tabular}{|l|l|l|l|l|}
\hline VGIC & GPCR & C & TH & O \\
\hline
\end{tabular}

Enzyme

\begin{tabular}{l|l|l|l|l|l|l|l|l|l|l|l}
\hline VGIC & GPCR & C & T & L & O \\
\hline
\end{tabular}

Fig. 2 Pain targets identified by Pubmed scraping. The search was performed in April 2020. (a) "Large topics," assessed by total publications without time restriction to indicate overall interest in this topic, sorted by the Total column. (b) "Rising topics," sorted by the difference between the publications within the last 3 years minus the 3 years before. (c) "Novel topics," considering targets exceeding 10 publications within the last 3 years but not in the 3 years earlier; the delta was used for sorting. The cumulative bar chart at the bottom shows the distribution by target type. VGIC $=$ voltage-gated ion channel, $\mathrm{GPCR}=\mathrm{G}$ protein-coupled receptor, $\mathrm{T}=$ transporter, $\mathrm{C}=$ catalytic receptor, $\mathrm{L}=$ ligand-gated ion channel, $\mathrm{O}=$ other the dorsal root ganglia (DRG) and their trafficking to the nerve endings seems to increase [27]. Moreover, with a prolonged inflammatory event, peripheral receptors seem to account for the majority of the analgesic effect [28]. Peripherally restricted $\mu$-opioid receptor antagonists methylnaltrexone, alvimopan, and naloxegol could allow to reduce doselimiting side effects of blood-brain barrier-permeable agonists, e.g., constipation [29]. A similar strategy should work for developing kappa-receptor agonists. Efforts have resulted in several compounds including ADL 10-0101 (discontinued after phase II) [30], topical loperamide for pain due to repeated finger lancing [31], and oxycodegol (NKTR-181, after completed phase III not commercialized due to FDA advisory board vote) $[32,33]$.

Novel k-receptor agonists include CR665 (not further developed after phase II), which showed efficacy in alleviating symptoms of visceral pain [34]: JT09 designed for oral administration [35], difelikefalin (CR845, phase III completed 2020) [36], and TRK-820 (not further developed after phase III) [37] - investigated in pruritus. $\delta$-opioid receptor agonists include GIC-1001 (phase II started in 2013) [38, 39]. In summary, there is a lot of activity to expand the opioid-based therapeutic options.

\section{Prostaglandin Receptors}

These GPCRs include $\mathrm{DP}_{1}\left(\mathrm{PGD}_{2}\right.$ receptor), $\mathrm{EP}_{1}-\mathrm{EP}_{4}$ (PGE receptors), FP (PGF receptor), IP (PGI receptor), and TP (TXA receptor). It has been shown that murine peripheral nociceptive neurons express IP, $\mathrm{EP}_{1}, \mathrm{EP}_{3}$, and $\mathrm{EP}_{4}$ mRNAs [40]. The respective mediators and the generating enzymes are discussed in the second chapter. The sensitizing effects of $\mathrm{PGE}_{2}$ and PGI are well known [41], characterized by a sensitization of TRPV1 channels in DRG neurons downstream of $\mathrm{EP}_{1}$ and IP receptors through PKA and PKC dependent pathways [42]. Sensory neuron sensitization occurs also through $\mathrm{PGE}_{2}$ effects downstream of PKA phosphorylation on voltage-gated $\mathrm{Na}_{\mathrm{v}} 1.8$ and $\mathrm{Na}_{\mathrm{v}} 1.9[43,44]$ and voltage-gated $\mathrm{Ca}_{\mathrm{v}} 3.2$ [45], as well as P2X3 receptors [46, 47] and TRPV1 $[48,49]$. Alternatively, downstream of PKA, PKCE may be activated, by means of Epac1 (the exchange protein directly activated by cAMP) [50]. Production of inflammatory prostaglandins through cyclooxygenase 1 and 2 is the mainstream target of anti-inflammatory and analgesic therapy. A new contribution to the action of ibuprofen might be TRPA1 inhibition by a metabolite [51]. A novel approach might be a more selective targeting of IP, $\mathrm{EP}_{1}, \mathrm{EP}_{3}$, and $\mathrm{EP}_{4}$. Such antagonists are available, for IP selexipag [52], for $\mathrm{EP}_{1}$ ONO-8130 [53], 
and for $\mathrm{EP}_{4}, \mathrm{BGC} 20-1531$ (phase I in 2009, not developed further) [54] and CR6086 (phase II started in 2017) [55]. However, it was argued that a simultaneous inhibition of these receptors might be required for analgesia, considering that combined but not separate IP and $\mathrm{EP}_{4}$ inhibition was effective [56]. $\mathrm{EP}_{3}$ knockout mice have a phenotype in a neuropathic pain model [57], but the antagonists have at least also other functions like antiaggregatory [58] and controlling micturesis [59].

\section{Cannabinoid Receptors}

Despite a debate regarding psychotropics with at times a more political than medical agenda, this needs consideration. Regarding pain, there is a large body of literature [60]. A recent meta-analysis focusing on the clinical use of cannabinoids covered 28 trials with chronic pain assessment (2454 participants) and, despite limited effect size, revealed an overall greater pain relief with cannabinoids than with placebo [61]. There are two cannabinoid receptors, $\mathrm{CB}_{1}$ and $\mathrm{CB}_{2}$, both Gi-coupled GPCRs. As there is selective pharmacology, it is important whether $\mathrm{CB}_{1}, \mathrm{CB}_{2}$, or both receptors should be targeted. Although it was argued that peripheral $\mathrm{CB}_{1}$ is the main target for analgesia [62,63], this is complicated by a regulation of these receptors in different pathophysiological conditions [64]. To limit central adverse effects, there are efforts towards the development of peripherally restricted $\mathrm{CB}_{1}$ agonists [65]. In addition to cannabinoid receptor agonism, positive allosteric modulation has the potential of a better side effect profile. ZCZ011 was analgesic in inflammatory and neuropathic pain models [66] and GAT211 acted against paclitaxel-induced neuropathy [67].

Further, an upregulation of endogenous ligands might be an option. Such endocannabinoids are anandamide (AEA) and 2-arachidonoylglycerol (2-AG). These are broken down by monoacylglycerol lipase (MAGL) and fatty acid amide hydrolase (FAAH), and their inhibition can elevate endocannabinoid levels. Spinal and supraspinal mechanisms contributed to analgesia from systemic FAAH inhibition, but this also has central side effects. A peripherally restricted FAAH inhibitor URB937 lacking such side effects caused $\mathrm{CB}_{1}$-mediated antinociceptive effects on inflammatory pain $[68,69]$. Clinical development of FAAH inhibition failed for PF-04457845 tested against osteoarthritis [70], while BIA102474 had severe side effects (interrupted phase I trial in 2016) [71]. Also, MAGL inhibition has been clinically tested: JZL184 raises 2-acylglycerol levels in the brain but has substantial central side effects [72]. FAAH and MAGL inhibition by PF-3845 and JZL184 is synergistic [73]. In particular, compounds with two targets have been sought. Dual FAAH inhibitor and TRPV1 antagonists AA-5-HT and OMDM-198 have analgesic potential, and might be promising in case the benefits of the dual action outweighs the disadvantages [74].
OMDM-198 had a neutral profile on body core temperature, this having been prohibitive for further progress of many TRPV1 antagonists [75]. Dual FAAH and COX2 inhibitor ARN2508 reduced intestinal inflammation [76]. Currently, there are several synthetic cannabinoids clinically used for nausea and vomiting, such as nabilone and dronabinol, that are also used off-label as pain treatment [77], with inhaled cannabinoids often used in conjunction with first-line analgesics. Current research is supportive of a role for cannabinoids in analgesia; however, additional carefully carried out trials are required.

\section{$\mathrm{PAC}_{1}$ Receptor}

The pituitary adenylate cyclase-activating polypeptide (PACAP) type I receptor $\left(\mathrm{PAC}_{1} \mathrm{R}\right)$ is part of the vasoactive intestinal peptide/secretin/glucagon family of GPCRs and is also expressed in the peripheral nervous tissue [78]. Structure and ligand-binding have been clarified $[79,80]$. Activation of $\mathrm{PAC}_{1} \mathrm{R}$ via PACAP or the agonist maxadilan were shown to induce and maintain nociceptive behaviors in rodents [81, 82], and attempts at blocking the receptor proved successful in attenuating formalin-induced pain [83]. PACAP38 is a potent inducer of migraine attacks with an increased selectivity towards $P_{A C} R$. Therefore, inhibition of the receptor is probed for migraine, e.g., by anti-PAC ${ }_{1} \mathrm{R}$ antibodies $\mathrm{AMG} 301$ (phase II completed 2019) [84] or by the development of small-molecule antagonists [85]. The established antibiotic doxycycline in a subantimicrobial dose facilitates agonistbinding to $\mathrm{PAC}_{1} \mathrm{R}$, which could allow to exploit an antiinflammatory and neuroprotective potential [86].

\section{5-HT ${ }_{1}$ Receptors}

Serotonin receptors are classified into seven groups known as $5-\mathrm{HT}_{1}$ to $5-\mathrm{HT}_{7}$; all are GPCRs except 5$\mathrm{HT}_{3}$ [87]. Members of this group have been targeted for the treatment of various types of painful conditions including neuropathic pain, migraine, and cluster headaches. The current theory of the pathophysiology of migraine highlights the role of the trigeminocervical complex under the effect of increased afferent activity. Additionally, the respective activity releases CGRP and PACAP from these nerves, leading to plasma extravasation [88]. Triptans have been a long-standing option for migraine treatment since the 1990s and are selective 5$\mathrm{HT}_{1 \mathrm{~B} / 1 \mathrm{D}}$ receptor agonists, with some entities having affinity for the $5-\mathrm{HT}_{1 \mathrm{~F}}$ receptor [89]. It is assumed that at least part of the mechanism relies on activation of 5$\mathrm{HT}_{1}$ receptors in the trigeminal ganglion, leading to reduced neuropeptide release, while CNS effects have not been excluded [90]. The main drawback of using triptans is their potential for vasoconstriction, due to 
activation of $5-\mathrm{HT}_{1 \mathrm{~B}}$ receptors. For selective $5 \mathrm{HT}_{1 \mathrm{~F}}$ activation, a small but significant effect was found for lasmiditan, which was approved in 2019 [91].

Injection of serotonin into the muscle is painful in human volunteers [92]. Serotonin injection pain can be inhibited via the $5-\mathrm{HT}_{2 \mathrm{~B}}$ receptor in mice [93], and a role of this receptor was also demonstrated in neuropathic pain [94] while being assumed for migraine [95].

RS-127445 is a $5-\mathrm{HT}_{2 \mathrm{~B}}$ receptor antagonist which reduced allodynia after nerve injury [96]. So far, there are no clinical studies with this target. Drugs like selective serotonin reuptake inhibitors can reduce systemic levels of inflammatory cytokines (e.g., IL-1 $\alpha$, IL-6, IL-8, IL-12, IFN- $\gamma$ ) [97]. Within this category, the peripherally restricted $\mathrm{N}$-methyl-citalopram has been patented and reported but not investigated for analgesic use [98].

\section{Proton-Sensitive GPCRs}

There are many acid-modulated proteins, among which are four GPCRs, occurring in a variety of tissues. These include GPR4, GPR68, GPR132, and GPR65 [99]. The $\mathrm{pH}$ sensitivity and the expression patterns favor GPR68 (also OGR1) as a neuronal pH sensor, as it is found in about $29 \%$ of all sensory neurons and in $78 \%$ of putative nociceptors, indicated by the small-diameter neuron marker peripherin [100]. A role in inflammatory pain has been demonstrated [101, 102], and pharmacological inhibition resulted in attenuated colitis-associated pain [103]. Other potential uses to limit cellular acid-sensing, e.g., in cancer or cardiac ischemia [104, 105], require careful consideration of the usefulness of this approach for analgesia.

\section{Histamine}

Histamine is mainly released by mast cells and activates four GPCRs (histamine receptors $\mathrm{H}_{1}, \mathrm{H}_{2}, \mathrm{H}_{3}$, and $\mathrm{H}_{4}$ ) involved in physiological and pathological processes. In terms of sensory physiology, histamine levels increase in inflammation, but the effects have been mostly associated with itch and allergy. There is evidence for $\mathrm{H}_{3}$ and $\mathrm{H}_{4}$ involvement in the modulation of nerve injury-induced neuropathic pain as well as in inflammatory pain models [106-108]. So far, there is only preclinical data to support the use of $\mathrm{H}_{3}$ and $\mathrm{H}_{4}$ antagonists for minimizing hypersensitivity [109]. The combination of peripheral and central effects might explain why $\mathrm{H}_{3}$ agonists as well as antagonists might be beneficial [110]. $\mathrm{H}_{4}$ receptor antagonists are further in development [111]. JNJ 7777120 inhibited a rabbit immune response to sheep erythrocytes [112], and adriforant (ZPL-3893787, discontinued after phase II) was anti-inflammatory in a phase IIa study for atopic dermatitis [113].

\section{C5a Complement Receptor}

The complement system is an essential driver of innate immunity through opsonization and killing of bacteria. Three convergent activation pathways result in the formation of the membrane attack complex, through a precursor molecule called C5. The biologically active fragment C5a, as well as $\mathrm{C} 3 \mathrm{a}$, were shown to sensitize capsaicin-induced calcium transients in DRG neurons [114]. The C5a receptor mRNA codes for a GPCR in sensory neurons, which can induce thermal hyperalgesia requiring TRPV1 and NGF contribution. Moreover, C5a triggers arachidonic acid metabolism, and $\mathrm{PGE}_{2}$ synthesis [115], most likely through $\mathrm{C} 5 \mathrm{a}$ receptor 1 activation. $\mathrm{C} 5 \mathrm{aR}$ antagonism has been attempted with several strategies, among which a more recent one implies allosteric inhibition with DF2593A, proven to be effective in inflammatory pain models [116]. Anti-C5aR antibodies were effective at inhibiting the development of arthritis in rodents [117]. On the clinical side, selective $\mathrm{C} 5 \mathrm{aR}$ inhibition by avacopan (CCX168, phase III completed, new drug application accepted) has been investigated in patients with vasculitis [118], the monoclonal antibody NNC0215-0384 (not further developed after phase I) in rheumatoid arthritis $[119,120]$, and antiC5aR antibody avdoralimab has been lined up against inflammatory responses in the lung [121].

\section{Prokineticins}

Prokineticin receptor 1 and 2 are GPCRs, activated by cytokine prokineticin 2 (Bv8). Both are expressed by neurons and have a role in pain $[122,123]$. These receptors can sensitize ion channels, through kinases described below, including TRPV1 and acid-sensing ion channels [124]. PC1, an inhibitor prokineticin 1 [125], reduced neuropathic pain [126]. So far, this is in the preclinical stage; efforts to drug these targets have been summarized [127].

\section{Sensory Neuron Ion Channels}

\section{Sodium Channels}

Voltage-gated sodium channels $\left(\mathrm{Na}_{\mathrm{v}}\right)$ play a major role in determining neuronal membrane excitability, which highlights their contribution to the genesis and maintenance of pain signals [128]. The mammalian $\mathrm{Na}_{\mathrm{v}}$ family members have different expression patterns and possess heterogeneous electrophysiological properties $[129,130] . \mathrm{Na}_{\mathrm{v}}$ pharmacology is comprised essentially of blockers, some among the most wellestablished drugs for local anesthesia (lidocaine, bupivacaine), type I antiarrhythmics (mexiletine), or anticonvulsants (lamotrigine, carbamazepine, phenytoin) [131]. Inflammation has been shown to be associated with upregulation of $\mathrm{Na}_{\mathrm{v}} 1.7$ and $\mathrm{Na}_{\mathrm{v}} 1.8[132,133]$, and $\mathrm{Na}_{\mathrm{v}} 1.7$ deletion 
abolished inflammatory pain responses in animal models [134]. Moreover, changes in activity, specifically decreased activation thresholds and ectopic discharges, most likely contribute to allodynia or hyperalgesia in neuropathic pain states [135], with certain lines of therapy including $\mathrm{Na}_{\mathrm{v}}$ blockers. Therefore, it seems valuable to pursue selective pharmacological tools targeting $\mathrm{Na}_{\mathrm{v}}$ subtypes. However, this development is ongoing for a considerable time and with substantial effort, indicating the difficulty to generate such subtype-specific and effective drugs [136-138]. Clinical trials have been exploring the utility of lidocaine patches in arthritis [139] and also alternatives to small-molecule antagonists, e.g., peptides (AM6120, AM-8145, AM-0422) or $\mathrm{Na}_{\mathrm{v}} 1.7$ monoclonal antibodies [140]. Progress in development has been summarized [141].

\section{Calcium Channels}

There are ten calcium channels based on their alpha subunit, historically labeled by initials of substances acting on these, and more recently by genetic similarity. There are three families, the low-voltage-activated (T-type) $\mathrm{Ca}_{\mathrm{V}} 3 . \mathrm{x}$ channels and the high-voltage activated calcium channels, which can be differentiated into dihydropyridine-sensitive (L-type) $\mathrm{Ca}_{\mathrm{V}} 1 . \mathrm{x}$ and dihydropyridine-insensitive $\mathrm{Ca}_{\mathrm{v}} 2 . \mathrm{x}$. Antagonists of these voltage-sensitive channels are clinically used, in particular for targeting the cardiovascular system. Therefore, it has to be carefully considered whether there is an opportunity for systemic analgesic action [142]. Despite that, verapamil is a prophylactic option for cluster headache [143]. However, for migraine, L-type channel blockers and substances with a calcium-inhibitory component are considered [144]. Finally, several classic voltage-gated calcium channel inhibitors increase cytosolic calcium. It was shown that in the case of nifedipine, this is due to activation of TRPM3, TRPA1, and ionotropic glutamate receptors of the NMDA subtype [145]. A more novel approach might include antagonists of $\mathrm{Ca}_{\mathrm{v}} 2.2$ [146]. Based on the caveats mentioned above, it is interesting whether a weak calcium-channel inhibitory component might contribute to the overall action of an analgesic drug. $\mathrm{Ca}_{\mathrm{v}} 3.1$ has also emerged as an interesting target for analgesia in the context of neuropathic pain; Z944 (phase I in 2014) is a selective antagonist [147].

\section{TRP Channels}

Transient receptor potential (TRP) channels are grouped into 7 families, totaling 28 members [148]. The respective chapter is somewhat overrepresented as an example, but also as it reflects the core expertise of the authors. The scope of this review is broader; TRP channel-directed development of analgesics has been addressed in more focal reviews [149-151].

TRPV1 is the best-investigated pain target without a medically available antagonist. It is a well-established pain sensor, which is characterized by different modalities of activation. TRPV1 can be activated by temperatures over about $41{ }^{\circ} \mathrm{C}$, chemical compounds (capsaicin, resiniferatoxin), and low $\mathrm{pH}$ and can be modulated downstream of a variety of bonafide inflammatory stimuli (e.g., bradykinin, prostaglandins), mostly through PKC-dependent pathways. Further stimulation can be mitigated through PKA phosphorylation [152], phosphatidyl-inositol-phosphates [153], and reactive oxygen species (ROS) effects, to a certain degree [154].

Nevertheless, TRPV1 is downstream of many inflammatory signaling pathways and pursuing strategies involving their inhibition might prove worthwhile. In the case of TRPV1, the consequence of locally applied capsaicin depends on the concentration and can lead to sensitization [155-158]. However, local capsaicin can also trigger desensitization of primary sensory afferents with analgesic outcomes, e.g., in the form of $<$ $1 \%$ over-the-counter ointments indicated for the treatment of neuropathic and musculoskeletal pain [159]. Interestingly, doing this does not generate any meaningful changes in mechanical sensitivity. Transdermal $8 \%$ capsaicin patches are approved for postherpetic neuralgia-associated neuropathic pain [160]. Development of TRPV1 antagonists was highly pursued by the pharmaceutical industry, and one of the most important hurdles to be overcome seems to be minimizing off-target effects on body temperature. There are already pre-clinically confirmed modality-specific compounds, which largely leave body temperature untouched [161]. DWP-05195 and NEO-6860 have reached phase II trials (completed 2014 and 2016) for the treatment of neuropathic pain and osteoarthritis, respectively $[162,163]$, while tivanisiran, a small interference RNA inhibitor of TRPV1, failed its endpoints in a phase III trial for dry eye syndrome in 2019 [164]. Resolvin E1 has been shown to reduce substance $P$ potentiation of TRPV1 in DRGs [165] and has reached phase I clinical trials in 2019 [166]; it might be useful for the treatment of rheumatoid arthritis, or other inflammatory conditions. A recent metaanalysis points towards differences in the role of rat and human TRPV1 thermoregulation, potentially a reason for the relatively poor translation of many antagonist effects in humans [167]. An interesting strategy might be heralded by the use of photoswitchable fatty acids, which could allow exposure of an optically defined area, as it is standard for photodynamic therapy. TRPV1 activation by photoswitchable capsaicin could allow highly localized neuronal ablation [168]. In summary, the development programs by most large pharmaceutical players have resulted in many substances, key side effects like self-inflicted burn injury and elevated body core temperature were slowly overcome, but the human trials so far had disappointing efficacy [169].

TRPA1 is even more promiscuous than TRPV1, as it is gated by a very wide range of stimuli including natural chemical compounds, drugs, calcium, voltage change [170], and UV radiation [171, 172], to name a few. In addition, TRPA1 
has been shown to be sensitized by PKA [173] and prolonged agonist application $[174,175]$. For a more comprehensive view over TRPA1 activation mechanisms as well as agonists and antagonists, see [148, 176, 177]. One of the main challenges in developing TRPA1 antagonists lies in a notable species difference, where in rodents, the effects may lead to underestimating potential clinical efficacy [178]. HC-030031 or A-967079 were the most promising antagonists, but have not been progressed to clinical testing. A phase II trial for neuropathic pain in diabetic neuropathy with GRC 17536 failed to meet the primary endpoint in 2014 [179]. Other attempts include ODM-108 [180], for neuropathic pain and CB625 for acute surgical pain, both terminated in phase I [181]. Alternative strategies, such as drug repurposing for TRPA1, might see the use of desvenlafaxine, paliperidone, and febuxostat as TRPA1 blockers [182]. With the advent of potent TRPA1 agonists, a new human TRPA1 model can be used to test TRPA1 antagonists in humans [183]. Aside from pain, other diseases could benefit from TRPA1 inhibition [184]. However, similar to TRPV1, TRPA1 has been known for so long that the progress towards a usable analgesic is somewhat disappointing [185].

TRPM8 is viewed as the canonical cold transducer [186] and is also activated by menthol, which is routinely used for its analgesic properties in preparations to alleviate inflammatory pain in sports injuries or arthritis $[187,188]$. There is an intriguing interplay between TRPM8 activity and inflammatory mediators. For example bradykinin, a proinflammatory mediator, exerts an inhibitory effect on TRPM8 activity, while TRPM8 activation by cold causes downregulation of proinflammatory TNF $\alpha$ [189]. TRPM8 antagonist RQ-00434739 reduced activity of afferents in bladder inflammation [190]. Systemic application of PF-05105679 successfully inhibited the cold pressor response of human subjects, but also led to unexpected hot sensations (discontinued after phase I completed in 2011) [191]. Also, AMG-333 was tested in phase I in 2013, but terminated thereafter without reported results [192]. Substantial progress has been made in the further development of agonists and antagonists [193].

TRPV4 is expressed in a large fraction of primary afferents and responds to, e.g., decrease of the osmolarity [194]. The knockout mice showed reduced mechanical and acidosisinduced pain [195]. Potent pharmacological tools have been developed [196]. Animal experiments suggested a pathophysiological role, e.g., in pulmonary, pancreatic, and bladder inflammation [197]. TRPV4 antagonist GSK2798745 has been reported as well-tolerated in a recent phase I trial [198]. The phase II trials for chronic cough [199] and LPS-induced alveolar barrier disruption [200] have been terminated due to a low probability of achieving the primary endpoint. In a third trial in 11 subjects with heart failure, alveolar diffusion capacity was not significantly changed [201]. Despite being beyond the peak of publication activity, it remains interesting whether this can be converted into human therapeutic benefit.

TRPV3 is mentioned here, despite reports of preferential expression in non-neuronal cells. Reduction of keratinocyte ATP release and with that the reduction of sensitization or activation was put forward as mode of action. TRPV3 antagonist GRC15300 was tested in a phase II clinical trial and terminated in 2013 after it failed to reduce neuropathic pain [202].

TRPV2 is heat sensitive. The higher thermal threshold compared with TRPV1 [203], which can be modulated [204], caused the speculation that this might be the sensor for noxious heat damage. The lack of an apparent phenotype of TRPV2 knockouts as well as TRPV1/TRPV2 double knockouts [205] limited interest for analgesic purpose.

TRPM2 might be an option to target pain [206], but its role in temperature sensing $[207,208]$ indicates that this might need to be overcome first to uncover analgesic potential.

TRPM3 activation evokes pain-related behavior in animals [209], and the contribution to heat pain in mice as part of a triad of redundancy in heat perception render this interesting [210]. In addition, TRPM3 is upregulated in inflammatory conditions, which increases the overlap with and the interaction with signaling of TRPV1 and TRPA1 [211]. TRPM3 is found in human sensory neurons [212], and concentrations of volatile anesthetics not exceeding the minimal alveolar concentration by far can act as TRPM3 antagonists [213].

\section{Potassium Channels}

Potassium channels are the largest and most diverse ion channel family with about 80 members [214]. As for the topics above, there are more focused reviews [215-217]. The potassium channels can be separated into four major groups, all present in primary afferent neurons. These are voltage-gated $\mathrm{K}^{+}$channels $\left(\mathrm{K}_{\mathrm{v}}\right.$ families $\left.\mathrm{K}_{\mathrm{v}} 1-\mathrm{K}_{\mathrm{v}} 12\right), \mathrm{Ca}^{2+}$-activated $\mathrm{K}^{+}$ channels $\left(\mathrm{K}_{\mathrm{Ca}}\right.$ families $\left.\mathrm{K}_{\mathrm{Ca}} 1-\mathrm{K}_{\mathrm{Ca}} 5\right)$, two-pore $\mathrm{K}^{+}$channels $\left(\mathrm{K}_{2 \mathrm{P}}\right.$ families $\left.\mathrm{K}_{2 \mathrm{P}} 1-\mathrm{K}_{2 \mathrm{P}} 17\right)$, and inwardly-rectifying $\mathrm{K}^{+}$channels ( $\mathrm{K}_{\mathrm{ir}}$ families $\left.\mathrm{K}_{\mathrm{ir}} 1-\mathrm{K}_{\mathrm{ir}} 7\right)$.

The respective channels are discussed regarding their function in peripheral neurons [218]. Contribution to axonal conduction can reduce action potential frequency, partially also seen as action potential shape change. In particular $\mathrm{K}_{\mathrm{v}} 2.1$, $\mathrm{K}_{\mathrm{v}} 3.4, \mathrm{~K}_{\mathrm{v}} 9.1$ and $\mathrm{K}_{\mathrm{Ca}} 1.1$ have been discussed to contribute to this in a frequency-dependent fashion, and the role of the Tjunction might be therefore considered [219].

At least as interesting are channels which modulate spike initiation at the peripheral terminals, affecting resting membrane potential and action potential threshold. An antinociceptive decrease in primary afferent excitability can be brought about by opening potassium channels. This will hyperpolarize for a channel with an equilibrium potential below the resting membrane potential, but also increased 
potassium conductance without a change in resting membrane potential will stabilize against excitation. To this end, $\mathrm{K}_{\mathrm{v}} 1$ $\left(\mathrm{K}_{\mathrm{v}} 1.1 / \mathrm{K}_{\mathrm{v}} 1.2\right), \mathrm{K}_{\mathrm{v}} 7\left(\mathrm{~K}_{\mathrm{v}} 7.2 / \mathrm{K}_{\mathrm{v}} 7.3\right), \mathrm{K}_{2 \mathrm{P}}$ (TREK1, TREK2, TRAAK), $\mathrm{K}_{\mathrm{Ca}} 1.1$ are primarily considered, and this includes some controversy regarding expression in sensory neuron subtypes [215]. $\mathrm{K}_{\mathrm{v}} 1.1 / \mathrm{K}_{\mathrm{v}} 1.2$ are mainly found in large nonnociceptive neurons [220]. $\mathrm{K}_{\mathrm{v}} 7$ channels, encoded by KCNQ1-5 historically named "M-channel" as it explained the observed non-inactivating potassium "M-current," are a focus of pharmaceutical development since $\mathrm{K}_{\mathrm{v}} 7$ activation has demonstrated analgesic potential for inflammatory and neuropathic pain [221, 222]. Many of the respective studies used $\mathrm{K}_{\mathrm{v}} 7$ blocker XE-991 or $\mathrm{K}_{\mathrm{v}} 7$ activator retigabine [223, 224]. For currently used analgesics, a contribution of potassium channels to their analgesic action has to be considered, e.g., paracetamol metabolite NAPQI, meclofenamic acid, and diclofenac activate $\mathrm{K}_{\mathrm{v}} 7.2$ [225, 226]. Given homo- and heterotetramer formation, e.g., $\mathrm{K}_{\mathrm{v}} 7.2 / \mathrm{K}_{\mathrm{v}} 7.3$ [227, 228], development of analgesics also depends on the generation of subtype-specific drugs. New $\mathrm{K}_{\mathrm{v}} 7.2$ agonists like ICA-27243 show antinociceptive effects and demonstrate active development in this area [229].

$\mathrm{K}_{2 \mathrm{P}}$ channel activators could also reduce excitability of afferent neurons [230]. $\mathrm{K}_{2 \mathrm{P}} 2.1$ (TREK-1) activated by GI530159 reduced excitability of rat sensory neurons [231] and antinociceptive effects of riluzole were ascribed to this channel [232]. Selective activators of $\mathrm{K}_{2 \mathrm{P}} 2.1$ (TREK-1) and $\mathrm{K}_{2 \mathrm{P}}$ 10.1(TREK-2) allow probing these channels as analgesic targets [233]. Cloxyquin activates $\mathrm{K}_{2 \mathrm{P}} 18.1$ (TRESK) [234]. Clinically established medications and endogenous substances are known to activate these targets [235], but painrelated studies are still rare and no clinical trials have been performed.

A search for substances tested in registered clinical trials concerning human pain modulation via potassium channels shows 4-aminopyridine, flupirtine, and maxipost. 4aminopyridine, including the slow-release formulation fampridine, has shown some benefits in multiple sclerosis [236]. For the study testing 4-aminopyridine in GuillainBarre syndrome patients [237] no results were published. The mechanism of action of 4-aminopyridine is unclear, since in addition to the $\mathrm{K}_{\mathrm{v}} 1$ inhibition, also a $\mathrm{Ca}_{\mathrm{v}} 2.2$ facilitation was demonstrated [238]. A change in pain was only a minor aspect [239]. Potassium channel opener flupirtine reduced human neuronal excitability [240].

Maxipost (BMS 204352) acts via multiple channels, including $\mathrm{K}_{\mathrm{Ca}} 1.1, \mathrm{~K}_{\mathrm{v}} 7.2, \mathrm{~K}_{\mathrm{v}} 7.3$, and $\mathrm{K}_{\mathrm{v}} 7.4$, but the anxiolytic effect demonstrates that this has a relevant central component $[241,242]$. A headache-focused trial shows headacheinduction by maxipost, indicating a role of $\mathrm{BK}_{\mathrm{Ca}}$ channels in headache pathophysiology [243]. The same group has also reported that opening of ATP-sensitive potassium channels was associated with occurrence of headache [244].

\section{Chloride Channels}

Intraneuronal chloride homeostasis is maintained by multiple players, and the outline of a topical review [245] has been used here to focus on analgesic potential. Chloride channels are comprised of GABAA and glycine receptors, calciumactivated chloride channels (CaCC), $\mathrm{ClC}$ family of chloride channels and transporters, cystic fibrosis transmembrane conductance regulator (CFTR), volume-regulated anion channels (VRAC), and maxi-anion channels. All of these adjust intracellular chloride levels, impacting on excitability of sensory neurons. The equilibrium potential of chloride depends on the intracellular $\mathrm{Cl}^{-}$concentration, such that in case of a high concentration, channel opening can cause depolarization [246, 247]. The hypothesis that neuronal $\mathrm{Cl}^{-}$accumulation can amplify $\mathrm{Cl}^{-}$efflux and, consequently, alter sensory signaling has been supported by targeting $\mathrm{NKCC} 1\left(\mathrm{Na}^{+}-\mathrm{K}^{+}-2\right.$ $\mathrm{Cl}^{-}$transporter). The respective knockout animals had reduced thermal responses [248] and NKCC1 inhibitor bumetanide reduced inflammatory pain in the formalin test [249]. Inflammatory mediators bradykinin, $\mathrm{PGE}_{2}, \mathrm{NGF}$, and ATP inhibit $\mathrm{KCC} 2\left(\mathrm{~K}^{+}-\mathrm{Cl}^{-}\right.$cotransporter), a main player in $\mathrm{Cl}^{-}$ outflow, and facilitate chloride import through NKCC1, which as net effect increases excitability [250].

Calcium-activated chloride channels include anoctamins, which consist of 10 channels. For the first member, anoctamin 1 , expression was predominantly found in small DRG neurons [251], and a contribution to excitability of neurons has been demonstrated [252]. Human anoctamin 1 can be inhibited by MONNA with an IC50 of about $1 \mu \mathrm{M}$ [253] and animal data point towards an analgesic effect [254], but this needs to be further scrutinized, also helped by new antagonists [255]. Functions of anoctamin 1 in other systems, e.g., epithelial secretion, have to be considered for side effects [256]. Bestrophins (Best1-4) are also chloride channels, with expression in intermediate-sized sensory neurons [257]. Members can be activated by slight intracellular calcium elevation, which would allow an amplification of minor signals. A role in a neuropathic pain model for bestrophin 1 has been described [258], but the pharmacological tools to advance this are still limited. The voltage-gated chloride channel CIC3 was found in small sensory neurons, and upregulation reduced excitability [259]. TMEM206 has recently been described as a proton-activated chloride channel, but it appears predominantly expressed in the central nervous system [260]. Cystic fibrosis transmembrane conductance regulator is a chloride channel mainly known due to the consequence of the recessive genotype. It is found in neurons, peripheral and central [261], and contributes to neuronal ATP release [262]. The lack of pain phenotypes in CFTR patients questions a role of this channel in disease pathophysiology.

Volume-regulated anion channels respond to osmotic changes [263]. LRRC8A, an essential member, is found in 
DRG neurons [264]. Whether it can be targeted to control chloride levels remains to be elucidated. Maxi-anion channels are widely expressed and can be recruited by cellular stress [265]. This includes inflammatory conditions, which were shown to regulate SLCO2A1 [266]. So far, pain as part of a syndrome has only been described in case reports.

GABAA receptors are found on sensory neurons, and local GABA injection increases excitability in mice and humans [267, 268]. An antinociceptive effect could be expected from GABAA antagonists, but systemic application of substances penetrating the blood-brain barrier have a convulsant effect [269]. Peripherally restricted GABAA receptor antagonists, e.g., bicuculline methiodide, were so far not reported to inhibit pain, which might suggest that there is no tonic GABA release contributing to baseline excitability.

\section{Acid-Activated lon Channels}

Acidosis is one of the main features of inflammation, with protons being sourced through cell lysis along with other mediators and by relative ischemia. Tissue acidosis leads to nociception, by direct gating or through sensitization to other agonists [270]. Canonically, proton-gated acid-sensing ion channels (ASICs) [271] form a group of voltage-insensitive sodium channels, with four members (ASIC1-4) [272]. This feature is also present in a variety of other channels, including TRPV1, TRPV4, TRPC4, TRPC5, TRPP2, P2X purinoceptors, inward rectifier $\mathrm{K}^{+}$channels, voltageactivated $\mathrm{K}^{+}$channels, L-type $\mathrm{Ca}^{+}$channels, $\mathrm{HCN}$ channels, gap junction channels and $\mathrm{Cl}^{-}$channels [273], and can be sensitized by inflammatory mediators [274, 275]. In humans, low $\mathrm{pH}$-induced pain in the range of acidosis occurrence is mediated by TRPV1 [276], whether other targets contribute substantially in inflammatory conditions is currently unknown. The most likely target for ASIC analgesia in inflammation remains ASIC3, with substantial expression in the peripheral nervous system [277, 278]. In a human trial, ASIC blocker PPC-5650 had no relevant effect on mechanical, thermal, electrical, and chemical stimulations of the esophagus [279].

\section{Mechanoreceptors}

Mechanotransduction is fundamental to the environmental interaction of living organisms. Sensing of mechanical stimuli, innocuous or noxious, is strongly affected by inflammation, as most inflammatory conditions are accompanied by protective hyperalgesia [280, 281] and allodynia [282]. Mechanosensation, mechanonociception and the differentiation between these two sensory modalities represent a longstanding interest in neuroscience research. Competing theories regarding how they function are the labeled line theory of somatosensation and the population-coding model
[283, 284]. More and more light is shed on the molecular pathways of mechanosensitivity. Key players include Piezo2 [285], $\mathrm{Na}_{\mathrm{v}} 1.1$ [286], neuronal $\mathrm{S} 1 \mathrm{P}$ receptor $\mathrm{S}_{1} \mathrm{P}_{3}$ [287], TRPV4 [288], and epithelial $\mathrm{Na}^{+}$channel (ENaC) [289]. In addition, several cellular microcompartments such as primary cilia, caveolae, or integrins can sense the stiffness of the extracellular matrix [290, 291].

Sensory neurons respond to sphingosine 1 phosphate (S1P), involving TRP ion channels [292], but the contribution to neuropathic pain also involves non-neuronal cells, e.g., through the S1P receptor 1 in astrocytes [293]. Sphingosine 1 phosphate contributes to inflammation [294], but this signaling is also involved in acute mechanonociception by $\mathrm{S}_{3} \mathrm{P}_{3}$

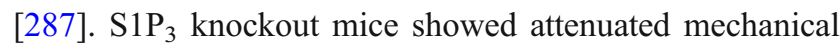
pain and inflammatory thermal hypersensitivity. There are two FDA-approved $\mathrm{S} \mathrm{P}_{1}$ antagonists, namely fingolimod and siponimod. Fingolimod stimulates S1P receptor internalization and has so far been therapeutically used against multiple sclerosis relapse [295]. Fingolimod reduces neuropathic pain, however, by reducing central sensitization in the dorsal horn [296]. A further trial exploring its utility in neuropathic pain is underway [297].

An interesting argument has been made in the case of TRPV4, an established sensor of shear stress and change in osmolarity, referring to a role in transducing forces in cell contacts [290]. TRPV4 deficient mice seem to be protected when being faced with acute lung injury [298] and pharmacological inhibition leads to similar results [299], reducing neutrophil infiltration and levels of inflammatory mediators such as IL-6.

In the long-enigmatic mechanotransduction, the late discovery of the unusual Piezo cation channels stands out [300]. The rodent and the human form of Piezo2 respond to low mechanical forces [285, 301, 302]. Bradykinin has been shown to increase Piezo2 mechanosensitive currents via PKC and PKA pathways in sensory neurons [303]. However, the primary function of the Piezo channels seems to be touch, and there is less contribution to stronger pain-inducing stimuli. Neurons lacking Piezo2 responded robustly to noxious pinch [304]. When touch becomes allodynic in inflammation, Piezo2 seems to contribute, and human subjects with a loss of function mutation report less sensitivity to capsaicininduced neurogenic inflammation [305]. A relief from inflammatory pain can only be hypothesized, but this still awaits the availability of an antagonist. For Piezo1, a negative interaction with Piezo2 has been demonstrated [306].

\section{HCN Channels}

Hyperpolarization-activated cyclic nucleotide-gated channels (HCN1-4) are nonselective cation channels conducting both sodium and potassium ions [307]. HCN upregulation in the trigeminal ganglion has been demonstrated for inflammation 
at the dura mater [308] and HCN2 knockout mice exhibit diminished heat hyperalgesia in inflammatory pain models [309]. HCN3 has been largely excluded from having any relevant implications in inflammatory pain [310]. HCN2 and HCN4 are modulated by cAMP and PKA, which might be selectively targeted [311]. Ivabradine, a peripherally restricted general HCN blocker, provided analgesia in inflammatory and neuropathic pain mouse models [312]. However, in healthy volunteers, ivabradine lacked impressive analgesic properties but decreased heart rate, indicating that more HCN2-specific blockers might be required [313]. To this end, compounds selective towards HCN1/2, such as MEL55A, might yield better results on this front [314].

\section{Purinergic Signaling}

Purinergic receptors are divided into three main groups: $\mathrm{P} 1$ with members $A_{1}, A_{2 A}, A_{2 B}, A_{3}$ is $G$ protein-coupled, the $P 2$ family has been divided into the P2X ion channels P2X1$\mathrm{P} 2 \mathrm{X} 7$ and the P2Y G protein-coupled receptors with 8 members. Purinergic signaling is an important driver of inflammation as ATP is released into extracellular space by inflammatory cells $[315,316]$, and iontophoretic ATP application into human skin caused a concentration-dependent pain response [317]. An in-depth review for purinergic signaling in pain has been provided [318].

The role of P2X receptors in pain has been reviewed [319]. A role in nociception has been shown for the purinergic receptors P2X2 and P2X3, which can form heterodimers [320]. $\mathrm{P} 2 \mathrm{X} 3$ receptors are attractive analgesic targets due to their exclusive expression on sensory neurons [321]. A-317491 reduced inflammatory and neuropathic pain in rats [322], with further improvement of pharmacokinetics and a reduction of thermal and mechanical hyperalgesia in an endometriosis pain model [323]. P2X3 antagonist gefapixant (AF-219) reduced chronic cough in a phase II trial [324]. AF-219 has advanced to phase III, BLU-5937 to phase II, and the progress in development has been recently summarized [325]. P2X4 [326] and P2X7 [327] are also involved in pain, but their primary mechanism works through microglia. As purinergic GPCRs have not been given a separate paragraph, it should be mentioned that neuronal P2Y1 activation has been shown to elicit sensitization through TRPV1 [328]. With the release of ATP, also ADP, AMP and adenosine are generated. Targeting adenosine A1 receptors with GR79236X failed to reduce pain due to a third molar extraction [329].

\section{Enzymes in Sensory Neurons}

\section{Protein Kinase A}

Many inflammatory mediators' signaling pathways converge to an increase in intracellular levels of cAMP (e.g., prostaglandins, bradykinin). Among downstream targets of cAMP, contributing to neuronal hypersensitivity, is the AMP-dependent protein kinase (PKA), itself a sensitizer of pain-transducing targets, including TRPV1 [330], TRPV4 [331], and TRPA1 [173], as well as $\mathrm{Na}_{\mathrm{v}} 1.8$ [332] and $\mathrm{Na}_{\mathrm{v}} 1.7$ [333]. PKA activity in inflammatory hyperalgesia plays an important role in its onset as well as in maintenance, as PKA inhibitors have shown reduction of hyperalgesia in animal models [334, 335]. PKA has four regulatory subunits, of which $R 1 \beta$ has a predominantly neuronal expression pattern, and the respective knockout mice have a phenotype in inflammatory pain [336]. However, there are so far only inhibitors for multiple protein kinases (AGC inhibitors), with effects also on PKA for cancer treatment [337, 338], but not PKA subtype-specific antagonists.

An alternative pathway for cAMP involves the exchange proteins directly activated by cAMP (Epac), which function to catalyze the exchange of GDP to GTP on small Rap proteins, leading eventually to $\mathrm{PKC} \varepsilon$-and mitogen-activated protein kinase activation [339]. Epac function seems to be intertwined with alterations in nociception; for example, Epac activation leads to TRPV1 sensitization, an effect blocked by inhibiting downstream targets $\mathrm{PKC} \alpha$ and $\mathrm{PKC} \varepsilon$ [340]. Epac-selective cAMP analogue 8-pCPT has been shown to sensitize mechanically evoked Piezo2-mediated currents in DRG neurons and induce mechanical allodynia through Epac1 [341]. More recently, Epac inhibitor ESI-09 was used to suppress chemotherapy-induced pain [342] or inflammatory pain [343], but so far, Epac modulators have been limited to preclinical research [344].

\section{Protein Kinase C}

Protein kinase C (PKC) is important for regulating several neuronal functions, with sensitizing effects on many ion channels involved in nociception, such as TRPV1 [345, 346], ASICs [347, 348], and $\mathrm{Na}_{\mathrm{v}} \mathrm{s}$ [332, 349]. Since PKC activity is sensitive to intracellular levels of calcium, it is also subject to modulation by inflammatory mediators acting through the PLC pathway, many of which are discussed below. Among the $16 \mathrm{PKC}$ isoforms, $\mathrm{PKC} \varepsilon$ seems to be critical for the development of acute inflammation, as shown with genetic deletion and pharmacological inhibition [350]. So far, PKC inhibitors, as many other kinase inhibitors, were mostly developed regarding their antitumor activity. Preclinical and clinical efforts in development were summarized [351]. The furthest progress was made for aprinocarsen which failed in phase III for lung cancer [352]. Subtype-specific knockouts have demonstrated less neuropathic pain, e.g., for PKC $\gamma$ [353]. The importance of PKC subtypes for pain has been discussed [354]. The PKC $\varepsilon$ inhibitor KAI-1678 (studies completed in 2011) was well tolerated, but had no beneficial effect for postherpetic neuralgia and postoperative orthopedic pain 
$[355,356]$. Overall, for PKC, the challenge remains to find a sufficiently nociception-specific approach, which is equally valid for all ubiquitous kinases.

Anchoring of PKC, PKA, and also phosphatase 3A to their targets occurs through adapter proteins, for these enzymes in particular through the A-kinase anchoring proteins (AKAP); this serves to facilitate sensitization driven by bradykinin and $\mathrm{PGE}_{2}$ in certain channels, e.g., TRPV1 [357] and TRPA1 [358]. These anchoring proteins have specific interfaces to their phosphorylated targets, which could avoid the side effects of the kinases' many targets, but allow to inhibit a specific interaction [359]. However, this has so far also remained elusive.

\section{Mitogen-Activated Protein Kinases}

MAPKs are a diverse family of serine-threonine kinases which include extracellular signal-regulated kinase (ERK), p38, and c-Jun N-terminal kinase (JNK) [360]. These signaling cascades are involved in cell proliferation, and respective inhibitors have largely been evaluated or used for cancer. However, these kinases are also involved in sensitization, and their analgesic potential, directly on neurons or indirectly, e.g., reducing tumor progression, needs to be discussed [361]. In DRGs, MAPKs are activated under cellular stress conditions and proinflammatory cytokines exposure, e.g., NGF, $\mathrm{TNF} \alpha$, and thermal stimulation [362-364]. MAPK inhibitors have been extensively used for alleviating allodynia and hyperalgesia in animal models of inflammatory pain. Below are recent preclinical and clinical developments pertaining to this complex pathway. ERK inhibition with U0126 resulted in improved thermal hyperalgesia after capsaicin injection [365], normalized indices of mechanical allodynia and heat hyperalgesia [366], and alleviated chemotherapy-induced neuropathy [367]. Compounds in late stages of development or already on the market include selumetinib, which reduced pain in children with inoperable plexiform neurofibromas, again the relative importance of desensitization versus slowing of disease progression being unclear [368]. P38 inhibitors appeared to be effective in rheumatoid arthritis (PH797804, discontinued after phase II) [369], the inflammasome was inhibited by CDD-450 (ATI-450, phase II, new ongoing study) [370, 371], and pain after nerve injury was reduced by dilmapimod (SB-681323, phase II trials completed several years ago) [372]. JNK contributes to inflammatory pain, also via non-neuronal cells in the DRG $[362,373]$. Whether MAPK inhibitors prove to be useful as analgesics for patients without need for antitumor therapy or even within this group remains an open question.

\section{Src}

Src is a ubiquitously expressed tyrosine kinase, with important roles in several signaling pathways, including cell growth, division, and survival [374]. It is also strongly linked with a number of targets of inflammatory mediators (e.g., NGF) triggering the PI3K-PKB-Src pathway, and leading to TRPV1 upregulation [375]. TRPM8 function also depends on the phosphorylation state, which is regulated by Src [376]. Similarly, the role of Src in inflammation and neuropathic pain has been investigated in conjecture to the NMDA receptor complex, whose function it also enhances [377]. Using a Src inhibitor peptide, the authors suppressed both inflammation and nerve injury-induced pain, leaving other sensory functions intact. Non-specific tyrosine kinase inhibitors which also target Src, e.g., dasatinib, imatinib, are used therapeutically against several types of cancer, where they also inhibit cancer-induced pain [378], but have not been investigated so far in terms of analgesia.

\section{Interleukin Receptors, at Least Also on Sensory Neurons}

Interleukins are numbered, which obfuscates that these are clustered in superfamilies, labeled by a prominent or early member. Here, according to the review structure, these are primarily sorted based on whether they act on a receptor on sensory neurons. An overview of cytokine targets in pain has been provided $[379,380]$.

\section{IL-1}

The IL-1 receptor has been found on sensory neurons [381], although there is also conflicting evidence, where the receptor was only on DRG-supplying vessels [382]. IL-1 $\beta$-increased excitability of isolated sensory neurons should settle this issue [383]. The IL-1 superfamily consists mostly of proinflammatory mediators, key members are IL- $1 \alpha$, IL-1 $\beta$, IL-18, IL-33,

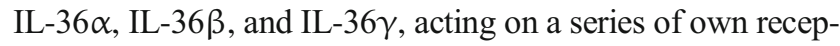
tors [384]. There are also antagonists to these respective receptors, e.g., IL-1Ra, IL-36Ra, which can belong to other superfamilies. IL- $1 \alpha$ has been labeled as a dual function cytokine with a nuclear localization sequence in its precursor region, in addition to it targeting its cell membrane receptor [385]. IL-1 $\beta$ potently induces hyperalgesia, e.g., in skin or in joints [386, 387]. The cascade is complex and involves $\mathrm{PGE}_{2}$, substance $\mathrm{P}$, nitric oxide, and endothelial adhesion molecules. Vice versa, IL-1 $\beta$ occurs also downstream upon injection of well-established inflammatory agents [388]. That review also discussed IL-1 $\beta$ involvement in glia-neuron interaction, assuming a role in neuromodulation in persistent pain states.

In clinical studies, IL- $1 \alpha$ and IL- $1 \beta$ administration leads to fever and generalized systemic inflammation, parenting strategies for disrupting the respective pathway [389, 390]. There is no doubt about the merit of targeting IL- 1 signaling in pathophysiology. There are antibodies against anti-IL- $1 \alpha$ and anti-IL-1 $\beta$ and against the IL-1 receptor [391], and with 
the first mention of therapeutic antibodies, a review of this treatment strategy is provided [392, 393]. A monoclonal antibody against IL- $1 \alpha$ reduced pain in refractory cancer patients and improved quality of life [394]. A strategy to scavenge IL$1 \beta$ before it binds to its target is through soluble receptor decoys rilonacept, gevokizumab, and canakinumab [395]. IL-1 receptors can be blocked by recombinant antibodies; anakinra was the first one to be approved in 2001 for rheumatoid arthritis and its use has been expanded to other autoinflammatory diseases [391].

A novel strategy serving this purpose is in the form of a chimeric IL- $1 \alpha / \mathrm{IL}-1 \beta$ structure, inactive until conversion to the active form at sites of inflammation [396], potentially reducing the risk of infection. It should be mentioned that the IL1R1 receptor antibody AMG108 (development discontinued) has not shown substantial effects in clinical trials [397]. All of these entities are clinically investigated in trials spanning a broad spectrum of diseases, and it remains to be scrutinized more thoroughly if they can be helpful in inflammationinduced hyperalgesia [391].

\section{IL-6}

IL-6 receptor presence in sensory neurons was shown by mRNA [398] and on a protein level, using glycoprotein 130like immunoreactivity [399]. TLR activation in monocytes and macrophages due to extracellular damage induces mRNA-transcription of IL- 6 through the NF- $\mathrm{KB}$ pathway, along with other potent pro-inflammatory cytokines, in a similar fashion to TNF $\alpha$ and IL-1 $\beta$ [400]. $\mathrm{PGE}_{2}$, e.g., produced by macrophages, also stimulates IL-6 release [401, 402]. Classic IL-6 signaling works by forming a hexameric complex comprising two molecules each of IL-6, the membrane bound or the soluble form of the IL-6 receptor and the signaling receptor component gp130 [403-406]. Signaling is mediated through the ubiquitous gp130 via the JAK/STAT transduction pathway. The role of IL-6 varies according to the organ it is produced in; in hepatocytes, it induces acute-phase proteins, such as the C-reactive protein [407], while in bone tissue, it is tightly linked with osteoclastogenesis and bone remodeling [408]. IL-6 is elevated in several models of peripheral nerve injury [409-411], and targeting IL-6 attenuates neuropathic pain [412]. Moreover, IL-6 induced calcium transients in a third of cultured rat DRG neurons, and longer exposure increased NK1 receptor immunoreactivity and substance P induced calcium transients [399]. Satellite glia cells were found to also exhibit increased levels of IL-6 and its receptor upon constriction injuries of the sciatic nerve, suggesting involvement in sensitization [413].

Therapeutic approaches are mainly based on monoclonal antibodies, targeting IL- 6 by sirukumab and siltuximab [414, 415] or the IL-6 receptor by tocilizumab [403]. So far, diseases responsive to tocilizumab seem to be characterized by long-term IL-6 action (Castleman disease, rheumatoid arthritis); the respective efforts have been summarized [416, 417]. Tocilizumab showed promising results for discogenic low back pain [418]. Several studies also pointed towards differential effects of IL- 6 versus IL-6 receptor antibodies, suggesting alternative signaling pathways not involving the IL-6 receptor [419].

IL-6 superfamily members with an association to inflammation and pain are leukemia inhibitory factor (LIF), oncostatin $\mathrm{M}$, which are found on sensory neurons, with IL27 and IL-35 discussed in the "Immune Reaction" section.

\section{Leukemia Inhibitory Factor}

In contrast to the proinflammatory function of LIF, there is also evidence of an anti-inflammatory and even neuroprotective role [420], with both points of view summarized elsewhere [421]. LIF receptor mRNA and protein have been identified in murine DRG neurons [422, 423]. Nevertheless, testing of LIF monoclonal antibodies seems to be directed towards other fields than nociception, e.g., infertility [424]. After less successful interventions on chemotherapy-induced neuropathic pain [425], it has shown promise for pancreatic cancer [426].

\section{Oncostatin M}

Oncostatin M signals through gp130 and the oncostatin Mspecific subunit beta, which is also expressed in sensory neurons, colocalized with TRPV1 and the P2X3 purinergic receptor [427]. One of its main roles seems to be in the development of nociceptors, as genetic ablation of oncostatin $\mathrm{M}$ resulted in reduced sensitivity to noxious mechanical and thermal stimuli [428]. This is in line with evidence of oncostatin Mdependent heat-induced hypersensitivity via TRPV1 sensitization [429]. A wider use has been demonstrated with inflammatory heart failure [430]. A trial with oncostatin M monoclonal antibody GSK2330811 has completed phase I (phase II ongoing) [431]. Therapeutic options for a more general antiinflammatory use can still be conceptualized.

\section{IL-4 and IL-13}

IL-4 receptors are found in both mouse and human sensory neurons and elicit functional responses [432]. A new concept is a fusion protein of two anti-inflammatory interleukins; the IL4-10 fusion protein has shown an analgesic effect in vivo in a model of osteoarthritis [433, 434]. Related to IL-4 is IL-13, which is secreted by immune cells and changes the phenotype of local macrophages towards an anti-inflammatory phenotype. Peripherally administered IL-13 reduced allodynia in a neuropathic pain model [435]. Targeting IL-4 and IL-13 with the monoclonal antibody dupilumab has proven clinically 
effective against inflammatory conditions, for atopic dermatitis patients $[436,437]$ as well as in chronic rhinosinusitis [438, 439]. This is in line with a similar effect of Janus kinase inhibitor delgocitinib (phase II studies in 2020), which reduces IL-13, IL-4, and IL-31 levels [440].

\section{IL-17}

IL-17 receptors have been found on sensory neurons, can sensitize mechanical nociception, and prolonged exposure changes the expression of pain-related targets, e.g., TRPV4 [441, 442]. IL-17 family members IL-17A-IL-17F are produced by a $\mathrm{T}$ helper cell subset called Th17. These cytokines signal through a set of heterodimeric receptors, comprised of an IL-17RA chain, and a second chain, serving ligand specificity [443]. The canonical activation leads into NF-kB and MAPK pathway activation, including ERK, p38, JNK, and CCAAT-enhancer-binding proteins (C/EBP) [443, 444]. IL$17 \mathrm{~A}$ might have the potential to mediate mechanical hyperalgesia through receptors on nociceptive neurons [442]. Recent successful therapeutic approaches have mainly targeted the progression of psoriasis inflammation, e.g., by IL17A-blocking antibodies secukinumab and ixekizumab and the IL-17RA-targeting antibody brodalumab [445-448]. A small-scale study showed a decline in pain ratings in psoriatic patients with subclinical joint inflammation [449].

\section{IL-31 and IL-33}

These interleukins were reported in conjunction with allergic diseases and itch [432]. The receptors for IL-31 and IL-33 are on sensory neurons, and the mediators can directly excite mouse DRG neurons [450, 451]. IL-31 was found to signal through the brain natriuretic peptide and is also involved in the antinociceptive as well as pruritogenic actions of morphine [452]. Hypertrophic scars can be associated with itch and pain [453], and the IL-31 signaling in this tissue was upregulated [454]. Nemolizumab, an antibody against the IL-31 receptor reduced pruritus in atopic dermatitis [455]. In psoriatic patients, lesioned skin had lower pain thresholds and elevated IL-33 expression compared with control skin [456]. There is substantial preclinical evidence supporting that this target could be exploited [457], and human trials using monoclonal antibodies against IL-33 or ST2 are in early stages [458-460].

\section{IL-2}

The IL-2 receptor was found to be expressed in the DRGs, in particular on small and medium-sized neurons, and its activation increased pain thresholds [461]. However, the recombinant IL-2 variant, aldesleukin is prescribed for metastatic kidney cancer or metastatic melanoma, indicating that analgesia is not the primary therapeutic effect.

\section{Neurotrophin Receptors}

Neurotrophins, such as NGF and BDNF, are induced in inflammatory conditions $[462,463]$. They work via the tyrosine kinase-coupled receptors of the Trk family and, depending on the concentration and duration of exposure, can elicit hyperalgesic effects [464]. The receptors for NGF and other neurotrophins are found on sensory neurons $[465,466]$, which is also the reason why NGF is frequently added to primary afferent neuron cultures.

Injection of NGF produces acute hyperalgesia, most likely through trkA signaling. In the long term, NGF causes sensitization through many effects, including mobilization to the membrane [467] and regulation of expression [468], axonal transport [469], axonal growth [470], and neuronal survival [471]. NGF increases expression of receptors involved in generating painful sensations, such as ASICs, sodium channels, and bradykinin receptors, and by release of neuropeptides [472-475]. The proinflammatory actions of NGF can be inhibited, with a reduction of allodynia and thermal hyperalgesia demonstrated more than 20 years ago [476]. Since then, therapeutic options have increased, including scavenging of NGF by antibodies, inhibition of NGF binding to trkA, and the inhibition of trkA function [477]. Despite intermediate setbacks from arthritis therapy, the monoclonal antibodies against NGF are an important contribution of antiinflammatory options [478], e.g., for arthritis, but also for low back pain [479]. BDNF receptors were found in the sensory neurons and an antibody directed against BDNF reduced bone cancer pain [480]. The central effects, also useful for other diseases, make this less of a pain target. The therapeutic options for GDNF, BDNF and NGF have been recently summarized [481].

\section{Other Targets on Sensory Neurons}

\section{TLR4}

Toll-like receptors (TLRs) are a family of well-conserved transmembrane receptors that initiate immune cell responses by recognition of pathogen-associated molecular patterns [482]. Their expression extends from immune cells to glial cells and DRG neurons [483-485]. TLR ligands have been shown to induce upregulation of several inflammatory mediators in DRG cultures [486, 487] and particularly TLR4 has emerged as an interesting target for inflammatory pain [488]. It was hypothesized that TLR4 might facilitate conversion towards chronic pain states [489] and also help maintain it [490]. TLR4 as a target to control neurogenic inflammation has been discussed [491]. Monoclonal anti-TLR4 antibody NI-0101 (phase II completed in 2018) did not show efficacy for rheumatoid arthritis [492]. TLR4 antagonist TAK-242 has antinociceptive effects in rodent neuropathic pain, low back 
pain and disc degeneration, experimental pancreatitis, and ischemia-reperfusion-induced pain [493-496]. Suppressor of cytokine signaling 3 (SOCS3) allows an anti-inflammatory intervention through TLR4 [497]. This could be enhanced by paeoniflorin, but immunomodulation by this compound has consequences, including the inhibition of the inflammasome and TRPV1 [498], and the potential of suppressor of cytokine signaling 3 cannot be judged with the available results.

\section{Prolactin Receptor}

The prolactin receptor, a type I cytokine receptor, is activated by prolactin, a polypeptide hormone with major roles in lactation and reproduction among serving regulatory effects in growth, development, and immune functions [499]. Prolactin production has been described for several tissues, including the pituitary gland, CNS, immune cells, placenta, and mammary glands [500, 501]. The main downstream effector pathway of prolactin/ prolactin receptor signaling is the JAK/STAT pathway, and MAPK is also activated [502]. Nevertheless, the prolactin receptor is intriguing in the context of nociception due to its prolactin-dependent sensitization predominantly in females, which also worked in isolated sensory neurons of females [503, 504]. More specifically, it has been hypothesized that the female sex hormone estradiol regulates translation of prolactin receptor mRNA. Alternative splicing generates a long and a short isoform of the prolactin receptor [503], and the latter seems to regulate neuronal excitability via TRPA1, TRPV1, and TRPM8 channels and modulate opioid-induced hyperalgesia [505, 506]. Pharmacological tools are available, e.g., competitive antagonist Delta1-9-G129R-hPRL [507] or the monoclonal antibody (LFA102, phase I in 2012, continued as X213 in 2016), which has been evaluated against prostate and breast cancer [508, 509]. Delta1-9-G129R-hPRL could antagonize prolactin-induced sensitization of ASICs [510]. A consequence of prolactin receptor signaling inhibition could be the dysfunction of pituitary homeostasis, e.g., pituitary hyperplasia; therefore, it is critical to consider potential side effects of prolactin receptor antagonists when attempting to establish analgesic control [511].

\section{CIC-6}

This is an electrogenic $2 \mathrm{Cl}^{-} / \mathrm{H}^{+}$exchanger with expression in afferent neurons, localized intracellularly to late endosomes [512]. ClC-6 knockout mice tolerated noxious heat longer, which might render this an interesting target to inhibit once an antagonist has been discovered.

\section{Programmed Cell Death 1}

The programmed cell death 1 receptor (PD-1) belongs to the immunoglobulin superfamily and is expressed by $\mathrm{T}$ cells [513], and also in the periphery, e.g., on epithelial and endothelial cells. The ligand PD-L1 acts as an immune suppressor and is expressed by several types of tumors, including melanomas [514]. However, the receptor and its ligand PD-L1 are also found on DRGs, and PD-L1 was shown to reduce excitability through PD-1 in rodent and human primary sensory neurons [514, 515]. Conversely, blocking the PD-L1/PD-1 pathway elicited spontaneous pain. PD-1 was required for opioid antinociception, demonstrated in knockout mice, but also with the clinically used monoclonal anti-PD-1 antibody nivolumab [516]. An association between the soluble ligand SPD-1 and pain in cancer patients has been reported [517]. Several immune checkpoints inhibitors involving the PD1/ PD-L1 pathway are approved for cancer treatment [518]; however, an overview of pain scores in treated patients is not yet available. Adverse neuromuscular effects should be mentioned [519]. Nevertheless, before this can be used as antinociceptive or opioid-enhancing, the challenge remains to disentangle immunosuppressive action from the antinociceptive one.

\section{Mediators and Antagonists Acting on Sensory Neurons}

Mediators and targets of these play overlapping roles in inflammation and inflammatory disorders. For sorting in this review, molecules with many targets were sorted in "Mediators and Antagonists Acting on Sensory Neurons," when the mediator appeared more essential than a particular of its respective receptors on sensory neurons. However, in case no such receptor is known, the target is mentioned in "Neurotrophin Receptors." Mediators can trigger the release of other mediators, generating a stimulus pattern. Some mediators can function bimodally, serving as proinflammatory or anti-inflammatory, depending on the context. Mediators which are not direct effectors of the nociceptive neurons can still be essential components of an inflammatory cascade. Therefore, targeting these in a disease-modifying approach might provide means to disrupt pathophysiology, and justifies to expect an analgesic potential and therefore discussion here.

\section{Lipid Mediators}

These are diverse and include e.g., prostaglandins, leukotrienes, hydroperoxyeicosatetraenoic acids (HPETEs), hydroxyeicosatetraenoic acids (HETEs), and epoxyeicosatrienoic acids (EETs). The generating pathways 
as well as options to intervene were well summarized [520, 521].

Prostaglandins originate from membrane phospholipids, which under the catalytic activity of PLA2 and PLA1 generate arachidonic acid and lysophospholipids. Arachidonic acid is further processed by cyclooxygenase 1, regulating baseline levels of prostaglandins, and cyclooxygenase 2 inducing prostaglandin production during inflammation. Additionally, in the brain, arachidonic acid is liberated from 2arachidonoylglycerol through endocannabinoid hydrolysis [522]. As the concentration of the important mediators critically depends on a rate-limiting enzyme activity, the latter has been successfully targeted. Cyclooxygenases are widely expressed in many tissues [523]; the resulting mediators are primarily not generated by the sensory neurons and depend on the involved cells [524]. The respective drugs are most established $[41,523]$ and among the most frequently used analgesics [525]. Lipidomic screens demonstrated that the available drugs have a differential effect on the resulting mediator patterns [520]. There are still efforts for further development [526].

Lipoxygenases convert arachidonic acid to leukotrienes, HPETEs and HETEs. An important role in leukotriene biosynthesis is held by the 5-LOX-activating protein (FLAP); as the name suggests, it serves to enhance enzyme activity, doing so through binding to arachidonic acid and presenting 5-LOX to it [527]. Potentially targetable sites along the leukotriene metabolic pathway therefore include FLAP, 5-LOX, LTA4, and LTB4 receptors [520]. FLAP as a target in inflammatory diseases has been discussed [528]. Some of the more advanced FLAP inhibitors include licofelone (phase III in 2010, no new drug application) for osteoarthritis [529], and veliflapon (phase III in 2006, no new drug application) for cardiovascular pathology [530]. Other attempts at developing FLAP inhibitors mainly oriented them towards asthma treatment with compounds such as MK-0591 (quiflapon, discontinued after phase II in 2015) [531], or GSK2190915 (several phase II trials, completed many years ago) [532]. 5LOX inhibitor development has also been pursued, outputting compounds such as flavocoxid (discontinued after phase I) [533] and atreleuton (VIA-2291, discontinued after phase III) [534]. Diflapolin, a dual inhibitor of 5-LOX and soluble epoxide hydrolase, emerged as a promising anti-inflammatory tool [535]. LTB4, an end product of the LOX signaling pathway has been involved in inflammation [536] and has been shown to generate hyperalgesia in an intracutaneous injection model in humans [537]. Interestingly, its receptors, GPCRs BLT1 and BLT2, seem to have antagonizing functions, with BLT2 activation being pronociceptive and BLT1 activation being antinociceptive, e.g., converging on TRPV1 [538]. Although pharmacological tools exist for these targets, it remains to be seen how clinical development unfolds.

\section{Lysophospholipids}

Lysophospholipids share one acyl chain, which remains after cleavage of phosphatidic acid by phospholipase A1 and A2 or by cleavage of acyl-lysophosphatidic acid or lysophosphatidylcholine by lysophospholipase D (autotaxin). Lysophosphatidic acid is a more general term describing several variations of the molecule, depending on the degree of saturation and the length of the acyl chain [539]. LPA modulates the function of members of most ion channel families [540]. In addition, there are also phospholipid receptors, in particular on cells of the immune system [541]. LPA has been shown to be involved in the genesis of neuropathic pain through direct intrathecal injection [542]. In humans, it seems that LPA levels correlate with the severity of pain symptoms in patients with various types of neuropathies [543]. LPAgenerating autotaxin levels correlate with the intensity of pruritus symptoms in patients with cholestatic itch [544]. In contrast to previous findings of direct TRP channel activation [545], LPA18:1 more substantially activates satellite glial cells and Schwann cells, suggesting an indirect neuromodulatory action [546]. LPA receptor antagonists are under development, and being tested for a number of pathologies, with analgesia not as the primary focus $[539,547,548]$.

\section{Tumor Necrosis Factor Superfamily}

TNF inhibitors are clinically used for more than 30 years. This therapeutic group has become medically important and is therefore mentioned here not as a novel approach, but as a benchmark for the potency of other approaches discussed below.

The TNF superfamily is comprised of 19 ligands and 29 receptors [549] of which probably TNF $\alpha$ is the most important and extensively studied due to its strong proinflammatory effects [550]. TNF $\alpha$ acts pronociceptive; unilateral injection of TNF $\alpha$ caused a bilateral TRPV1-dependent pain, which involves PKC, prostaglandin E2, and IL-1 $\beta$ [551]. Painrelated behavior induced by the PKC activator PMA was reduced in mice treated by an anti-TNF $\alpha$ antibody [552]. TNF $\alpha$ is cleaved from a membrane-bound precursor by the metalloproteinase TNF $\alpha$-converting enzyme (TACE). During the immune response, a variety of cells release $\mathrm{TNF} \alpha$, including activated macrophages, dendritic cells, monocytes, NK cells, CD4+ T cells, CD8+ T cells, microglia, and astrocytes [553, 554]. TNF $\alpha$ acts on TNF receptor 1 and TNF receptor 2 [555]. These receptors are found on various cell types, but it should be mentioned that they are upregulated in the DRG during inflammation [550]. In rats, intrathecal knockdown of the TNF receptor 1 decreased inflammatory hyperalgesia [556]. Based on the strong preclinical effects, antibodies against TNF $\alpha$ have been developed and are on the market since 1988 [557]. The primary indication is autoimmune disease, 
including rheumatoid arthritis, psoriasis, Crohn's disease, ulcerative colitis $[558,559]$. Clinical trials investigating peripheral pain using TNF $\alpha$ inhibitors had a promising start [560] but, overall, provided mixed results. Infliximab was not better than placebo in patients with disc herniation-induced sciatica [561] and etanercept showing varying improvements in acute lumbosacral radiculopathy $[560,562,563]$. Finally, adverse reactions at the injection site should be mentioned [564].

\section{Trypsin}

Trypsin belongs to the PA clan superfamily of serine proteases. Pathophysiology can be differentiated between the pancreas and other sites. For acute pancreatitis, an antinociceptive effect of inhibition of serine proteases was shown [565], and protease-activated receptor 2 (PAR2) contributes to this [566]. In line with this, PAR2 also contributes to pain in pancreatic cancer [567].

In tumors, PAR2 is triggered as a result of increased levels of proteolytic activity [568]. PAR2 contributes to inflammatory pain [569], in particular to mechanical-induced pain [570]. For trypsin, also an activation of vagal neurons through PAR1 has been demonstrated [571]. In the peripheral nervous system, the endogenous serine proteinase inhibitor serpin $3 \mathrm{~A}$ inhibits leukocyte elastase, and inhibition of leukocyte elastase reduced neuropathic pain in mice [572].

\section{Substance $\mathbf{P}$}

Substance $\mathrm{P}$ was identified in the early 1930 s as a vasodilating substance and structurally characterized approximately 40 years later as a undecapeptide [573, 574]. It serves as the ligand for the neurokinin receptor 1 with roles in, among others, pain and inflammation $[575,576]$. Substance $P$ is released from a series of immune cells [577] but also from terminals of primary sensory neurons in response to stimulation [578]. Upon release, or after local injection, substance $\mathrm{P}$ has been shown to increase inflammatory cytokine levels whereas a neurokinin 1 receptor antagonist was effective in reducing sensitization in an incisional model [579]. Intracellular signaling following neurokinin 1 receptor activation involves PLC-dependent intracellular calcium elevations, and also PKC and PKA activation [580, 581]. In terms of clinical use for neurokinin 1 receptor antagonists, they are attractive for targeting inflammation, but have been oriented towards reducing chemotherapy-induced nausea and vomiting, e.g., aprepitant [582]. Neurokinin 1 receptor antagonists have been considered for headache [583], but results have been disappointing [584, 585]. Also for other types of pain, in contrast to preclinical results, human data showed no analgesia for neurokinin 1 receptor inhibition [586]. A potential benefit of a more complex inhibition of multiple neurokinin receptors is unclear, or whether targeting this pathway can serve to potentiate analgesia in certain circumstances.

\section{CGRP}

Calcitonin gene-related peptide is a neuropeptide expressed in a fraction of sensory neurons and released upon their activation in a calcium-dependent manner [587]. Not too many new classes of analgesics have become available in the past, but targeting CGRP is one of these, with clear benefit for migraine patients [588]. Fremanezumab, galcanezumab, eptinezumab target CGRP, while erenumab targets the CGRP receptor.

Activity in the trigeminal system is thought to reflect headache. CGRP stimulated trigeminal activity [589] and CGRP antagonist olcegepant reduced trigeminal activity [590]. Mechanisms underlying sex-dependent differences in animals and humans are unclear [591]. Despite effective phase III trials for small molecule antagonists, poorly published concerns regarding liver toxicity effect have halted further development. Animal models support a role of CGRP in liver disease [592]. The proof of concept was put to success with monoclonal antibodies against CGRP and the CGRP receptor [588]. Given their success and independence from triptan responders, there is new incentive for further consideration and development of small-molecule antagonists [593]. This paragraph was placed in the mediator section, as the functional role of CGRP receptors on neurons is unclear. CGRP does not excite the terminals [594], is found on Schwann cells and on central but not peripheral axons [595], and the site of action is also proximal to the ganglion [596], assumably postsynaptic.

\section{Acidosis}

Local $\mathrm{pH}$ decrease is a robust follow-up of the onset of inflammation, resulting from immune cell infiltration, increased demand in oxygen and energy, and accelerated glycolysis and acidic molecule secretion, such as lactic acid [597]. In addition, local phagocytic bursts result in a dramatic increase in local proton concentrations [598]. This in turn has been shown to stimulate proinflammatory factor secretion, such as TNF $\alpha$ and IL-1 $\beta[599,600]$. Low $\mathrm{pH}$ has been shown repeatedly to be an activator of sensory neurons $[601,602]$. Several structures can in principle sense low $\mathrm{pH}$, including acid-sensing ion channels (ASICs), $\mathrm{K}_{2 \mathrm{P}}$ channels, the four proton-sensitive GPCRs discussed above, and TRPV1 [270, 603]. Peptide isolation from the black mamba venom has also revealed an interesting new group of molecules, mambalgins, targeting acid sensors with analgesic effects [604, 605]. Recently, it has been reinforced that in humans, TRPV1 is the main contributor to mild and pathophysiologically relevant acidosisinduced pain in the skin [276], which supports using 
modality-specific TRPV1 antagonists as a new tool for inflammatory pain.

\section{ADAMTS}

ADAMTS abbreviates for "a disintegrin and metalloproteinase with thrombospondin motifs." In contrast to ADAMS, which are mainly cell membrane proteins, ADAMTS are secreted enzymes [606]. This family is comprised of 19 members of which ADAMTS-4 (aggrecanase-1) uses chondroitin sulfate hyaluronan-binding proteoglycans as a substrate, including aggrecan [607]. ADAMTS-4 and ADAMTS-5 are proteases with important developmental roles [608], associated with inflammatory disorders, in particular osteoarthritis, where cartilage degradation results in joint pain [609]. Aggrecan is attached to the surface of chondrocytes, and with it the bulk of chondroitin sulfate, a critical water absorbing component of the cartilaginous structure [610]. The cleaving process mediated by ADAMTS-4 and ADAMTS- 5 releases the chondroitin sulfate-modified C-terminus from the chondrocytes into the synovium, and inhibitors could prevent osteoarthritis cartilage loss. In this regard, several substances with antagonizing effects have been investigated, including disease-modifying anti-rheumatic drugs, nonsteroidal antiinflammatory drugs, and statins [608]. Tissue inhibitor of metalloproteinase TIMP-3 could serve as a prototype for biological treatments $[611,612]$. In summary, these targets appear to reduce pain primarily through disease modification. For ADAMTS-13, despite some search hits, pain occurs also only disease-associated and the literature does not suggest analgesic potential.

\section{Glutamate Carboxypeptidase II}

Glutamate production, to which this enzyme contributes, is a basis of this important neurotransmitter, and might be an alternative to inhibition of receptors for glutamate [613]. Mice deficient of this enzyme had less neuropathic pain [614], and an orally available antagonist for this enzyme reduced neuropathic pain [615].

\section{Amino Acid Metabolism}

Amino acids are typically not classified as mediators, but are nevertheless discussed here. Tumors and other fast-dividing tissues depend on metabolites, including glucose and amino acids. Therefore, nutrient deprivation of these has been tested to limit tumor growth [616]. Amino acids of interest are glutamine, serine, methionine, asparagine, and arginine [617]. Therefore, key enzymes of the respective metabolic reactions have been considered targets, and this might be extended to the control of pain. Caloric restriction has been associated with a reduction of pain in rodents [618, 619]. A change in amino acid composition has also been useful in low back pain patients [620], although a normalization of lowered amino acid levels was observed. A dietary intervention also improved chronic pancreatitis, again with a mixed effect on plasma amino acid levels [621].

Attempts to target individual amino acid metabolism for pain included glutaminase inhibition. However, antagonist CB-839 failed to reduce cancer-induced bone pain, which might be due to more metabolic flexibility of the tumor than expected [622]. Another option would be targeting transmembrane amino acid transporters. It remains to be determined whether a metabolic intervention allows to reduce pain with an acceptable level of adverse effects.

\section{IL-36}

IL-36 $\alpha$, IL-36 $\beta$, and IL-36 $\gamma$ have been outlined as relevant promoters for skin psoriasis, psoriatic arthritis, and rheumatoid arthritis [623]. The anti-inflammatory cytokine interleukin-36Ra is reduced in psoriasis [624] and anti-IL-36 receptor antibodies reduced tissue inflammation in a psoriasis mouse model [625]. IL-38, the most recent addition to the IL1 superfamily, is an anti-inflammatory cytokine, acting through inhibition of the IL-36 receptor [626], and reduces IL-1 $\beta$, IL-6, IL-8, IL- $1 \alpha$, and TNF- $\alpha$ [623, 627, 628].

\section{Immune Reaction}

The general function of the immune system and the many and differentiated approaches for anti-inflammatory intervention are beyond the scope of this effort and are regularly reviewed. The aim of this last chapter is to point the reader to recent literature on this topic, in particular for matters considered of relevance to pain.

\section{Cytokines as Part of the Immune Reaction}

Therapeutic options to target cytokines in inflammatory diseases have been discussed [629].

\section{IL-18 and IL-37}

IL-18, first described as "interferon gamma-inducing factor," is structurally close to IL-1 $\beta$. It is nevertheless functionally distinct [630], e.g., it does not induce $\mathrm{PGE}_{2}$ production [631]. The IL-18 receptor is primarily found in immune cells [632]. In rats, intrathecal IL-18 application reduced pain withdrawal thresholds and IL-18 scavenging by an antibody or a binding protein alleviated nerve injury-induced hypersensitivity [633, 634]. The respective mechanism appears to involve spinal microglia. IL-18-binding protein is a constitutively secreted protein, with higher affinity for IL-18 than the IL-18R $\alpha$ and 
is supposed to act as a down-regulator of Th1 immune responses through IL-18 binding and reduction of IFN $\gamma$ induction [635]. Tadekinig alfa is a recombinant human IL-18binding protein that has been under clinical scrutiny for the treatment of adult-onset Still's disease [636] and could hold promise for providing analgesia in inflammatory diseases with imbalance between IL-18 and the IL-18 binding protein. IL37 is an endogenous suppressor of proinflammatory cytokine secretion, reducing IL- $1 \beta$, IL- 8 , IL- $1 \alpha$, and TNF $\alpha$ in patients with systemic inflammatory diseases [637]. IL-37 in association with the IL-18-binding protein inhibits the IL-18 receptor alpha [638]; in addition, SMAD family member 3 is discussed as a target [639]. For anti-inflammatory interleukins, application of a recombinant form might be an option and has been used for other interleukins [640]. Recombinant IL-37 is available and might serve as a viable strategy for reducing inflammation [641]. However, until the moment of writing, this has not been clinically investigated.

\section{Colony-Stimulating Factors}

Granulocyte colony-stimulating factor (G-CSF) and granulocyte-macrophage colony-stimulating factor (GM$\mathrm{CSF}$ ) have been shown to act directly on the respective receptors on DRG neurons, causing sensitization [642]. G-CSF is the primary driver of neutrophil differentiation. Binding of GCSF to its receptor induces signal transduction through STAT3, PI3K, and ERK [643]. Recombinant G-CSF filgrastim and lenograstim are clinically used for neutrophil regeneration after chemotherapy or myeloablation [644]. Adverse effects include inflammation, swelling, pain, and stinging; the most common adverse effect of pegfilgrastim and lenograstim is bone pain $[645,646]$. In addition, there seems to be a role for microglia in G-CSF-driven neuronal hyperexcitability [647]. G-CSF monoclonal antibodies have entered clinical trials [648] and show some promise for the treatment of persistent pain following inflammation resolution.

GM-CSF is principally expressed in myeloid precursors, mature monocytes, and granulocytes [649]. The respective receptor is found on myeloid cells, in particular monocytes and granulocytes [650]. GM-CSF signals through JAK2/STAT5a/b in addition to PI3K, RAS/MAPK, and NF-KB [651]. Recombinant GM-CSF accelerates wound healing [652], with an obvious implication of inhibition of this mechanism. Studies using GM-CSF knockout mice and monoclonal antibodies against GM-CSF have shown that the cytokine is key in the development of osteoarthritis and rheumatoid arthritis-associated pain [653]. Moreover, silencing GM-CSF signaling in a model of peripheral nerve ligation induced analgesia, supporting a role in neuropathic pain upon intrathecal and not peripheral delivery of anti-GM-CSF receptor antibodies [654]. Clinical studies involving mavrilimumab were promising for targeting this pathway in rheumatoid arthritis [655] and could be explored further as a tool for providing analgesia in inflammatory conditions.

Macrophage colony-stimulating factor (M-CSF or CSF1) expression is increased in DRG neurons following peripheral nerve injury with the M-CSF receptor mRNA being induced in spinal microglia [656]. Recombinant M-CSF given intrathecally led to mechanical allodynia, while blocking its receptor suppressed mechanical allodynia after SNI [657].

\section{IL-12}

Interleukin 12 is produced in monocytes, macrophages, and dendritic cells [658]. IL-12 generates mechanical but not thermal hyperalgesia upon intraplantar injection into the rat hindpaw, with the endothelin B receptor being reported to mediate this action [659]. Endothelin B receptors are expressed on DRG neurons; however, endothelin 1 and synthetic agonist IRL-1620 decrease the excitability of DRG neurons [660], which seems contradictory to the IL-12 effect being mediated through endothelin B receptors. Only one of two heteromeric IL-12 subunits has been identified in the mouse DRG and was surprisingly downregulated after sciatic nerve damage [661]. Nevertheless, patients receiving recombinant IL-12 infusion as therapy for various types of cancer, reported painful symptoms, such as arthralgias [662] or headaches and abdominal pain [663], allowing to consider anti-IL-12 as a concept.

\section{IL-27 and IL-35}

IL-27 and IL-35 are structurally different (heterodimeric cytokines) to the original members, however still considered a part of the IL-6 superfamily. Genetic ablation of IL-27 was shown to deprive mice of an innate IL-10-dependent antinociceptive reaction in a nerve injury model [664]. IL-27 acts anti-inflammatory, limiting thermal and mechanical sensation, as mice lacking IL-27 or its receptor spontaneously showed chronic pain-like hypersensitivity, with reversal of the behaviors upon recombinant IL-27 injection [665]. Anti-inflammatory cytokine IL-35 was antinociceptive in an autoimmune encephalomyelitis pain model [666]. The anti-inflammatory properties of IL-35 were also shown in a model of diabetic neuropathy, associated with JNK downregulation [667] and neuroprotective microglial M2 polarization [668].

\section{IL-23}

Interleukin 23 is mainly released from dermal dendritic cells in skin psoriasis models. This stimulates a $\gamma \delta-\mathrm{T}$ cell subset, triggering IL-17 and IL-22 secretion [669], and can lead to itch, pain, and discomfort. Interestingly, a TRPV1- and $\mathrm{Na}_{\mathrm{v}} 1.8$-positive subpopulation of sensory neurons was 
required for the IL-23 production of dermal dendritic cells, the signaling pathway from nociceptors to dermal dendritic cells is unclear [670].

\section{Interferons}

Receptors for type I interferons IFN- $\alpha$ and IFN- $\beta$ are expressed in small and medium-sized DRG neurons. The activation of these receptors increases excitability and produces mechanical pain in mice [671].

The receptor for type II interferon gamma (IFN $\gamma$ ) has also been reported on DRG neurons [672]. IFN $\gamma$ is produced by $\mathrm{T}$ cells and other immune cells [673] and has a proinflammatory role [674] acting on microglia [675]. IFN $\gamma$ is medically used for osteopetrosis and chronic granulomatous disease, the antibody against IFN $\gamma$ emapalumab for the treatment of haemophagocytic lymphohistiocytosis [676]. In summary, this does not indicate a relevant analgesic potential for interferons.

\section{IL-10}

Interleukin 10 is considered an important anti-inflammatory cytokine, signaling through the IL-10 receptor which is found primarily on leukocytes [677]; an expression on sensory neurons has not been reported. Pathways include STAT1, STAT3, PI3K, and p38 MAPK [678, 679], inhibiting the synthesis of proinflammatory cytokines such as IFN- $\gamma$, IL-2, IL3, TNF $\alpha$, and GM-CSF.

Recombinant IL-10 has been tested as anti-inflammatory treatment in clinical trials, but results were heterogeneous, e.g., disappointing for rheumatoid arthritis, but promising for psoriasis [680]. However, also proinflammatory actions were observed [681], including flu-like symptoms [682]. Given the many studies, a general anti-inflammatory and thereby analgesic role seems unlikely.

\section{Chemokines}

Chemokines are a family of cytokines with around 50 members. These small secreted proteins act on GPCRs and have important roles in leukocyte chemotaxis [683]. Some of the receptors are also expressed at the level of primary afferents [684]. A function of these is neuron to glia signaling, e.g., sensory neuron CX3CL1 induces microglial activation via CX3CR1, as well as glia to neuron signaling, e.g., CCL2 and CXCL1 from spinal astrocytes acting on neuronal CCR2 and CXCR2. Moreover, it has been shown that a series of chemokines, many of which secreted by resident leukocytes, can exert direct excitatory effects on primary sensory neurons, and also lead to the release of substance $\mathrm{P}$ [685]. This might account for some of the increased pain sensitivity in a variety of inflammatory conditions. The challenge for effective analgesic therapeutics to emerge is targeting proalgesic effects without undermining useful immune function, hence the relative paucity of clinical trials exploring chemokine receptor antagonists' analgesia.

\section{Free Radicals in Inflammation}

The framework describing the role of redox reactions in cellular homeostasis and pathological processes is more recently known as "the redox code" [686] or similarly the "reactive species interactome" [687]. Reactive oxygen species are well-documented, with one of the most important being superoxide. Produced mainly in the mitochondria, by interaction of leak electrons with oxygen or through $\mathrm{NAD}^{+}$oxidation, via xanthine oxidase [688] or even as a result of COX or LOX function, superoxide is reduced to the subsequent ROS species, hydrogen peroxide and the hydroxyl radical. The latter is especially unstable and reacts readily, with membrane lipids fueling lipid peroxidation processes and even with DNA [689]. The role of ROS in the early stages of inflammation or tissue injury is well established, as they are produced during the respiratory burst in phagocytic cells [690]. More so, ROS production is a result of most antitumor drugs and the main mechanism by which photodynamic therapy works [691]. The intense pain generated by photodynamic therapy is explained by a photosensitizing effect on primary sensory neurons, namely the subpopulations expressing TRPA1 and TRPV1, which have also been shown to be directly gated by ROS $[171,172,692]$. With regard to reactive nitrogen species, nitric oxide matches one of the smallest molecular sizes with an extremely important role in vascular biology, acting as an endogenous vasodilator [693]. NO is produced by nitric oxide synthases. Coded by separate genes on different chromosomes, nitric oxide synthases are either constitutive (endothelial, neuronal eNOS, nNOS) or inducible (iNOS). The first two produce transient pico- to nanomolar concentrations of $\mathrm{NO}$ and are dependent on intracellular calcium levels, whereas iNOS is calcium-independent and results in long-lasting micromolar concentrations of NO [694]. Some NO results from swallowed nitrite $\left(\mathrm{NO}_{2}{ }^{-}\right)$, or from nitrites in the UVA or blue light-exposed skin [695]. In sensory neurons, NO plays a very important role in modulating pain sensitivity during inflammation [696, 697], as confirmed by the analgesic effect of NO synthesis inhibitors [698]. Downstream of NO, soluble guanylate cyclase activation takes effect, leading to increases in cGMP [699], also in central spinal cord neurons [700]. Direct infusion of NO causes pain in humans [701] and TRPA1 and TRPV1 have been shown to be NO sensors [702]. Reactive sulfur species are less well characterized than the others, potentially due to less stability in experimental conditions. Interestingly, there is an emerging interest for interaction with RNS $\left(\mathrm{NO} / \mathrm{H}_{2} \mathrm{~S}\right.$ crosstalk) and the formation of sulfur/nitrogen reactive species (nitrosopersulfide, SSNO) 
[687] and HNO in the presence of hydrogen sulfide [703, 704]. Further, NO can disrupt cysteine bonds and form S-nitrosylated residues, with structural consequences for (membrane) proteins [705]. Inhibiting or scavenging reactive species has not been a convincing strategy to combat pain and pathophysiology. Inhibiting the target of these reactive species, in particular TRPA1, might be more promising.

\section{NLRP3}

NLRP3 (NALP3) is a Nod-like receptor subset with an inflammasome-forming pattern recognition receptor of the innate immune system, a multimeric protein complex with NLRP3 as the sensor component, alongside adaptor protein ASC and the effector caspase 1, and is representative of a major inflammatory pathway [706, 707]. Downstream effects of NLRP3 activation include increased levels of proinflammatory mediators, spearheaded by IL- $1 \beta$, eventually accounting for hypersensitivity [708]. Moreover, this particular inflammasome is triggered in conditions such as gout, rheumatoid arthritis, and fibromyalgia [709]. The clinical progress with several antagonists for the NLRP3 pathway has been reviewed [710]. Targeting the NLRP3 inflammasome has been attempted with varying degrees of success. Tranilast, approved in 1982, has been found to inhibit the assembly of NLRP3 inflammasome [711]. However, tranilast can induce cystitis [712], which might be partial agonistic through TRPA1 [713]. MCC950 [714-716] and dapansutrile have reached phase II [717] and could be a promising new approach.

\section{Conclusion}

This work aimed at summarizing the status quo of preclinical and clinical research of well-established targets for analgesia as well as showcasing novel, potentially addressable elements of a multitude of signaling pathways involved in nociception, the majority of which, of inflammatory nature. One must always consider farreaching repercussions, especially pertaining to immune system function and pathology-appropriate treatment scenarios. However, too many new approaches fail due to translational hurdles, adverse effects, lack of efficacy, but also regulations. A positive outlook is that most of the presented strategies involve specificity towards one or several targets (e.g., monoclonal antibodies), some already in different phases of clinical trials.

Acknowledgements Open access funding provided by Medical University of Vienna.
Required Author Forms Disclosure forms provided by the authors are available with the online version of this article.

\section{Compliance with Ethical Standards}

Conflict of Interest The authors declare that they have no conflict of interest.

Abbreviations 2-AG, 2-Arachidonoylglycerol; 5- $H T$, Serotonin; 5- $H T_{1-}$ 7, Serotonin receptors 1-7; ADAMTS, A disintegrin and metalloproteinase with thrombospondin motifs; $A D P$, Adenosine diphosphate; $A E A$, Anandamide; $A M P$, Adenosine monophosphate; $A S I C$, Proton-gated acid-sensing ion channel; $A T P$, Adenosine triphosphate; $B D N F$, Brainderived neurotrophic factor; $B P S$, British Pharmacological Society; $C$ / $E B P S$, CCAAT-enhancer-binding proteins; $\mathrm{CaCC}$, Calcium-activated chloride channels; $C a_{v}$, Voltage-gated calcium channels; $C B_{1-2}$, Cannabinoid receptors; $C C$, C-C motif chemokine; $C F T R$, Cystic fibrosis transmembrane conductance regulator; $C G R P$, Calcitonin gene-related peptide; $\mathrm{ClC}$, Chloride channel family; $\mathrm{COX}$, Cyclooxygenase; $\mathrm{CX} 3 \mathrm{C}$, C-X3-C motif chemokine; $D D C$, Dermal dendritic cells; $D P 1$, PGD2 receptor; $D R G$, Dorsal root ganglia; EETs, Epoxyeicosatrienoic acids; $E N a C$, Epithelial $\mathrm{Na}^{+}$channel; $E P_{1-4}$, PGE receptors; Epac, Exchange factor directly activated by cAMP; ERK, Extracellular signal-regulated kinase; $F A A H$, Fatty acid amide hydrolase; FDA, Food and Drug Administration; FLAP, 5-LOX-activating protein; $F P$, PGF receptor; $G$ $C S F$, Granulocyte colony-stimulating factor; $G D N F$, Glial cell linederived neurotrophic factor; $G D P$, Guanosine diphosphate; $G M-C S F$, Granulocyte-macrophage colony-stimulating factor; $G P C R$, G proteincoupled receptor; GTP, Guanosine triphosphate; $H_{1-4}$, Histamine receptors $1-4 ; H_{C N}$, Hyperpolarization-activated cyclic nucleotide-gated channels 1-4; HETES, hydroxyeicosatetraenoic acids; HGCN, Hyperbolic graph convolutional neural network; HPETES, Hydroperoxyeicosatetraenoic acids; $I F N$, Interferon; $I L$, Interleukins; $I P$, PGI receptor; IUPHAR, International Union of Basic and Clinical Pharmacology; JNK, c-Jun N-terminal kinase; $K C C 2, \mathrm{~K}^{+}-\mathrm{Cl}^{-}$ cotransporter; $K_{i r}$, Inwardly rectifying $\mathrm{K}^{+}$channels; $L I F$, Leukemia inhibitory factor; $L O X$, Lipoxygenase; $L P A$, Lysophosphatidic acid; $L T B 4$, Leukotriene B4; $M A G L$, Monoacylglycerol lipase; $M A P K$, Mitogen-activated protein kinase; $M-C S F$, Macrophage colony-stimulating factor; $N a_{v}$, Voltage-gated sodium channels; $N F-k B$, Nuclear factor kappalight-chain-enhancer of activated B cells; $N G F$, Nerve growth factor; $N K 1$, Neurokinin 1; NKCC1, $\mathrm{Na}^{+}-\mathrm{K}^{+}-2 \mathrm{Cl}^{-}$transporter; $N L R P 3$, NODlike receptor family subset; $N O$, Nitric oxide; $N O S$, Nitric oxide synthase; OSM, Oncostatin M; PAC1R, PACAP type I receptor; PACAP, Pituitary adenylate cyclase-activating polypeptide; $P A R$, Protease-activated receptor; $P D-1$, Programmed cell death 1 receptor; $P D-L 1$, Programmed cell death 1 ligand $1 ; P G D_{2}$, Prostaglandin D2; $P G E$, Prostaglandin E; $P G F$, Prostaglandin F; PGI, Prostacyclin; $P I 3 K$, Phosphatidylinositol 3-kinase; $P K A$, Protein kinase A; $P K C$, Protein kinase C; $P L A$, Phospholipase; $P L C$, Phospholipase $\mathrm{C} ; R G D$, Rat Genome Database; $R O S$, Reactive oxygen species; $S 1 P$, Sphingosine-1-phosphate; $S 1 P R$, Sphingosine-1phosphate receptor; SOCS3, Suppressor of cytokine signaling 3; STAT, Signal transducer and activator of transcription; TACE, TNF $\alpha$ converting enzyme; TIMP, Tissue inhibitor of metalloproteinase; $T N F \alpha$, Tumor necrosis factor alpha; TP, TXA receptor; trkA, Neurotrophic receptor tyrosine kinase 1; TRP, Transient receptor potential (channels); TXA, Thromboxane A; VRAC, Volume-regulated anion channels

Open Access This article is licensed under a Creative Commons Attribution 4.0 International License, which permits use, sharing, adaptation, distribution and reproduction in any medium or format, as long as you give appropriate credit to the original author(s) and the source, provide a link to the Creative Commons licence, and indicate if changes were made. The images or other third party material in this article are included in the article's Creative Commons licence, unless indicated 
otherwise in a credit line to the material. If material is not included in the article's Creative Commons licence and your intended use is not permitted by statutory regulation or exceeds the permitted use, you will need to obtain permission directly from the copyright holder. To view a copy of this licence, visit http://creativecommons.org/licenses/by/4.0/.

\section{References}

1. Yaksh TL, Woller SA, Ramachandran R, Sorkin LS. The search for novel analgesics: targets and mechanisms. F1000Prime Rep 2015; 7. https://doi.org/10.12703/P7-56.

2. Saleem M, Naz H. Analgesics: New Target and Sources. Pain Relief - From Analgesics to Alternative Therapies. 2017 [cited 10 May 2020]. https://doi.org/10.5772/67853.

3. Yekkirala AS, Roberson DP, Bean BP, Woolf CJ. Breaking barriers to novel analgesic drug development. Nat Rev Drug Discov 2017;16: 810. https://doi.org/10.1038/nrd.2017.202.

4. Zhang J-M, An J. Cytokines, inflammation, and pain. Int Anesthesiol Clin 2007;45: 27-37. https://doi.org/10.1097/AIA. 0b013e318034194e.

5. Matsuda M, Huh Y, Ji R-R. Roles of inflammation, neurogenic inflammation, and neuroinflammation in pain. J Anesth 2019;33: 131-139. https://doi.org/10.1007/s00540-018-2579-4.

6. Simmons DL. What makes a good anti-inflammatory drug target? Drug Discov Today 2006;11: 210-219. https://doi.org/10.1016/ S1359-6446(05)03721-9.

7. Yeung YT, Aziz F, Guerrero-Castilla A, Arguelles S. Signaling pathways in inflammation and anti-inflammatory therapies. Curr Pharm Des 2018;24: 1449-1484. https://doi.org/10.2174/ 1381612824666180327165604.

8. Mollanazar NK, Smith PK, Yosipovitch G. Mediators of chronic pruritus in atopic dermatitis: getting the itch out? Clin Rev Allergy Immunol 2016;51: 263-292. https://doi.org/10.1007/s12016-0158488-5.

9. Wangzhou A, Paige C, Neerukonda SV, Dussor G, Ray PR, Price TJ. A pharmacological interactome platform for discovery of pain mechanisms and targets. bioRxiv. 2020; 2020.04.14.041715. https://doi.org/10.1101/2020.04.14.041715.

10. Sayers E. The E-utilities In-Depth: Parameters, Syntax and More. Entrez Programming Utilities Help [Internet]. National Center for Biotechnology Information (US); 2018. Available: https://www. ncbi.nlm.nih.gov/books/NBK25499/.

11. IUPHAR/BPS Guide to PHARMACOLOGY. [cited 10 May 2020]. Available: https://www.guidetopharmacology.org/ download.jsp..

12. $\mathrm{Fu} \mathrm{LD}$, Aliferis $\mathrm{C}$. Models for predicting and explaining citation count of biomedical articles. AMIA Annu Symp Proc 2008; 222 226

13. Yang H, Lee HJ. Research trend visualization by MeSH terms from PubMed. Int J Environ Res Public Health 2018;15. https:// doi.org/10.3390/ijerph15061113.

14. Insel PA, Snead A, Murray F, Zhang L, Yokouchi H, Katakia T, et al. GPCR expression in tissues and cells: are the optimal receptors being used as drug targets? Br J Pharmacol 2012;165: 16131616. https://doi.org/10.1111/j.1476-5381.2011.01434.x.

15. Csanády L. A new target for G protein signaling. Elife. 2017;6. https://doi.org/10.7554/eLife.31106.

16. Salzer I, Ray S, Schicker K, Boehm S. Nociceptor signalling through ion channel regulation via GPCRs. Int J Mol Sci 2019;20. https://doi.org/10.3390/ijms20102488.

17. Brack A, Rittner HL, Machelska H, et al. Endogenous peripheral antinociception in early inflammation is not limited by the number of opioid-containing leukocytes but by opioid receptor expression. Pain. 2004;108: 67-75. https://doi.org/10.1016/j.pain.2003.12. 008.

18. Labuz D, Mousa SA, Schäfer M, Stein C, Machelska H. Relative contribution of peripheral versus central opioid receptors to antinociception. Brain Res 2007;1160: 30-38. https://doi.org/10. 1016/j.brainres.2007.05.049.

19. Rau KK, Caudle RM, Cooper BY, Johnson RD. Diverse immunocytochemical expression of opioid receptors in electrophysiologically defined cells of rat dorsal root ganglia. J Chem Neuroanat 2005;29: 255-264. https://doi.org/10.1016/j. jchemneu.2005.02.002.

20. Stein C, Schäfer M, Machelska H. Attacking pain at its source: new perspectives on opioids. Nat Med 2003;9: 1003-1008. https://doi.org/10.1038/nm908.

21. Willer JC, Roby A, Ernst M. The enkephalinase inhibitor, GB 52, does not affect nociceptive flexion reflexes nor pain sensation in humans. Neuropharmacology. 1986;25: 819-822. https://doi.org/ 10.1016/0028-3908(86)90004-3.

22. Fournie-Zaluski MC, Chaillet P, Bouboutou R, et al. Analgesic effects of kelatorphan, a new highly potent inhibitor of multiple enkephalin degrading enzymes. Eur J Pharmacol 1984;102: 525528. https://doi.org/10.1016/0014-2999(84)90575-2.

23. Roques BP, Fournié-Zaluski M-C, Wurm M. Inhibiting the breakdown of endogenous opioids and cannabinoids to alleviate pain. Nat Rev Drug Discov 2012;11: 292-310. https://doi.org/10.1038/ $\operatorname{nrd} 3673$.

24. Thanawala V, Kadam VJ, Ghosh R. Enkephalinase inhibitors: potential agents for the management of pain. Curr Drug Targets 2008;9: 887-894. https://doi.org/10.2174/138945008785909356.

25. Reaux-Le Goazigo A, Poras H, Ben-Dhaou C, et al. Dual enkephalinase inhibitor PL265: a novel topical treatment to alleviate corneal pain and inflammation. Pain. 2019;160: 307-321. https://doi.org/10.1097/j.pain.0000000000001419.

26. Sehgal N, Smith HS, Manchikanti L. Peripherally acting opioids and clinical implications for pain control. Pain Physician 2011;14: 249-258.

27. Puehler W, Zöllner C, Brack A, et al. Rapid upregulation of mu opioid receptor mRNA in dorsal root ganglia in response to peripheral inflammation depends on neuronal conduction. Neuroscience. 2004;129: 473-479. https://doi.org/10.1016/j. neuroscience.2004.06.086.

28. Machelska H, Schopohl JK, Mousa SA, Labuz D, Schäfer M, Stein C. Different mechanisms of intrinsic pain inhibition in early and late inflammation. J Neuroimmunol 2003;141: 30-39. https:// doi.org/10.1016/s0165-5728(03)00213-3.

29. Pergolizzi Jr JV, Christo PJ, LeQuang JA, Magnusson P. The Use of Peripheral $\mu$-Opioid Receptor Antagonists (PAMORA) in the management of opioid-induced constipation: an update on their efficacy and safety. Drug Des Devel Ther 2020;14: 1009-1025. https://doi.org/10.2147/DDDT.S221278.

30. Eisenach JC, Carpenter R, Curry R. Analgesia from a peripherally active kappa-opioid receptor agonist in patients with chronic pancreatitis. Pain. 2003;101: 89-95. https://doi.org/10.1016/s03043959(02)00259-2.

31. Rush University Medical Center. Topical Loperamide Gel for Pain Reduction During Repeat Finger Lancing. 2015. https:// ClinicalTrials.gov/show/NCT02711891.

32. Nektar Therapeutics. A Phase 2 study to assess the efficacy, tolerability, and safety of NKTR-181 in subjects with chronic OA knee pain. 2012. https://ClinicalTrials.gov/show/NCT01619839.

33. Nektar Therapeutics. Long-term safety and tolerability study of NKTR-181 in subjects with chronic low back pain or chronic non-cancer pain. 2015. https://ClinicalTrials.gov/show/ NCT02367820. 
34. Arendt-Nielsen L, Olesen AE, Staahl C, et al. Analgesic efficacy of peripheral kappa-opioid receptor agonist CR665 compared to oxycodone in a multi-modal, multi-tissue experimental human pain model: selective effect on visceral pain. Anesthesiology. 2009;111: 616-624. https://doi.org/10.1097/ALN. 0b013e3181af6356.

35. Beck TC, Reichel CM, Helke KL, Bhadsavle SS, Dix TA. Nonaddictive orally-active kappa opioid agonists for the treatment of peripheral pain in rats. Eur J Pharmacol 2019;856: 172396. https:// doi.org/10.1016/j.ejphar.2019.05.025.

36. Cara Therapeutics I. A phase 2 study to evaluate analgesic effect of IV CR845 for pain following bunionectomy surgery. https:// ClinicalTrials.gov/show/NCT01789476;. 2013.

37. Toray Industries I. TRK-820 study in subjects on hemodialysis with or without uremic pruritus. https://ClinicalTrials.gov/show/ NCT03002233;. 2016.

38. Cenac N, Castro M, Desormeaux C, et al. A novel orally administered trimebutine compound (GIC-1001) is anti-nociceptive and features peripheral opioid agonistic activity and Hydrogen Sulphide-releasing capacity in mice. Eur J Pain 2016;20: 723 730. https://doi.org/10.1002/ejp.798.

39. gicare Pharma Inc, JSS Medical Research Inc, Algorithme Pharma Inc. A phase 2a, proof-of-concept study of GIC-1001 in the management of visceral pain during sedation-free, full colonoscopy. https://ClinicalTrials.gov/show/NCT01926444;. 2013.

40. Oida H, Namba T, Sugimoto Y, et al. In situ hybridization studies of prostacyclin receptor mRNA expression in various mouse organs. Br J Pharmacol 1995;116: 2828-2837. https://doi.org/10. 1111/j.1476-5381.1995.tb15933.x.

41. Ferreira SH. Prostaglandins, aspirin-like drugs and analgesia. Nat New Biol 1972;240: 200-203. https://doi.org/10.1038/ newbio240200a0.

42. Moriyama T, Higashi T, Togashi K, et al. Sensitization of TRPV1 by EP1 and IP reveals peripheral nociceptive mechanism of prostaglandins. Mol Pain 2005;1: 3. https://doi.org/10.1186/17448069-1-3.

43. Amaya F, Wang $\mathrm{H}$, Costigan $\mathrm{M}$, et al. The voltage-gated sodium channel $\mathrm{Na}(\mathrm{v}) 1.9$ is an effector of peripheral inflammatory pain hypersensitivity. J Neurosci 2006;26: 12852-12860. https://doi. org/10.1523/JNEUROSCI.4015-06.2006.

44. Villarreal CF, Sachs D, Cunha F de Q, Parada CA, Ferreira SH. The role of $\mathrm{Na}(\mathrm{V}) 1.8$ sodium channel in the maintenance of chronic inflammatory hypernociception. Neurosci Lett 2005;386: 72 77. https://doi.org/10.1016/j.neulet.2005.04.060.

45. Chemin J, Mezghrani A, Bidaud I, et al. Temperature-dependent modulation of $\mathrm{CaV} 3 \mathrm{~T}$-type calcium channels by protein kinases $\mathrm{C}$ and A in mammalian cells. J Biol Chem 2007;282: 32710 32718. https://doi.org/10.1074/jbc.M702746200.

46. Wang C, Li G-W, Huang L-YM. Prostaglandin E2 potentiation of $\mathrm{P} 2 \mathrm{X} 3$ receptor mediated currents in dorsal root ganglion neurons. Mol Pain 2007;3: 22. https://doi.org/10.1186/1744-8069-3-22.

47. Meves H. The action of prostaglandins on ion channels. Curr Neuropharmacol 2006;4: 41-57.

48. Gu Q, Kwong K, Lee L-Y. Ca2+ transient evoked by chemical stimulation is enhanced by PGE2 in vagal sensory neurons: role of cAMP/PKA signaling pathway. J Neurophysiol 2003;89: 19851993. https://doi.org/10.1152/jn.00748.2002.

49. Lopshire JC, Nicol GD. The cAMP transduction cascade mediates the prostaglandin E2 enhancement of the capsaicin-elicited current in rat sensory neurons: whole-cell and single-channel studies. J Neurosci 1998;18: 6081-6092.

50. Sachs D, Villarreal C, Cunha F, Parada C, Ferreira S. The role of PKA and PKCepsilon pathways in prostaglandin E2-mediated hypernociception. Br J Pharmacol 2009;156: 826-834. https:// doi.org/10.1111/j.1476-5381.2008.00093.x.
51. De Logu F, Li Puma S, Landini L, et al. The acyl-glucuronide metabolite of ibuprofen has analgesic and anti-inflammatory effects via the TRPA1 channel. Pharmacol Res 2019;142: 127-139. https://doi.org/10.1016/j.phrs.2019.02.019.

52. Coghlan JG, Channick R, Chin K, et al. Targeting the prostacyclin pathway with selexipag in patients with pulmonary arterial hypertension receiving double combination therapy: insights from the randomized controlled GRIPHON study. Am J Cardiovasc Drugs 2018;18: 37-47. https://doi.org/10.1007/s40256-017-0262-z.

53. Miki T, Matsunami M, Nakamura S, Okada H, Matsuya H, Kawabata A. ONO-8130, a selective prostanoid EP1 receptor antagonist, relieves bladder pain in mice with cyclophosphamideinduced cystitis. Pain. 2011;152: 1373-1381. https://doi.org/10. 1016/j.pain.2011.02.019.

54. Antonova M, Wienecke T, Maubach K, Thomas E, Olesen J, Ashina M. The pharmacological effect of BGC20-1531, a novel prostanoid EP4 receptor antagonist, in the prostaglandin E2 human model of headache. J Headache Pain 2011;12: 551-559. https://doi.org/10.1007/s10194-011-0358-9.

55. Rottapharm Biotech. A Study of the EP4 antagonist CR6086 in combination with methotrexate, in DMARD-naïve patients with early rheumatoid arthritis. 2017.https://ClinicalTrials.gov/show/ NCT03163966.

56. Sugita R, Kuwabara H, Kubota K, et al. Simultaneous inhibition of PGE2 and PGI2 signals is necessary to suppress hyperalgesia in rat inflammatory pain models. Mediators Inflamm 2016;2016: 9847840. https://doi.org/10.1155/2016/9847840.

57. Treutlein E-M, Kern K, Weigert A, et al. The prostaglandin E2 receptor EP3 controls CC-chemokine ligand 2-mediated neuropathic pain induced by mechanical nerve damage. J Biol Chem 2018;293: 9685-9695. https://doi.org/10.1074/jbc.RA118. 002492.

58. Singh J, Zeller W, Zhou N, et al. Antagonists of the EP3 receptor for prostaglandin E2 are novel antiplatelet agents that do not prolong bleeding. ACS Chem Biol 2009;4: 115-126. https://doi.org/ $10.1021 / \mathrm{cb} 8002094$.

59. $\mathrm{Su} \mathrm{X}$, Leon $\mathrm{LA}, \mathrm{Wu} \mathrm{CW}$, et al. Modulation of bladder function by prostaglandin EP3 receptors in the central nervous system. Am J Physiol Renal Physiol 2008;295: F984-994. https://doi.org/10. 1152/ajprenal.90373.2008.

60. Woodhams SG, Chapman V, Finn DP, Hohmann AG, Neugebauer V. The cannabinoid system and pain. Neuropharmacology. 2017;124: 105-120. https://doi.org/10. 1016/j.neuropharm.2017.06.015.

61. Whiting PF, Wolff RF, Deshpande S, et al. Cannabinoids for medical use: a systematic review and meta-analysis. JAMA. 2015;313: 2456-2473. https://doi.org/10.1001/jama.2015.6358.

62. Agarwal N, Pacher P, Tegeder I, et al. Cannabinoids mediate analgesia largely via peripheral type 1 cannabinoid receptors in nociceptors. Nat Neurosci 2007;10: 870-879. https://doi.org/10. 1038/nn1916.

63. Mulpuri Y, Marty VN, Munier JJ, et al. Synthetic peripherallyrestricted cannabinoid suppresses chemotherapy-induced peripheral neuropathy pain symptoms by CB1 receptor activation. Neuropharmacology. 2018;139: 85-97. https://doi.org/10.1016/j. neuropharm.2018.07.002.

64. Starowicz K, Finn DP. Cannabinoids and pain: sites and mechanisms of action. Adv Pharmacol 2017;80: 437-475. https://doi. org/10.1016/bs.apha.2017.05.003.

65. Seltzman HH, Shiner C, Hirt EE, et al. Peripherally selective cannabinoid 1 receptor (CB1R) agonists for the treatment of neuropathic pain. J Med Chem 2016;59: 7525-7543. https://doi.org/10. 1021/acs.jmedchem.6b00516.

66. Ignatowska-Jankowska BM, Baillie GL, Kinsey S, et al. A cannabinoid CB1 receptor-positive allosteric modulator reduces neuropathic pain in the mouse with no psychoactive effects. 
Neuropsychopharmacology. 2015;40: 2948-2959. https://doi.org/ 10.1038/npp.2015.148.

67. Slivicki RA, Xu Z, Kulkarni PM, et al. Positive allosteric modulation of cannabinoid receptor type 1 suppresses pathological pain without producing tolerance or dependence. Biol Psychiatry 2018;84: 722-733. https://doi.org/10.1016/j.biopsych.2017.06. 032 .

68. Sasso O, Wagner K, Morisseau C, Inceoglu B, Hammock BD, Piomelli D. Peripheral FAAH and soluble epoxide hydrolase inhibitors are synergistically antinociceptive. Pharmacol Res 2015;97: 7-15. https://doi.org/10.1016/j.phrs.2015.04.001.

69. Clapper JR, Moreno-Sanz G, Russo R, et al. Anandamide suppresses pain initiation through a peripheral endocannabinoid mechanism. Nat Neurosci 2010;13: 1265-1270. https://doi.org/ 10.1038/nn.2632.

70. Huggins JP, Smart TS, Langman S, Taylor L, Young T. An efficient randomised, placebo-controlled clinical trial with the irreversible fatty acid amide hydrolase-1 inhibitor PF-04457845, which modulates endocannabinoids but fails to induce effective analgesia in patients with pain due to osteoarthritis of the knee. Pain. 2012;153: 1837-1846. https://doi.org/10.1016/j.pain.2012. 04.020 .

71. Kaur R, Sidhu P, Singh S. What failed BIA 10-2474 Phase I clinical trial? Global speculations and recommendations for future Phase I trials. J Pharmacol Pharmacother 2016;7: 120-126. https://doi.org/10.4103/0976-500X.189661.

72. Long JZ, Li W, Booker L, et al. Selective blockade of 2arachidonoylglycerol hydrolysis produces cannabinoid behavioral effects. Nat Chem Biol 2009;5: 37-44. https://doi.org/10.1038/ nchembio.129.

73. Ghosh S, Kinsey SG, Liu Q-S, et al. Full fatty acid amide hydrolase inhibition combined with partial monoacylglycerol lipase inhibition: augmented and sustained antinociceptive effects with reduced cannabimimetic side effects in mice. J Pharmacol Exp Ther 2015;354: 111-120. https://doi.org/10.1124/jpet.115. 222851.

74. Maione S, De Petrocellis L, de Novellis V, et al. Analgesic actions of N-arachidonoyl-serotonin, a fatty acid amide hydrolase inhibitor with antagonistic activity at vanilloid TRPV1 receptors. Br J Pharmacol 2007;150: 766-781. https://doi.org/10.1038/sj.bjp. 0707145.

75. Maione S, Costa B, Piscitelli F, et al. Piperazinyl carbamate fatty acid amide hydrolase inhibitors and transient receptor potential channel modulators as "dual-target" analgesics. Pharmacol Res 2013;76: 98-105. https://doi.org/10.1016/j.phrs.2013.07.003.

76. Sasso O, Migliore M, Habrant D, et al. Multitarget fatty acid amide hydrolase/cyclooxygenase blockade suppresses intestinal inflammation and protects against nonsteroidal antiinflammatory drug-dependent gastrointestinal damage. FASEB J 2015;29: 2616-2627. https://doi.org/10.1096/fj.15-270637.

77. Lynch ME, Campbell F. Cannabinoids for treatment of chronic non-cancer pain; a systematic review of randomized trials. $\mathrm{Br} \mathrm{J}$ Clin Pharmacol 2011;72: 735-744. https://doi.org/10.1111/j. 1365-2125.2011.03970.x.

78. Vaudry D, Falluel-Morel A, Bourgault S, et al. Pituitary adenylate cyclase-activating polypeptide and its receptors: 20 years after the discovery. Pharmacol Rev 2009;61: 283-357. https://doi.org/10. 1124/pr.109.001370.

79. Wang J, Song X, Zhang D, et al. Cryo-EM structures of PAC1 receptor reveal ligand binding mechanism. Cell Res 2020;30: 436-445. https://doi.org/10.1038/s41422-020-0280-2.

80. Kobayashi K, Shihoya W, Nishizawa T, et al. Cryo-EM structure of the human PAC1 receptor coupled to an engineered heterotrimeric G protein. Nat Struct Mol Biol 2020;27: 274-280. https://doi.org/10.1038/s41594-020-0386-8.
81. Yokai M, Kurihara T, Miyata A. Spinal astrocytic activation contributes to both induction and maintenance of pituitary adenylate cyclase-activating polypeptide type 1 receptor-induced long-lasting mechanical allodynia in mice. Mol Pain 2016;12. https://doi. org/10.1177/1744806916646383.

82. Ohnou T, Yokai M, Kurihara T, et al. Pituitary adenylate cyclaseactivating polypeptide type 1 receptor signaling evokes longlasting nociceptive behaviors through the activation of spinal astrocytes in mice. J Pharmacol Sci 2016;130: 194-203. https://doi. org/10.1016/j.jphs.2016.01.008.

83. Takasaki I, Nakamura K, Shimodaira A, et al. The novel smallmolecule antagonist of PAC1 receptor attenuates formalininduced inflammatory pain behaviors in mice. J Pharmacol Sci 2019;139: 129-132. https://doi.org/10.1016/j.jphs.2018.11.011.

84. Rubio-Beltrán E, Correnti E, Deen M, et al. PACAP38 and PAC1 receptor blockade: a new target for headache? J Headache Pain 2018;19: 64. https://doi.org/10.1186/s10194-018-0893-8.

85. Takasaki I, Ogashi H, Okada T, et al. Synthesis of a novel and potent small-molecule antagonist of PAC1 receptor for the treatment of neuropathic pain. Eur J Med Chem 2020;186: 111902. https://doi.org/10.1016/j.ejmech.2019.111902.

86. Yu R, Zheng L, Cui Y, Zhang H, Ye H. Doxycycline exerted neuroprotective activity by enhancing the activation of neuropeptide GPCR PAC1. Neuropharmacology. 2016;103: 1-15. https:// doi.org/10.1016/j.neuropharm.2015.11.032.

87. Nichols DE, Nichols CD. Serotonin receptors. Chem Rev 2008;108: 1614-1641. https://doi.org/10.1021/cr078224o.

88. Moreno-Ajona D, Chan C, Villar-Martínez MD, Goadsby PJ. Targeting CGRP and 5-HT1F receptors for the acute therapy of migraine: a literature review. Headache. 2019;59 Suppl 2: 3-19. https://doi.org/10.1111/head.13582.

89. Lanfumey L, Hamon M. 5-HT1 receptors. Curr Drug Targets CNS Neurol Disord 2004;3: 1-10. https://doi.org/10.2174/ 1568007043482570 .

90. Ahn AH, Basbaum AI. Where do triptans act in the treatment of migraine? Pain. 2005;115: 1-4. https://doi.org/10.1016/j.pain. 2005.03.008.

91. Knievel K, Buchanan AS, Lombard L, et al. Lasmiditan for the acute treatment of migraine: Subgroup analyses by prior response to triptans. Cephalalgia. 2020;40: 19-27. https://doi.org/10.1177/ 0333102419889350.

92. Babenko V, Graven-Nielsen T, Svensson P, Drewes AM, Jensen TS, Arendt-Nielsen L. Experimental human muscle pain induced by intramuscular injections of bradykinin, serotonin, and substance P. Eur J Pain 1999;3: 93-102. https://doi.org/10.1053/ eujp.1998.0103.

93. Lin S-Y, Chang W-J, Lin C-S, Huang C-Y, Wang H-F, Sun W-H. Serotonin receptor 5-HT2B mediates serotonin-induced mechanical hyperalgesia. J Neurosci 2011;31: 1410-1418. https://doi.org/ 10.1523/JNEUROSCI.4682-10.2011.

94. Urtikova N, Berson N, Van Steenwinckel J, et al. Antinociceptive effect of peripheral serotonin 5-HT2B receptor activation on neuropathic pain. Pain. 2012;153: 1320-1331. https://doi.org/10. 1016/j.pain.2012.03.024.

95. Segelcke D, Messlinger K. Putative role of 5-HT2B receptors in migraine pathophysiology. Cephalalgia. 2017;37: 365-371. https://doi.org/10.1177/0333102416646760.

96. Pineda-Farias JB, Velázquez-Lagunas I, Barragán-Iglesias P, Cervantes-Durán C, Granados-Soto V. 5-HT2B receptor antagonists reduce nerve injury-induced tactile allodynia and expression of 5-HT2B receptors. Drug Dev Res 2015;76: 31-39. https://doi. org/10.1002/ddr.21238.

97. Hou R, Ye G, Liu Y, et al. Effects of SSRIs on peripheral inflammatory cytokines in patients with generalized anxiety disorder. Brain Behav Immun 2019;81: 105-110. https://doi.org/10.1016/ j.bbi.2019.06.001. 
98. Bismuth-Evenzal Y, Roz N, Gurwitz D, Rehavi M. N-methylcitalopram: a quaternary selective serotonin reuptake inhibitor. Biochem Pharmacol 2010;80: 1546-1552. https://doi.org/10. 1016/j.bcp.2010.07.035.

99. Huang Y-H, Su Y-S, Chang C-J, Sun W-H. Heteromerization of G2A and OGR1 enhances proton sensitivity and proton-induced calcium signals. J Recept Signal Transduct Res 2016;36: 633644. https://doi.org/10.3109/10799893.2016.1155064.

100. Huang C-W, Tzeng J-N, Chen Y-J, Tsai W-F, Chen C-C, Sun W$\mathrm{H}$. Nociceptors of dorsal root ganglion express proton-sensing Gprotein-coupled receptors. Mol Cell Neurosci 2007;36: 195-210. https://doi.org/10.1016/j.mcn.2007.06.010.

101. Chen Y-J, Huang C-W, Lin C-S, Chang W-H, Sun W-H. Expression and function of proton-sensing G-protein-coupled receptors in inflammatory pain. Mol Pain 2009;5: 39. https://doi. org/10.1186/1744-8069-5-39.

102. Wang J, Sun Y, Tomura H, Okajima F. Ovarian cancer G-proteincoupled receptor 1 induces the expression of the pain mediator prostaglandin E2 in response to an acidic extracellular environment in human osteoblast-like cells. Int J Biochem Cell Biol 2012;44: 1937-1941. https://doi.org/10.1016/j.biocel.2012.07. 015 .

103. Baebler K, Maeyashiki C, Busenhart P, et al. P087 A novel OGR1 (GPR68) inhibitor attenuates inflammation in a murine model of Acute Colitis. J Crohns Colitis 2018;12: S137-S137. https://doi. org/10.1093/ecco-jcc/jjx180.214.

104. Wiley SZ, Sriram K, Salmerón C, Insel PA. GPR68: an emerging drug target in cancer. Int J Mol Sci 2019;20. https://doi.org/10. 3390/ijms20030559.

105. Fukuda H, Ito S, Watari K, et al. Identification of a potent and selective GPR4 antagonist as a drug lead for the treatment of myocardial infarction. ACS Med Chem Lett 2016;7: 493-497. https://doi.org/10.1021/acsmedchemlett.6b00014.

106. Sanna MD, Stark H, Lucarini L, Ghelardini C, Masini E, Galeotti N. Histamine H4 receptor activation alleviates neuropathic pain through differential regulation of ERK, JNK, and P38 MAPK phosphorylation. Pain. 2015;156: 2492-2504. https://doi.org/10. 1097/j.pain.0000000000000319.

107. Popiolek-Barczyk K, Łażewska D, Latacz G, et al. Antinociceptive effects of novel histamine $\mathrm{H} 3$ and $\mathrm{H} 4$ receptor antagonists and their influence on morphine analgesia of neuropathic pain in the mouse. Br J Pharmacol 2018;175: 2897-2910. https://doi.org/10.1111/bph.14185.

108. Medhurst AD, Briggs MA, Bruton G, et al. Structurally novel histamine H3 receptor antagonists GSK207040 and GSK334429 improve scopolamine-induced memory impairment and capsaicin-induced secondary allodynia in rats. Biochem Pharmacol 2007;73: 1182-1194. https://doi.org/10.1016/j.bcp. 2007.01.007.

109. Obara I, Telezhkin V, Alrashdi I, Chazot PL. Histamine, histamine receptors, and neuropathic pain relief. Br J Pharmacol 2020;177: 580-599. https://doi.org/10.1111/bph.14696.

110. Hough LB, Rice FL. H3 receptors and pain modulation: peripheral, spinal, and brain interactions. J Pharmacol Exp Ther 2011;336: 30-37. https://doi.org/10.1124/jpet.110.171264.

111. Liu WL. Histamine H4 receptor antagonists for the treatment of inflammatory disorders. Drug Discov Today 2014;19: 1222 1225. https://doi.org/10.1016/j.drudis.2014.05.007.

112. Tripathi T, Shahid M, Khan HM, et al. In vivo study of histamine H4 receptor in immunomodulation. Bratisl Lek Listy 2012;113: 641-647. https://doi.org/10.4149/bll_2012_145.

113. Werfel T, Layton G, Yeadon M, et al. Efficacy and safety of the histamine H4 receptor antagonist ZPL-3893787 in patients with atopic dermatitis. J Allergy Clin Immunol 2019;143: 18301837.e4. https://doi.org/10.1016/j.jaci.2018.07.047.
114. Jang JH, Clark JD, Li X, Yorek MS, Usachev YM, Brennan TJ. Nociceptive sensitization by complement $\mathrm{C} 5 \mathrm{a}$ and $\mathrm{C} 3 \mathrm{a}$ in mouse. Pain. 2010;148: 343-352. https://doi.org/10.1016/j.pain.2009.11. 021.

115. Shutov LP, Warwick CA, Shi X, et al. The complement system component C5a produces thermal hyperalgesia via macrophageto-nociceptor signaling that requires NGF and TRPV1. J Neurosci 2016;36: 5055-5070. https://doi.org/10.1523/JNEUROSCI.324915.2016 .

116. Moriconi A, Cunha TM, Souza GR, et al. Targeting the minor pocket of $\mathrm{C} 5 \mathrm{aR}$ for the rational design of an oral allosteric inhibitor for inflammatory and neuropathic pain relief. Proc Natl Acad Sci U S A 2014;111: 16937-16942. https://doi.org/10.1073/pnas. 1417365111

117. Andersson C, Wenander CS, Usher PA, et al. Rapid-onset clinical and mechanistic effects of anti-C5aR treatment in the mouse collagen-induced arthritis model. Clin Exp Immunol 2014;177: 219-233. https://doi.org/10.1111/cei.12338.

118. Jayne DRW, Bruchfeld AN, Harper L, et al. Randomized trial of C5a receptor inhibitor avacopan in ANCA-associated vasculitis. J Am Soc Nephrol 2017;28: 2756-2767. https://doi.org/10.1681/ ASN.2016111179.

119. Novo Nordisk A/S. Dose-escalation Trial of Anti-C5aR Antibody in Healthy Subjects. 2008. https://ClinicalTrials.gov/show/ NCT02151409.

120. Novo Nordisk A/S. A Trial to Investigate the Safety, Tolerability, Pharmacokinetics and Pharmacodynamics of NNC0215-0384 Administered to Subjects With Moderate to Severe Rheumatoid Arthritis. 2013.https://ClinicalTrials.gov/show/NCT01955603.

121. Assistance Publique Hopitaux De Marseille, Innate Pharma. Avdoralimab an Anti-C5aR Antibody, in Patients With COVID19 Severe Pneumonia ( FORCE ). https://ClinicalTrials.gov/ show/NCT04371367;. 2020.

122. Negri L, Lattanzi R, Giannini E, et al. Impaired nociception and inflammatory pain sensation in mice lacking the prokineticin receptor PKR1: focus on interaction between PKR1 and the capsaicin receptor TRPV1 in pain behavior. J Neurosci 2006;26: 67166727. https://doi.org/10.1523/JNEUROSCI.5403-05.2006.

123. Maftei D, Vellani V, Artico M, Giacomoni C, Severini C, Lattanzi R. Abnormal pain sensation in mice lacking the prokineticin receptor PKR2: interaction of PKR2 with transient receptor potential TRPV1 and TRPA1. Neuroscience. 2020;427: 16-28. https://doi. org/10.1016/j.neuroscience.2019.12.003.

124. Qiu C-Y, Liu Y-Q, Qiu F, Wu J, Zhou Q-Y, Hu W-P. Prokineticin 2 potentiates acid-sensing ion channel activity in rat dorsal root ganglion neurons. J Neuroinflammation 2012;9: 108. https://doi. org/10.1186/1742-2094-9-108.

125. Balboni G, Lazzari I, Trapella C, et al. Triazine compounds as antagonists at Bv8-prokineticin receptors. J Med Chem 2008;51: 7635-7639. https://doi.org/10.1021/jm800854e.

126. Guida F, Lattanzi R, Boccella S, et al. PC1, a non-peptide PKR1preferring antagonist, reduces pain behavior and spinal neuronal sensitization in neuropathic mice. Pharmacol Res 2015;91: 36-46. https://doi.org/10.1016/j.phrs.2014.11.004.

127. Negri L, Maftei D. Targeting the prokineticin system to control chronic pain and inflammation. Curr Med Chem 2018;25: 38833894. https://doi.org/10.2174/0929867324666170713102514.

128. Bennett DL, Clark AJ, Huang J, Waxman SG, Dib-Hajj SD. The role of voltage-gated sodium channels in pain signaling. Physiol Rev 2019;99: 1079-1151. https://doi.org/10.1152/physrev.00052. 2017.

129. Catterall WA. From ionic currents to molecular mechanisms: the structure and function of voltage-gated sodium channels. Neuron. 2000;26: 13-25. https://doi.org/10.1016/S0896-6273(00)811332. 
130. Lampert A, O'Reilly AO, Reeh P, Leffler A. Sodium channelopathies and pain. Pflugers Arch - Eur J Physiol 2010;460: 249-263. https://doi.org/10.1007/s00424-009-0779-3.

131. Devor M. Sodium channels and mechanisms of neuropathic pain. J Pain 2006;7: S3-S12. https://doi.org/10.1016/j.jpain.2005.09. 006

132. Gould HJ, England JD, Soignier RD, et al. Ibuprofen blocks changes in $\mathrm{Na}$ v 1.7 and 1.8 sodium channels associated with complete Freund's adjuvant-induced inflammation in rat. J Pain 2004;5: 270-280. https://doi.org/10.1016/j.jpain.2004.04.005.

133. Toledo-Aral JJ, Brehm P, Halegoua S, Mandel G. A single pulse of nerve growth factor triggers long-term neuronal excitability through sodium channel gene induction. Neuron. 1995;14: 607611. https://doi.org/10.1016/0896-6273(95)90317-8.

134. Nassar MA, Stirling LC, Forlani G, et al. Nociceptor-specific gene deletion reveals a major role for Nav1.7 (PN1) in acute and inflammatory pain. Proc Natl Acad Sci U S A 2004;101: 12706 12711. https://doi.org/10.1073/pnas.0404915101.

135. Yatziv S-L, Devor M. Suppression of neuropathic pain by selective silencing of dorsal root ganglion ectopia using nonblocking concentrations of lidocaine. Pain. 2019;160: 2105-2114. https:// doi.org/10.1097/j.pain.0000000000001602.

136. Cardoso FC, Lewis RJ. Sodium channels and pain: from toxins to therapies. Br J Pharmacol 2018;175: 2138-2157. https://doi.org/ 10.1111/bph.13962.

137. Ma RSY, Kayani K, Whyte-Oshodi D, et al. Voltage gated sodium channels as therapeutic targets for chronic pain. J Pain Res 2019;12: 2709-2722. https://doi.org/10.2147/JPR.S207610.

138. Foadi N. Modulation of sodium channels as pharmacological tool for pain therapy-highlights and gaps. Naunyn Schmiedebergs Arch Pharmacol 2018;391: 481-488. https://doi.org/10.1007/ s00210-018-1487-3.

139. J. A.R. Laboratories. Comparison of prescription lidocaine patch to over the counter lidocaine patch and placebo for back pain and arthritis. 2016.https://ClinicalTrials.gov/show/NCT02749123.

140. Kingwell K. Nav1.7 withholds its pain potential. Nat Rev Drug Discov 2019. https://doi.org/10.1038/d41573-019-00065-0.

141. Kushnarev M, Pirvulescu IP, Candido KD, Knezevic NN Neuropathic pain: preclinical and early clinical progress with voltage-gated sodium channel blockers. Expert Opin Investig Drugs 2020;29: 259-271. https://doi.org/10.1080/13543784. 2020.1728254

142. Patel R, Montagut-Bordas C, Dickenson AH. Calcium channel modulation as a target in chronic pain control. Br J Pharmacol 2018;175: 2173-2184. https://doi.org/10.1111/bph.13789.

143. Petersen AS, Barloese MCJ, Snoer A, Soerensen AMS, Jensen RH. Verapamil and cluster headache: still a mystery. a narrative review of efficacy, mechanisms and perspectives. Headache. 2019;59: 1198-1211. https://doi.org/10.1111/head.13603.

144. Stubberud A, Flaaen NM, McCrory DC, Pedersen SA, Linde M. Flunarizine as prophylaxis for episodic migraine: a systematic review with meta-analysis. Pain. 2019;160: 762-772. https://doi. org/10.1097/j.pain.0000000000001456.

145. de Oliveira BA, Alves Rodrigues Santos SA, Menezes Pereira EW, Nogueira AB, Vieira Neto AE, José de Maria de Albuquerque de Melo Jr, et al. Orofacial antinociceptive effect of nifedipine in rodents is mediated by TRPM3, TRPA1, and NMDA processes. J Oral Facial Pain Headache 2020;34: 174 186. https://doi.org/10.11607/ofph.2491.

146. Pitake S, Middleton LJ, Abdus-Saboor I, Mishra SK. Inflammation induced sensory nerve growth and pain hypersensitivity requires the n-type calcium channel Cav2.2. Front Neurosci 2019;13: 1009. https://doi.org/10.3389/fnins.2019. 01009.

147. Choi S, Yu E, Hwang E, Llinás RR. Pathophysiological implication of CaV3.1 T-type Ca2+ channels in trigeminal neuropathic pain. PNAS. 2016;113: 2270-2275. https://doi.org/10.1073/pnas. 1600418113

148. Nilius B, Prenen J, Owsianik G. Irritating channels: the case of TRPA1. J Physiol (Lond) 2011;589: 1543-1549. https://doi.org/ 10.1113/jphysiol.2010.200717.

149. Weyer-Menkhoff I, Lötsch J. Human pharmacological approaches to TRP-ion-channel-based analgesic drug development. Drug Discov Today 2018;23: 2003-2012. https://doi.org/10.1016/j. drudis.2018.06.020.

150. González-Ramírez R, Chen Y, Liedtke WB, Morales-Lázaro SL. TRP channels and pain. 2nd ed. In: Emir TLR, editor. Neurobiology of TRP channels. Boca Raton: CRC Press/Taylor \& Francis; 2017. Available: http://www.ncbi.nlm.nih.gov/books/ NBK476120/.

151. Nazıroğlu M, Braidy N. Thermo-sensitive TRP channels: novel targets for treating chemotherapy-induced peripheral pain. Front Physiol 2017;8: 1040. https://doi.org/10.3389/fphys.2017.01040.

152. Jeske NA, Diogenes A, Ruparel NB, et al. A-kinase anchoring protein mediates TRPV1 thermal hyperalgesia through PKA phosphorylation of TRPV1. Pain. 2008;138: 604-616. https://doi.org/ 10.1016/j.pain.2008.02.022.

153. Cao E, Cordero-Morales JF, Liu B, Qin F, Julius D. TRPV1 channels are intrinsically heat sensitive and negatively regulated by phosphoinositide lipids. Neuron. 2013;77: 667-679. https://doi. org/10.1016/j.neuron.2012.12.016.

154. Chuang H, Lin S. Oxidative challenges sensitize the capsaicin receptor by covalent cysteine modification. PNAS. 2009;106: 20097-20102. https://doi.org/10.1073/pnas.0902675106.

155. Simone DA, Ngeow JY, Putterman GJ, LaMotte RH. Hyperalgesia to heat after intradermal injection of capsaicin Brain Res 1987;418: 201-203. https://doi.org/10.1016/00068993(87)90982-6.

156. Culp WJ, Ochoa J, Cline M, Dotson R. Heat and mechanical hyperalgesia induced by capsaicin. Cross modality threshold modulation in human C nociceptors. Brain. 1989;112 1317-1331. https://doi.org/10.1093/brain/112.5.1317.

157. LaMotte RH, Lundberg LE, Torebjörk HE. Pain, hyperalgesia and activity in nociceptive $\mathrm{C}$ units in humans after intradermal injection of capsaicin. J Physiol (Lond) 1992;448: 749-764. https://doi. org/10.1113/jphysiol.1992.sp019068.

158. Simone DA, Baumann TK, LaMotte RH. Dose-dependent pain and mechanical hyperalgesia in humans after intradermal injection of capsaicin. Pain. 1989;38: 99-107. https://doi.org/10.1016/ 0304-3959(89)90079-1.

159. Basith S, Cui M, Hong S, Choi S. Harnessing the therapeutic potential of capsaicin and its analogues in pain and other diseases. Molecules. 2016;21. https://doi.org/10.3390/molecules21080966.

160. Burness CB, McCormack PL. Capsaicin $8 \%$ patch: a review in peripheral neuropathic pain. Drugs. 2016;76: 123-134. https://doi. org/10.1007/s40265-015-0520-9.

161. Gomtsyan A, McDonald HA, Schmidt RG, et al. TRPV1 ligands with hyperthermic, hypothermic and no temperature effects in rats. Temperature (Austin) 2015;2: 297-301. https://doi.org/10.1080/ 23328940.2015.1046013.

162. Daewoong Pharmaceutical Co. LTD. Evaluate the efficacy and safety of DWP05195 in subjects with post-herpetic neuralgia. 2012.https://ClinicalTrials.gov/show/NCT01557010.

163. Neomed Institute. A proof-of-concept study assessing NEO6860 in osteoarthritis pain. 2016.https://ClinicalTrials.gov/show/ NCT02712957.

164. Sylentis SA. HELIX, a Double-masked Study of SYL1001 in Patients With Moderate to Severe Dry Eye Disease (DED). 2017.https://ClinicalTrials.gov/show/NCT03108664.

165. Jo YY, Lee JY, Park C-K. Resolvin E1 inhibits substance Pinduced potentiation of trpv 1 in primary sensory neurons. 
Mediators Inflamm 2016;2016. https://doi.org/10.1155/2016/ 5259321.

166. Resolvyx Pharmaceuticals I. Single and Multiple Ascending Oral Dose Study of RX-10001 in Healthy Volunteers. 2009. https:// ClinicalTrials.gov/show/NCT00941018.

167. Garami A, Shimansky YP, Rumbus Z, et al. Hyperthermia induced by transient receptor potential vanilloid-1 (TRPV1) antagonists in human clinical trials: Insights from mathematical modeling and meta-analysis. Pharmacol Ther 2020; 107474. https://doi. org/10.1016/j.pharmthera.2020.107474.

168. Stein M, Breit A, Fehrentz T, Gudermann T, Trauner D. Optical control of TRPV1 channels. Angew Chem Int Ed Engl 2013;52: 9845-9848. https://doi.org/10.1002/anie.201302530.

169. Takayama Y, Derouiche S, Maruyama K, Tominaga M. Emerging perspectives on pain management by modulation of TRP channels and ANO1. Int J Mol Sci 2019;20. https://doi.org/10.3390/ ijms20143411.

170. Zurborg S, Yurgionas B, Jira JA, Caspani O, Heppenstall PA. Direct activation of the ion channel TRPA1 by Ca2+. Nat Neurosci 2007;10: 277-279. https://doi.org/10.1038/nn1843.

171. Babes A, Sauer SK, Moparthi L, et al. Photosensitization in porphyrias and photodynamic therapy involves TRPA1 and TRPV1. J Neurosci 2016;36: 5264-5278. https://doi.org/10.1523/ JNEUROSCI.4268-15.2016.

172. Babes A, Ciotu CI, Hoffmann T, et al. Photosensitization of TRPA1 and TRPV1 by 7-dehydrocholesterol: implications for the Smith-Lemli-Opitz syndrome. Pain. 2017;158: 2475-2486. https://doi.org/10.1097/j.pain.0000000000001056.

173. Meents JE, Fischer MJM, McNaughton PA. Sensitization of TRPA1 by protein kinase A. PLoS One 2017;12. https://doi.org/ 10.1371/journal.pone.0170097.

174. Meents JE, Fischer MJM, McNaughton PA. Agonist-induced sensitisation of the irritant receptor ion channel TRPA1. J Physiol (Lond) 2016;594: 6643-6660. https://doi.org/10.1113/JP272237.

175. Ciotu CI, Tsantoulas C, Meents J, et al. Noncanonical ion channel behaviour in pain. Int J Mol Sci 2019;20. https://doi.org/10.3390/ ijms20184572.

176. Meents JE, Ciotu CI, Fischer MJM. TRPA1: a molecular view. J Neurophysiol 2018;121: 427-443. https://doi.org/10.1152/jn. 00524.2018 .

177. Nilius B, Flockerzi V. Mammalian transient receptor potential (TRP) cation channels. Preface. Handb Exp Pharmacol. 2014;223: v-vi.

178. Xiao B, Dubin AE, Bursulaya B, Viswanath V, Jegla TJ, Patapoutian A. Identification of transmembrane domain 5 as a critical molecular determinant of menthol sensitivity in mammalian TRPA1 channels. J Neurosci 2008;28: 9640-9651. https:// doi.org/10.1523/JNEUROSCI.2772-08.2008.

179. Glenmark Pharmaceuticals Ltd. India, Glenmark Pharmaceuticals S. A. A Clinical Trial to Study the Effects GRC 17536 in Patients With Painful Diabetic Peripheral Neuropathy (Painful Extremities Due to Peripheral Nerve Damage in Diabetic Patients). 2012. https://ClinicalTrials.gov/show/NCT01726413.

180. Orion Corporation OP, PRA Health Sciences. Safety, Tolerability, Pharmacokinetic and Pharmacodynamic Effects of ODM-108: in Healthy Male Volunteers. 2015. https://ClinicalTrials.gov/show/ NCT02432664

181. Koivisto A, Jalava N, Bratty R, Pertovaara A. TRPA1 Antagonists for Pain Relief. Pharmaceuticals (Basel) 2018;11. https://doi.org/ 10.3390/ph11040117.

182. Mihai DP, Nitulescu GM, Ion GND, Ciotu CI, Chirita C, Negres S. Computational drug repurposing algorithm targeting TRPA1 calcium channel as a potential therapeutic solution for multiple sclerosis. Pharmaceutics. 2019;11. https://doi.org/10.3390/ pharmaceutics 11090446.
183. Heber S, Gold-Binder M, Ciotu CI, et al. A human TRPA1specific pain model. J Neurosci 2019;39: 3845-3855. https://doi. org/10.1523/JNEUROSCI.3048-18.2019.

184. Heber S, Fischer MJM. Non-analgesic symptomatic or diseasemodifying potential of TRPA1. Med Sci (Basel) 2019;7. https:// doi.org/10.3390/medsci7100099.

185. Giorgi S, Nikolaeva-Koleva M, Alarcón-Alarcón D, Butrón L, González-Rodríguez S. Is TRPA1 burning down TRPV1 as druggable target for the treatment of chronic pain? Int J Mol Sci 2019;20. https://doi.org/10.3390/ijms20122906.

186. Dhaka A, Murray AN, Mathur J, Earley TJ, Petrus MJ, Patapoutian A. TRPM8 is required for cold sensation in mice. Neuron. 2007;54: 371-378. https://doi.org/10.1016/j.neuron. 2007.02.024.

187. Liu B, Fan L, Balakrishna S, Sui A, Morris JB, Jordt S-E. TRPM8 is the principal mediator of menthol-induced analgesia of acute and inflammatory pain. Pain. 2013;154: 2169-2177. https://doi. org/10.1016/j.pain.2013.06.043.

188. Eccles R. Menthol and related cooling compounds. J Pharm Pharmacol 1994;46: 618-630. https://doi.org/10.1111/j.20427158.1994.tb03871.x.

189. Wang X-P, Yu X, Yan X-J, et al. TRPM8 in the negative regulation of TNF $\alpha$ expression during cold stress. Sci Rep 2017;7: 1-11. https://doi.org/10.1038/srep45155.

190. Aizawa N, Ohshiro H, Watanabe S, Kume H, Homma Y, Igawa Y. RQ-00434739, a novel TRPM8 antagonist, inhibits prostaglandin E2-induced hyperactivity of the primary bladder afferent nerves in rats. Life Sci 2019;218: 89-95. https://doi.org/10.1016/ j.1fs.2018.12.031.

191. Winchester WJ, Gore K, Glatt S, et al. Inhibition of TRPM8 channels reduces pain in the cold pressor test in humans. J Pharmacol Exp Ther 2014;351: 259-269. https://doi.org/10.1124/jpet.114. 216010.

192. Amgen. single-ascending dose study of AMG 333 in healthy subjects and subjects with migraines. https://ClinicalTrials.gov/show/ NCT01953341;: 2013

193. González-Muñiz R, Bonache MA, Martín-Escura C, GómezMonterrey I. Recent progress in TRPM8 modulation: an update. Int J Mol Sci 2019;20. https://doi.org/10.3390/ijms20112618.

194. Liedtke W, Choe Y, Martí-Renom MA, et al. Vanilloid receptorrelated osmotically activated channel (VR-OAC), a candidate vertebrate osmoreceptor. Cell. 2000;103: 525-535. https://doi.org/10. 1016/s0092-8674(00)00143-4.

195. Suzuki M, Mizuno A, Kodaira K, Imai M. Impaired pressure sensation in mice lacking TRPV4. J Biol Chem 2003;278: 22664-22668. https://doi.org/10.1074/jbc.M302561200.

196. Lawhorn BG, Brnardic EJ, Behm DJ. Recent advances in TRPV4 agonists and antagonists. Bioorg Med Chem Lett 2020;30: 127022. https://doi.org/10.1016/j.bmcl.2020.127022.

197. Grace MS, Bonvini SJ, Belvisi MG, McIntyre P. Modulation of the TRPV4 ion channel as a therapeutic target for disease. Pharmacol Ther 2017;177: 9-22. https://doi.org/10.1016/j. pharmthera.2017.02.019.

198. Goyal N, Skrdla P, Schroyer R, et al. Clinical pharmacokinetics, safety, and tolerability of a novel, first-in-class TRPV4 ion channel inhibitor, GSK2798745, in healthy and heart failure subjects. Am J Cardiovasc Drugs 2019;19: 335-342. https://doi.org/10. 1007/s40256-018-00320-6.

199. GlaxoSmithKline, Biomedical Advanced Research, Development Authority. A study to assess the effectiveness and side effects of GSK2798745 in participants with chronic cough. https:// ClinicalTrials.gov/show/NCT03372603;. 2018.

200. GlaxoSmithKline, Biomedical Advanced Research, Development Authority. Effects of GSK2798745 on alveolar barrier disruption in a segmental lipopolysaccharide (LPS) challenge model. https:// ClinicalTrials.gov/show/NCT03511105;. 2018. 
201. Stewart GM, Johnson BD, Sprecher DL, et al. Targeting pulmonary capillary permeability to reduce lung congestion in heart failure: a randomized, controlled pilot trial. Eur J Heart Fail 2020. https://doi.org/10.1002/ejhf.1809.

202. Broad LM, Mogg AJ, Eberle E, Tolley M, Li DL, Knopp KL. TRPV3 in drug development. Pharmaceuticals (Basel) 2016;9. https://doi.org/10.3390/ph9030055.

203. Caterina MJ, Rosen TA, Tominaga M, Brake AJ, Julius D. A capsaicin-receptor homologue with a high threshold for noxious heat. Nature. 1999;398: 436-441. https://doi.org/10. $1038 / 18906$

204. Fricke TC, Echtermeyer F, Zielke J, et al. Oxidation of methionine residues activates the high-threshold heat-sensitive ion channel TRPV2. Proc Natl Acad Sci U S A 2019;116: 24359-24365. https://doi.org/10.1073/pnas.1904332116.

205. Park U, Vastani N, Guan Y, Raja SN, Koltzenburg M, Caterina MJ. TRP vanilloid 2 knock-out mice are susceptible to perinatal lethality but display normal thermal and mechanical nociception. $\mathrm{J}$ Neurosci 2011;31: 11425-11436. https://doi.org/10.1523/ JNEUROSCI.1384-09.2011

206. Jang Y, Cho PS, Yang YD, Hwang SW. Nociceptive roles of TRPM2 ion channel in pathologic pain. Mol Neurobiol 2018;55: 6589-6600. https://doi.org/10.1007/s12035-017-0862-2.

207. Tan $\mathrm{C}-\mathrm{H}, \mathrm{McNaughton} \mathrm{PA}$. The TRPM2 ion channel is required for sensitivity to warmth. Nature. 2016;536: 460-463. https://doi. org/10.1038/nature19074.

208. Song K, Wang H, Kamm GB, et al. The TRPM2 channel is a hypothalamic heat sensor that limits fever and can drive hypothermia. Science. 2016;353: 1393-1398. https://doi.org/10.1126/ science.aaf7537.

209. Vriens J, Owsianik G, Hofmann T, et al. TRPM3 is a nociceptor channel involved in the detection of noxious heat. Neuron. 2011;70: 482-494. https://doi.org/10.1016/j.neuron.2011.02.051.

210. Vandewauw I, De Clercq K, Mulier M, et al. A TRP channel trio mediates acute noxious heat sensing. Nature. 2018;555: 662-666. https://doi.org/10.1038/nature26137.

211. Mulier M, Van Ranst N, Corthout N, et al. Upregulation of TRPM3 in nociceptors innervating inflamed tissue. Elife. 2020;9. https://doi.org/10.7554/eLife.61103.

212. Vangeel L, Benoit M, Miron Y, et al. Functional expression and pharmacological modulation of TRPM3 in human sensory neurons. Br J Pharmacol 2020. https://doi.org/10.1111/bph.14994.

213. Kelemen B, Lisztes E, Vladár A, et al. Volatile anaesthetics inhibit the thermosensitive nociceptor ion channel transient receptor potential melastatin 3 (TRPM3). Biochem Pharmacol 2020;174: 113826. https://doi.org/10.1016/j.bcp.2020.113826.

214. Gutman GA, Chandy KG, Adelman JP, et al. International Union of Pharmacology. XLI. Compendium of voltage-gated ion channels: potassium channels. Pharmacol Rev 2003;55: 583-586. https://doi.org/10.1124/pr.55.4.9.

215. Du X, Gamper N. Potassium channels in peripheral pain pathways: expression, function and therapeutic potential. Curr Neuropharmacol 2013;11: 621-640. https://doi.org/10.2174/ 1570159X113119990042.

216. Tsantoulas C. Emerging potassium channel targets for the treatment of pain. Curr Opin Support Palliat Care 2015;9: 147-154. https://doi.org/10.1097/SPC.0000000000000131.

217. Busserolles J, Gasull X, Noël J. Potassium Channels and Pain. In: The Oxford Handbook of the Neurobiology of Pain [Internet]. 10 Jul 2018 [cited 10 May 2020]. https://doi.org/10.1093/oxfordhb/ 9780190860509.013.19.

218. Everill B, Rizzo MA, Kocsis JD. Morphologically identified cutaneous afferent DRG neurons express three different potassium currents in varying proportions. J Neurophysiol 1998;79: 1814 1824. https://doi.org/10.1152/jn.1998.79.4.1814.
219. Du X, Hao H, Gigout S, et al. Control of somatic membrane potential in nociceptive neurons and its implications for peripheral nociceptive transmission. Pain. 2014;155: 2306-2322. https://doi. org/10.1016/j.pain.2014.08.025.

220. Rasband MN, Park EW, Vanderah TW, Lai J, Porreca F, Trimmer JS. Distinct potassium channels on pain-sensing neurons. Proc Natl Acad Sci U S A 2001;98: 13373-13378. https://doi.org/10. 1073/pnas.231376298.

221. Rivera-Arconada I, Vicente-Baz J, Lopez-Garcia JA. Targeting Kv7 channels in pain pathways. Oncotarget. 2017;8: 1255412555. https://doi.org/10.18632/oncotarget.15261.

222. Gribkoff VK. The therapeutic potential of neuronal K V 7 (KCNQ) channel modulators: an update. Expert Opin Ther Targets 2008;12: 565-581. https://doi.org/10.1517/14728222. 12.5.565.

223. Xu W, Wu Y, Bi Y, Tan L, Gan Y, Wang K. Activation of voltage-gated $\mathrm{KCNQ} / \mathrm{Kv} 7$ channels by anticonvulsant retigabine attenuates mechanical allodynia of inflammatory temporomandibular joint in rats. Mol Pain 2010;6: 49. https://doi.org/10.1186/ 1744-8069-6-49.

224. Blackburn-Munro G, Jensen BS. The anticonvulsant retigabine attenuates nociceptive behaviours in rat models of persistent and neuropathic pain. Eur J Pharmacol 2003;460: 109-116. https:// doi.org/10.1016/s0014-2999(02)02924-2.

225. Ray S, Salzer I, Kronschläger MT, Boehm S. The paracetamol metabolite $\mathrm{N}$-acetylp-benzoquinone imine reduces excitability in first- and second-order neurons of the pain pathway through actions on KV7 channels. Pain. 2019;160: 954-964. https://doi.org/ 10.1097/j.pain.0000000000001474.

226. Peretz A, Degani N, Nachman R, et al. Meclofenamic acid and diclofenac, novel templates of $\mathrm{KCNQ} 2 / \mathrm{Q} 3$ potassium channel openers, depress cortical neuron activity and exhibit anticonvulsant properties. Mol Pharmacol 2005;67: 1053-1066. https://doi. org/10.1124/mol.104.007112.

227. Prole DL, Marrion NV. Ionic permeation and conduction properties of neuronal KCNQ2/KCNQ3 potassium channels. Biophys J 2004;86: 1454-1469. https://doi.org/10.1016/S0006-3495(04) 74214-9.

228. Stewart AP, Gómez-Posada JC, McGeorge J, et al. The Kv7.2/ Kv7.3 heterotetramer assembles with a random subunit arrangement. J Biol Chem 2012;287: 11870-11877. https://doi.org/10. 1074/jbc.M111.336511.

229. Valdor M, Wagner A, Fischer $\mathrm{H}$, et al. RNA interference-mediated silencing of Kv7.2 in rat dorsal root ganglion neurons abolishes the anti-nociceptive effect of a selective channel opener. J Pharmacol Toxicol Methods 2020;103: 106693. https://doi.org/ 10.1016/j.vascn.2020.106693.

230. Gada K, Plant LD. Two-pore domain potassium channels: emerging targets for novel analgesic drugs: IUPHAR Review 26. Br J Pharmacol 2019;176: 256-266. https://doi.org/10.1111/bph. 14518.

231. Loucif AJC, Saintot P-P, Liu J, et al. GI-530159, a novel, selective, mechanosensitive two-pore-domain potassium (K2P ) channel opener, reduces rat dorsal root ganglion neuron excitability. $\mathrm{Br}$ J Pharmacol 2018;175: 2272-2283. https://doi.org/10.1111/bph. 14098.

232. Poupon L, Lamoine S, Pereira V, et al. Targeting the TREK-1 potassium channel via riluzole to eliminate the neuropathic and depressive-like effects of oxaliplatin. Neuropharmacology. 2018;140: 43-61. https://doi.org/10.1016/j.neuropharm.2018.07. 026.

233. Lolicato M, Arrigoni C, Mori T, et al. K2P2.1 (TREK-1)-activator complexes reveal a cryptic selectivity filter binding site. Nature. 2017;547: 364-368. https://doi.org/10.1038/nature22988.

234. Wright PD, Weir G, Cartland J, et al. Cloxyquin (5chloroquinolin-8-ol) is an activator of the two-pore domain 
potassium channel TRESK. Biochem Biophys Res Commun 2013;441: 463-468.

235. Noël J, Sandoz G, Lesage F. Molecular regulations governing TREK and TRAAK channel functions. Channels (Austin) 2011;5: 402-409. https://doi.org/10.4161/chan.5.5.16469.

236. Macdonell R, Nagels G, Laplaud D-A, et al. Improved patientreported health impact of multiple sclerosis: The ENABLE study of PR-fampridine. Mult Scler 2016;22: 944-954. https://doi.org/ $10.1177 / 1352458515606809$.

237. FDA Office of Orphan Products Development. Assessment of chronic guillain-barre syndrome improvement with use of 4aminopyridine. 2002. https://ClinicalTrials.gov/show/ NCT00056810.

238. Wu Z-Z, Li D-P, Chen S-R, Pan H-L. Aminopyridines potentiate synaptic and neuromuscular transmission by targeting the voltageactivated calcium channel beta subunit. J Biol Chem 2009;284: 36453-36461. https://doi.org/10.1074/jbc.M109.075523.

239. Marzal-Alfaro MB, Martín Barbero ML, García Domínguez J, et al. Impact of fampridine on quality of life: clinical benefit in real-world practice. Eur J Hosp Pharm 2018;25: 138-143. https:// doi.org/10.1136/ejhpharm-2016-001129.

240. Fleckenstein J, Sittl R, Averbeck B, Lang PM, Irnich D, Carr RW. Activation of axonal Kv7 channels in human peripheral nerve by flupirtine but not placebo - therapeutic potential for peripheral neuropathies: results of a randomised controlled trial. J Transl Med 2013;11: 34. https://doi.org/10.1186/1479-5876-11-34.

241. Schrøder RL, Jespersen T, Christophersen P, Strøbaek D, Jensen BS, Olesen SP. KCNQ4 channel activation by BMS-204352 and retigabine. Neuropharmacology. 2001;40: 888-898. https://doi. org/10.1016/s0028-3908(01)00029-6.

242. Korsgaard MPG, Hartz BP, Brown WD, Ahring PK, Strøbaek D, Mirza NR. Anxiolytic effects of Maxipost (BMS-204352) and retigabine via activation of neuronal Kv7 channels. J Pharmacol Exp Ther 2005;314: 282-292. https://doi.org/10.1124/jpet.105. 083923.

243. Al-Karagholi MA-M, Ghanizada H, Nielsen CAW, et al. Opening of BKCa channels alters cerebral hemodynamic and causes headache in healthy volunteers. Cephalalgia. 2020; 333102420940681. https://doi.org/10.1177/0333102420940681.

244. Al-Karagholi MA-M, Hansen JM, Severinsen J, Jansen-Olesen I, Ashina M. The KATP channel in migraine pathophysiology: a novel therapeutic target for migraine. J Headache Pain 2017;18. https://doi.org/10.1186/s10194-017-0800-8.

245. Wilke BU, Kummer KK, Leitner MG, Kress M. Chloride - the underrated ion in nociceptors. Front Neurosci 2020;14. https://doi. org/10.3389/fnins.2020.00287.

246. Rocha-González HI, Mao S, Alvarez-Leefmans FJ. Na+,K+,2Clcotransport and intracellular chloride regulation in rat primary sensory neurons: thermodynamic and kinetic aspects. J Neurophysiol 2008;100: 169-184. https://doi.org/10.1152/jn. 01007.2007.

247. Carlton SM, Zhou S, Coggeshall RE. Peripheral GABA(A) receptors: evidence for peripheral primary afferent depolarization. Neuroscience. 1999;93: 713-722. https://doi.org/10.1016/s03064522(99)00101-3.

248. Sung KW, Kirby M, McDonald MP, Lovinger DM, Delpire E. Abnormal GABAA receptor-mediated currents in dorsal root ganglion neurons isolated from $\mathrm{Na}-\mathrm{K}-2 \mathrm{Cl}$ cotransporter null mice. J Neurosci 2000;20: 7531-7538.

249. Granados-Soto V, Arguelles CF, Alvarez-Leefmans FJ. Peripheral and central antinociceptive action of $\mathrm{Na}+\mathrm{K}+-2 \mathrm{Cl}$ - cotransporter blockers on formalin-induced nociception in rats. Pain. 2005;114: 231-238. https://doi.org/10.1016/j.pain.2004.12.023.

250. Funk K, Woitecki A, Franjic-Würtz C, Gensch T, Möhrlen F, Frings S. Modulation of chloride homeostasis by inflammatory mediators in dorsal root ganglion neurons. Mol Pain 2008;4: 32. https://doi.org/10.1186/1744-8069-4-32.

251. Cho H, Yang YD, Lee J, et al. The calcium-activated chloride channel anoctamin 1 acts as a heat sensor in nociceptive neurons. Nat Neurosci 2012;15: 1015-1021. https://doi.org/10.1038/nn. 3111.

252. Liu B, Linley JE, Du X, et al. The acute nociceptive signals induced by bradykinin in rat sensory neurons are mediated by inhibition of M-type $\mathrm{K}+$ channels and activation of $\mathrm{Ca} 2+$-activated $\mathrm{Cl}$ channels. J Clin Invest 2010;120: 1240-1252. https://doi.org/10. 1172/JCI41084.

253. Oh S-J, Hwang SJ, Jung J, et al. MONNA, a potent and selective blocker for transmembrane protein with unknown function 16/ anoctamin-1. Mol Pharmacol 2013;84: 726-735. https://doi.org/ 10.1124/mol.113.087502.

254. García G, Martínez-Rojas VA, Oviedo N, Murbartián J. Blockade of anoctamin- 1 in injured and uninjured nerves reduces neuropathic pain. Brain Res 2018;1696: 38-48. https://doi.org/10.1016/j. brainres.2018.06.001.

255. Seo Y, Lee HK, Park J, et al. Ani9, a novel potent small-molecule ANO1 inhibitor with negligible effect on ANO2. PLoS One 2016;11: e0155771. https://doi.org/10.1371/journal.pone. 0155771 .

256. Oh U, Jung J. Cellular functions of TMEM16/anoctamin. Pflugers Arch 2016;468: 443-453. https://doi.org/10.1007/s00424-0161790-0.

257. André S, Boukhaddaoui H, Campo B, et al. Axotomy-induced expression of calcium-activated chloride current in subpopulations of mouse dorsal root ganglion neurons. J Neurophysiol 2003;90: 3764-3773. https://doi.org/10.1152/jn.00449.2003.

258. Pineda-Farias JB, Barragán-Iglesias P, Loeza-Alcocer E, et al. Role of anoctamin-1 and bestrophin-1 in spinal nerve ligationinduced neuropathic pain in rats. Mol Pain 2015;11: 41. https:// doi.org/10.1186/s12990-015-0042-1.

259. Xu Z-Z, Chen Q-Y, Deng S-Y, et al. $17 \beta$-estradiol attenuates neuropathic pain caused by spared nerve injury by upregulating CIC-3 in the dorsal root ganglion of ovariectomized rats. Front Neurosci 2019;13: 1205. https://doi.org/10.3389/fnins.2019. 01205.

260. Yang J, Chen J, Del Carmen Vitery M, et al. PAC, an evolutionarily conserved membrane protein, is a proton-activated chloride channel. Science. 2019;364: 395-399. https://doi.org/10.1126/ science.aav9739.

261. Niu N, Zhang J, Guo Y, Yang C, Gu J. Cystic fibrosis transmembrane conductance regulator expression in human spinal and sympathetic ganglia. Lab Invest 2009;89: 636-644. https://doi.org/10. 1038/labinvest.2009.28.

262. Kanno T, Nishizaki T. CFTR mediates noradrenaline-induced ATP efflux from DRG neurons. Mol Pain 2011;7: 72. https:// doi.org/10.1186/1744-8069-7-72.

263. Jentsch TJ, Lutter D, Planells-Cases R, Ullrich F, Voss FK. VRAC: molecular identification as LRRC8 heteromers with differential functions. Pflugers Arch 2016;468: 385-393. https://doi. org/10.1007/s00424-015-1766-5.

264. Wang R, Lu Y, Gunasekar S, et al. The volume-regulated anion channel (LRRC8) in nodose neurons is sensitive to acidic $\mathrm{pH}$. JCI Insight 2017;2: e90632. https://doi.org/10.1172/jci.insight.90632.

265. Sabirov RZ, Merzlyak PG, Islam MR, Okada T, Okada Y. The properties, functions, and pathophysiology of maxi-anion channels. Pflugers Arch 2016;468: 405-420. https://doi.org/10.1007/ s00424-015-1774-5.

266. Kanai N, Lu R, Satriano JA, Bao Y, Wolkoff AW, Schuster VL. Identification and characterization of a prostaglandin transporter. Science. 1995;268: 866-869. https://doi.org/10.1126/science. 7754369 . 
267. Carr RW, Sittl R, Fleckenstein J, Grafe P. GABA increases electrical excitability in a subset of human unmyelinated peripheral axons. PLoS One 2010;5: e8780. https://doi.org/10.1371/journal. pone. 0008780 .

268. Lee PR, Yoon S-Y, Kim HW, Yeo J-H, Kim YH, Oh SB. Peripheral GABAA receptor-mediated signaling facilitates persistent inflammatory hypersensitivity. Neuropharmacology. 2018;135: 572-580. https://doi.org/10.1016/j.neuropharm.2018. 04.009 .

269. Rubio C, Rubio-Osornio M, Retana-Márquez S, Verónica Custodio ML, Paz C. In vivo experimental models of epilepsy. Cent Nerv Syst Agents Med Chem 2010;10: 298-309. https://doi. org/10.2174/187152410793429746.

270. Reeh PW, Kress M. Molecular physiology of proton transduction in nociceptors. Curr Opin Pharmacol 2001;1: 45-51. https://doi. org/10.1016/s1471-4892(01)00014-5.

271. Waldmann R, Champigny G, Bassilana F, Heurteaux C, Lazdunski M. A proton-gated cation channel involved in acidsensing. Nature. 1997;386: 173-177. https://doi.org/10.1038/ $386173 \mathrm{a} 0$.

272. Baron A, Lingueglia E. Pharmacology of acid-sensing ion channels - Physiological and therapeutical perspectives. Neuropharmacology. 2015;94: 19-35. https://doi.org/10.1016/j. neuropharm.2015.01.005.

273. Holzer P. Acid-sensitive ion channels and receptors. Handb Exp Pharmacol 2009; 283-332. https://doi.org/10.1007/978-3-54079090-7 9

274. Mamet J, Baron A, Lazdunski M, Voilley N. ProInflammatory mediators, stimulators of sensory neuron excitability via the expression of acid-sensing ion channels. J Neurosci 2002;22: 10662-10670. https://doi.org/10.1523/JNEUROSCI.22-2410662.2002 .

275. Cadiou H, Studer M, Jones NG, et al. Modulation of acid-sensing ion channel activity by nitric oxide. J Neurosci 2007;27: 1325113260. https://doi.org/10.1523/JNEUROSCI.2135-07.2007.

276. Heber S, Ciotu CI, Hartner G, et al. TRPV1 antagonist BCTC inhibits pH 6.0-induced pain in human skin. Pain. 2020. https:// doi.org/10.1097/j.pain.0000000000001848.

277. Izumi M, Ikeuchi M, Ji Q, Tani T. Local ASIC3 modulates pain and disease progression in a rat model of osteoarthritis. J Biomed Sci 2012;19: 77. https://doi.org/10.1186/1423-0127-19-77.

278. Voilley N, de Weille J, Mamet J, Lazdunski M. Nonsteroid antiinflammatory drugs inhibit both the activity and the inflammationinduced expression of acid-sensing ion channels in nociceptors. J Neurosci 2001;21: 8026-8033.

279. Olesen AE, Nielsen LM, Larsen IM, Drewes AM. Randomized clinical trial: efficacy and safety of PPC-5650 on experimental esophageal pain and hyperalgesia in healthy volunteers. Scand J Gastroenterol 2015;50: 138-144. https://doi.org/10.3109/ 00365521.2014 .966319 .

280. Meller ST. Thermal and mechanical hyperalgesia: A distinct role for different excitatory amino acid receptors and signal transduction pathways? APS J 1994;3: 215-231. https://doi.org/10.1016/ S1058-9139(05)80269-4.

281. Ren K, Dubner R. Inflammatory models of pain and hyperalgesia. ILAR J 1999;40: 111-118. https://doi.org/10.1093/ilar.40.3.111.

282. Lolignier S, Eijkelkamp N, Wood JN. Mechanical allodynia. Pflugers Arch 2015;467: 133-139. https://doi.org/10.1007/ s00424-014-1532-0.

283. Ma Q. Population coding of somatic sensations. Neurosci Bull 2012;28: 91-99. https://doi.org/10.1007/s12264-012-1201-2.

284. Braz J, Solorzano C, Wang X, Basbaum AI. Transmitting pain and itch messages: a contemporary view of the spinal cord circuits that generate gate control. Neuron. 2014;82: 522-536. https://doi.org/ 10.1016/j.neuron.2014.01.018.
285. Woo S-H, Ranade S, Weyer AD, et al. Piezo2 is required for Merkel-cell mechanotransduction. Nature. 2014;509: 622-626. https://doi.org/10.1038/nature13251.

286. Osteen JD, Herzig V, Gilchrist J, et al. Selective spider toxins reveal a role for the Nav1.1 channel in mechanical pain. Nature. 2016;534: 494-499. https://doi.org/10.1038/nature17976.

287. Hill RZ, Hoffman BU, Morita T, et al. The signaling lipid sphingosine 1-phosphate regulates mechanical pain. Elife. 2018;7. https://doi.org/10.7554/eLife.33285.

288. Pageon SV, Govendir MA, Kempe D, Biro M. Mechanoimmunology: molecular-scale forces govern immune cell functions. Mol Biol Cell 2018;29: 1919-1926. https://doi. org/10.1091/mbc.E18-02-0120.

289. Guo D, Liang S, Wang S, et al. Role of epithelial Na+ channels in endothelial function. J Cell Sci 2016;129: 290-297. https://doi. org/10.1242/jcs. 168831 .

290. Michalick L, Kuebler WM. TRPV4-A missing link between mechanosensation and immunity. Front Immunol 2020;11: 413. https://doi.org/10.3389/fimmu.2020.00413.

291. Hill RZ, Bautista DM. Getting in touch with mechanical pain mechanisms. Trends Neurosci 2020;43: 311-325. https://doi.org/ 10.1016/j.tins.2020.03.004.

292. Kittaka H, DeBrecht J, Mishra SK. Differential contribution of sensory transient receptor potential channels in response to the bioactive lipid sphingosine-1-phosphate. Mol Pain 2020;16: 1744806920903515 . https://doi.org/10.1177/ 1744806920903515 .

293. Chen Z, Doyle TM, Luongo L, et al. Sphingosine-1-phosphate receptor 1 activation in astrocytes contributes to neuropathic pain. PNAS. 2019;116: 10557-10562. https://doi.org/10.1073/pnas. 1820466116.

294. Kunkel GT, Maceyka M, Milstien S, Spiegel S. Targeting the sphingosine-1-phosphate axis in cancer, inflammation and beyond. Nat Rev Drug Discov 2013;12: 688-702. https://doi.org/ 10.1038/nrd4099.

295. Scott LJ. Fingolimod: a review of its use in the management of relapsing-remitting multiple sclerosis. CNS Drugs 2011;25: 673698. https://doi.org/10.2165/11207350-000000000-00000.

296. Doolen S, Iannitti T, Donahue RR, Shaw BC, Grachen CM, Taylor BK. Fingolimod reduces neuropathic pain behaviors in a mouse model of multiple sclerosis by a sphingosine- 1 phosphate receptor 1-dependent inhibition of central sensitization in the dorsal horn. Pain. 2018;159: 224-238. https://doi.org/10.1097/j.pain. 0000000000001106.

297. Mayo Clinic, National Cancer Institute. Fingolimod in treating patients with chemotherapy-induced neuropathy. 2019. https:// ClinicalTrials.gov/show/NCT03943498.

298. Yin J, Michalick L, Tang C, et al. Role of transient receptor potential vanilloid 4 in neutrophil activation and acute lung injury. Am J Respir Cell Mol Biol 2016;54: 370-383. https://doi.org/10. 1165/rcmb.2014-0225OC

299. Balakrishna S, Song W, Achanta S, et al. TRPV4 inhibition counteracts edema and inflammation and improves pulmonary function and oxygen saturation in chemically induced acute lung injury. Am J Physiol Lung Cell Mol Physiol 2014;307: L158-172. https://doi.org/10.1152/ajplung.00065.2014.

300. Coste B, Mathur J, Schmidt M, et al. Piezo1 and Piezo2 are essential components of distinct mechanically activated cation channels. Science. 2010;330: 55-60. https://doi.org/10.1126/science. 1193270.

301. Ranade SS, Woo S-H, Dubin AE, et al. Piezo2 is the major transducer of mechanical forces for touch sensation in mice. Nature. 2014;516: 121-125. https://doi.org/10.1038/nature13980.

302. Chesler AT, Szczot M, Bharucha-Goebel D, et al. The role of PIEZO2 in human mechanosensation. N Engl J Med 2016;375: 1355-1364. https://doi.org/10.1056/NEJMoa1602812. 
303. Dubin AE, Schmidt M, Mathur J, et al. Inflammatory signals enhance piezo2-mediated mechanosensitive currents. Cell Rep 2012;2: 511-517. https://doi.org/10.1016/j.celrep.2012.07.014.

304. Szczot M, Liljencrantz J, Ghitani N, et al. PIEZO2 mediates injury-induced tactile pain in mice and humans. Sci Transl Med 2018;10. https://doi.org/10.1126/scitranslmed.aat9892.

305. Murthy SE, Loud MC, Daou I, et al. The mechanosensitive ion channel Piezo2 mediates sensitivity to mechanical pain in mice. Sci Transl Med 2018;10. https://doi.org/10.1126/scitranslmed. aat9897.

306. Zhang M, Wang Y, Geng J, Zhou S, Xiao B. Mechanically activated piezo channels mediate touch and suppress acute mechanical pain response in mice. Cell Rep 2019;26: 1419-1431.e4. https://doi.org/10.1016/j.celrep.2019.01.056.

307. Ludwig A, Zong X, Jeglitsch M, Hofmann F, Biel M. A family of hyperpolarization-activated mammalian cation channels. Nature. 1998;393: 587. https://doi.org/10.1038/31255.

308. Cho H-J, Staikopoulos V, Furness JB, Jennings EA. Inflammation-induced increase in hyperpolarization-activated, cyclic nucleotide-gated channel protein in trigeminal ganglion neurons and the effect of buprenorphine. Neuroscience. 2009;162: 453-461. https://doi.org/10.1016/j.neuroscience. 2009.04.063.

309. Schnorr S, Eberhardt M, Kistner K, et al. HCN2 channels account for mechanical (but not heat) hyperalgesia during long-standing inflammation. PAIN. 2014;155: 1079. https://doi.org/10.1016/j. pain.2014.02.006.

310. Lainez S, Tsantoulas C, Biel M, McNaughton PA. HCN3 ion channels: roles in sensory neuronal excitability and pain. $\mathrm{J}$ Physiol (Lond) 2019;597: 4661-4675. https://doi.org/10.1113/ JP278211.

311. Herrmann S, Rajab H, Christ I, et al. Protein kinase A regulates inflammatory pain sensitization by modulating HCN2 channel activity in nociceptive sensory neurons. PAIN. 2017;158: 2012. https://doi.org/10.1097/j.pain.0000000000001005.

312. Young GT, Emery EC, Mooney ER, Tsantoulas C, McNaughton PA. Inflammatory and neuropathic pain are rapidly suppressed by peripheral block of hyperpolarisation-activated cyclic nucleotidegated ion channels. Pain. 2014;155: 1708-1719. https://doi.org/ 10.1016/j.pain.2014.05.021.

313. Lee MC, Bond S, Wheeler D, et al. A randomised, double-blind, placebo-controlled crossover trial of the influence of the HCN channel blocker ivabradine in a healthy volunteer pain model: an enriched population trial. Pain. 2019;160: 2554-2565. https://doi. org/10.1097/j.pain.0000000000001638.

314. Dini L, Del Lungo M, Resta F, et al. Selective blockade of HCN1/ $\mathrm{HCN} 2$ channels as a potential pharmacological strategy against pain. Front Pharmacol 2018;9. https://doi.org/10.3389/fphar. 2018.01252.

315. Dosch M, Gerber J, Jebbawi F, Beldi G. Mechanisms of ATP release by inflammatory cells. Int J Mol Sci 2018;19. https://doi. org/10.3390/ijms19041222.

316. Cauwels A, Rogge E, Vandendriessche B, Shiva S, Brouckaert P. Extracellular ATP drives systemic inflammation, tissue damage and mortality. Cell Death Dis 2014;5: e1102. https://doi.org/10. 1038/cddis.2014.70.

317. Hamilton SG, Warburton J, Bhattacharjee A, Ward J, McMahon SB. ATP in human skin elicits a dose-related pain response which is potentiated under conditions of hyperalgesia. Brain. 2000;123: 1238-1246. https://doi.org/10.1093/brain/123.6.1238.

318. Burnstock G. Purinergic mechanisms and pain. Adv Pharmacol 2016;75: 91-137. https://doi.org/10.1016/bs.apha.2015.09.001.

319. Zhang X, Li G. P2Y receptors in neuropathic pain. Pharmacol Biochem Behav 2019;186: 172788. https://oi.org/10.1016/j. pbb.2019.172788.
320. Vulchanova L, Olson TH, Stone LS, Riedl MS, Elde R, Honda $\mathrm{CN}$. Cytotoxic targeting of isolectin IB4-binding sensory neurons. Neuroscience. 2001;108: 143-155. https://doi.org/10.1016/ s0306-4522(01)00377-3.

321. Chen CC, Akopian AN, Sivilotti L, Colquhoun D, Burnstock G, Wood JN. A P2X purinoceptor expressed by a subset of sensory neurons. Nature. 1995;377: 428-431. https://doi.org/10.1038/ $377428 \mathrm{a} 0$.

322. Jarvis MF, Burgard EC, McGaraughty S, et al. A-317491, a novel potent and selective non-nucleotide antagonist of $\mathrm{P} 2 \mathrm{X} 3$ and $\mathrm{P} 2 \mathrm{X} 2 /$ 3 receptors, reduces chronic inflammatory and neuropathic pain in the rat. Proc Natl Acad Sci U S A 2002;99: 17179-17184. https:// doi.org/10.1073/pnas.252537299.

323. Yuan M, Ding S, Meng T, et al. Effect of A-317491 delivered by glycolipid-like polymer micelles on endometriosis pain. Int $\mathrm{J}$ Nanomedicine 2017;12: 8171-8183. https://doi.org/10.2147/IJN. S146569.

324. Abdulqawi R, Dockry R, Holt K, et al. P2X3 receptor antagonist (AF-219) in refractory chronic cough: a randomised, double-blind, placebo-controlled phase 2 study. Lancet. 2015;385: 1198-1205. https://doi.org/10.1016/S0140-6736(14)61255-1.

325. Marucci G, Dal Ben D, Buccioni M, et al. Update on novel purinergic $\mathrm{P} 2 \mathrm{X} 3$ and $\mathrm{P} 2 \mathrm{X} 2 / 3$ receptor antagonists and their potential therapeutic applications. Expert Opin Ther Pat 2019;29: 943 963. https://doi.org/10.1080/13543776.2019.1693542.

326. Inoue K. Role of the P2X4 receptor in neuropathic pain. Curr Opin Pharmacol 2019;47: 33-39. https://doi.org/10.1016/j.coph.2019. 02.001 .

327. Zhang W-J, Zhu Z-M, Liu Z-X. The role and pharmacological properties of the P2X7 receptor in neuropathic pain. Brain Res Bull 2020;155: 19-28. https://doi.org/10.1016/j.brainresbull. 2019.11.006.

328. Tominaga M, Wada M, Masu M. Potentiation of capsaicin receptor activity by metabotropic ATP receptors as a possible mechanism for ATP-evoked pain and hyperalgesia. Proc Natl Acad Sci U S A 2001;98: 6951-6956. https://doi.org/10.1073/pnas. 111025298.

329. Sneyd JR, Langton JA, Allan LG, Peacock JE, Rowbotham DJ. Multicentre evaluation of the adenosine agonist GR79236X in patients with dental pain after third molar extraction. Br J Anaesth 2007;98: 672-676. https://doi.org/10.1093/bja/aem075.

330. Rathee PK, Distler C, Obreja O, et al. PKA/AKAP/VR-1 module: A common link of Gs-mediated signaling to thermal hyperalgesia. J Neurosci 2002;22: 4740-4745.

331. Fan H-C, Zhang X, McNaughton PA. Activation of the TRPV4 ion channel is enhanced by phosphorylation. J Biol Chem 2009;284: 27884-27891. https://doi.org/10.1074/jbc.M109. 028803.

332. Vijayaragavan K, Boutjdir M, Chahine M. Modulation of Nav1.7 and Nav1.8 peripheral nerve sodium channels by protein kinase A and protein kinase C. J Neurophysiol 2004;91: 1556-1569. https:// doi.org/10.1152/jn.00676.2003.

333. Chatelier A, Dahllund L, Eriksson A, Krupp J, Chahine M. Biophysical properties of human Na v1.7 splice variants and their regulation by protein kinase A. J Neurophysiol 2008;99: 22412250. https://doi.org/10.1152/jn.01350.2007.

334. Aley KO, Levine JD. Role of protein kinase A in the maintenance of inflammatory pain. J Neurosci 1999;19: 2181-2186.

335. Malmberg AB. Protein kinase subtypes involved in injuryinduced nociception. Prog Brain Res 2000;129: 51-59. https:// doi.org/10.1016/S0079-6123(00)29005-5.

336. Malmberg AB, Brandon EP, Idzerda RL, Liu H, McKnight GS, Basbaum AI. Diminished inflammation and nociceptive pain with preservation of neuropathic pain in mice with a targeted mutation of the type I regulatory subunit of cAMP-dependent protein kinase. J Neurosci 1997;17: 7462-7470. 
337. Yap TA, Walton MI, Grimshaw KM, et al. AT13148 is a novel, oral multi-AGC kinase inhibitor with potent pharmacodynamic and antitumor activity. Clin Cancer Res 2012;18: 3912-3923. https://doi.org/10.1158/1078-0432.CCR-11-3313.

338. Leroux AE, Schulze JO, Biondi RM. AGC kinases, mechanisms of regulation and innovative drug development. Semin Cancer Biol 2018;48: 1-17. https://doi.org/10.1016/j.semcancer.2017. 05.011 .

339. Huang L-Y, Gu Y. Epac and nociceptor sensitization. Mol Pain 2017;13: 1744806917716234. https://doi.org/10.1177/ 1744806917716234.

340. Gu Y, Li G, Huang L-YM. Inflammation induces Epac-protein kinase $\mathrm{C}$ alpha and epsilon signaling in TRPV1-mediated hyperalgesia. Pain. 2018;159: 2383-2393. https://doi.org/10. 1097/j.pain.0000000000001346.

341. Eijkelkamp N, Linley JE, Torres JM, et al. A role for Piezo2 in EPAC1-dependent mechanical allodynia. Nat Commun 2013;4: 1682. https://doi.org/10.1038/ncomms2673.

342. Singhmar P, Huo X, Li Y, et al. Orally active Epac inhibitor reverses mechanical allodynia and loss of intraepidermal nerve fibers in a mouse model of chemotherapy-induced peripheral neuropathy. Pain. 2018;159: 884-893. https://doi.org/10.1097/j.pain. 0000000000001160.

343. Singhmar P, Huo X, Eijkelkamp N, et al. Critical role for Epac1 in inflammatory pain controlled by GRK2-mediated phosphorylation of Epac1. Proc Natl Acad Sci U S A. 2016;113: 30363041. https://doi.org/10.1073/pnas.1516036113.

344. Parnell E, Palmer TM, Yarwood SJ. The future of EPAC-targeted therapies: agonism versus antagonism. Trends Pharmacol Sci 2015;36: 203-214. https://doi.org/10.1016/j.tips.2015.02.003.

345. Bhave G, Hu H-J, Glauner KS, et al. Protein kinase C phosphorylation sensitizes but does not activate the capsaicin receptor transient receptor potential vanilloid 1 (TRPV1). Proc Natl Acad Sci U S A 2003;100: 12480-12485. https://doi.org/10.1073/pnas. 2032100100.

346. Cesare P, Dekker LV, Sardini A, Parker PJ, McNaughton PA. Specific involvement of PKC-epsilon in sensitization of the neuronal response to painful heat. Neuron. 1999;23: 617-624. https:// doi.org/10.1016/s0896-6273(00)80813-2.

347. Baron A, Deval E, Salinas M, Lingueglia E, Voilley N, Lazdunski M. Protein kinase $\mathrm{C}$ stimulates the acid-sensing ion channel ASIC2a via the PDZ domain-containing protein PICK1. J Biol Chem 2002;277: 50463-50468. https://doi.org/10.1074/jbc. M208848200.

348. Deval E, Salinas M, Baron A, Lingueglia E, Lazdunski M. ASIC2b-dependent regulation of ASIC3, an essential acidsensing ion channel subunit in sensory neurons via the partner protein PICK-1. J Biol Chem. 2004;279: 19531-19539. https:// doi.org/10.1074/jbc.M313078200.

349. Cang C-L, Zhang H, Zhang Y-Q, Zhao Z-Q. PKCepsilondependent potentiation of TTX-resistant Nav1.8 current by neurokinin-1 receptor activation in rat dorsal root ganglion neurons. Mol Pain 2009;5: 33. https://doi.org/10.1186/1744-8069-533.

350. Khasar SG, Lin YH, Martin A, et al. A novel nociceptor signaling pathway revealed in protein kinase $\mathrm{C}$ epsilon mutant mice. Neuron. 1999;24: 253-260. https://doi.org/10.1016/s08966273(00)80837-5.

351. Mochly-Rosen D, Das K, Grimes KV. Protein kinase C, an elusive therapeutic target? Nat Rev Drug Discov 2012;11: 937-957. https://doi.org/10.1038/nrd3871.

352. Paz-Ares L, Douillard J-Y, Koralewski P, et al. Phase III study of gemcitabine and cisplatin with or without aprinocarsen, a protein kinase C-alpha antisense oligonucleotide, in patients with advanced-stage non-small-cell lung cancer. J Clin Oncol 2006;24: 1428-1434. https://doi.org/10.1200/JCO.2005.04.3299.
353. Malmberg AB, Chen C, Tonegawa S, Basbaum AI. Preserved acute pain and reduced neuropathic pain in mice lacking PKCgamma. Science. 1997;278: 279-283. https://doi.org/10. 1126/science.278.5336.279.

354. Velázquez KT, Mohammad H, Sweitzer SM. Protein kinase C in pain: involvement of multiple isoforms. Pharmacol Res 2007;55: 578-589. https://doi.org/10.1016/j.phrs.2007.04.006.

355. Cousins MJ, Pickthorn K, Huang S, Critchley L, Bell G. The safety and efficacy of KAI-1678- an inhibitor of epsilon protein kinase $\mathrm{C}(\varepsilon \mathrm{PKC})$-versus lidocaine and placebo for the treatment of postherpetic neuralgia: a crossover study design. Pain Med 2013;14: 533-540. https://doi.org/10.1111/pme.12058.

356. Moodie JE, Bisley EJ, Huang S, Pickthorn K, Bell G. A singlecenter, randomized, double-blind, active, and placebo-controlled study of KAI-1678, a novel PKC-epsilon inhibitor, in the treatment of acute postoperative orthopedic pain. Pain Med 2013;14: 916-924. https://doi.org/10.1111/pme.12088.

357. Zhang X, Li L, McNaughton PA. Proinflammatory mediators modulate the heat-activated ion channel TRPV1 via the scaffolding protein AKAP79/150. Neuron. 2008;59: 450-461. https://doi. org/10.1016/j.neuron.2008.05.015.

358. Brackley AD, Gomez R, Guerrero KA, et al. A-kinase anchoring protein 79/150 scaffolds transient receptor potential A 1 phosphorylation and sensitization by metabotropic glutamate receptor activation. Sci Rep 2017;7: 1-17. https://doi.org/10.1038/s41598017-01999-4.

359. Fischer MJM, McNaughton PA. How anchoring proteins shape pain. Pharmacol Ther 2014;143: 316-322. https://doi.org/10. 1016/j.pharmthera.2014.04.001.

360. Johnson GL, Lapadat R. Mitogen-activated protein kinase pathways mediated by ERK, JNK, and p38 protein kinases, Science. 2002;298: 1911-1912. https://doi.org/10.1126/science.1072682.

361. Ji R-R, Gereau RW, Malcangio M, Strichartz GR. MAP kinase and pain. Brain Res Rev 2009;60: 135-148. https://doi.org/10. 1016/j.brainresrev.2008.12.011.

362. Gao Y-J, Ji R-R. Activation of JNK pathway in persistent pain. Neurosci Lett 2008;437: 180-183. https://doi.org/10.1016/j. neulet.2008.03.017.

363. Kumar S, Boehm J, Lee JC. p38 MAP kinases: key signalling molecules as therapeutic targets for inflammatory diseases. Nat Rev Drug Discov 2003;2: 717-726. https://doi.org/10.1038/ $\operatorname{nrd} 1177$.

364. Lin X, Wang M, Zhang J, Xu R. p38 MAPK: a potential target of chronic pain. Curr Med Chem 2014;21: 4405-4418. https://doi. org/10.2174/0929867321666140915143040.

365. Dai Y, Iwata K, Fukuoka T, et al. Phosphorylation of extracellular signal-regulated kinase in primary afferent neurons by noxious stimuli and its involvement in peripheral sensitization. $J$ Neurosci 2002;22: 7737-7745. https://doi.org/10.1523/ JNEUROSCI.22-17-07737.2002.

366. Obata K, Yamanaka H, Dai Y, et al. Differential activation of extracellular signal-regulated protein kinase in primary afferent neurons regulates brain-derived neurotrophic factor expression after peripheral inflammation and nerve injury. J Neurosci 2003;23: 4117-4126. https://doi.org/10.1523/JNEUROSCI.23-10-04117. 2003.

367. Maruta T, Nemoto T, Hidaka K, et al. Upregulation of ERK phosphorylation in rat dorsal root ganglion neurons contributes to oxaliplatin-induced chronic neuropathic pain. PLoS One 2019;14: e0225586. https://doi.org/10.1371/journal.pone. 0225586 .

368. Gross AM, Wolters PL, Dombi E, et al. Selumetinib in children with inoperable plexiform neurofibromas. N Engl J Med 2020;382: 1430-1442. https://doi.org/10.1056/NEJMoa1912735.

369. Pfizer. A study to evaluate the safety and pharmacokinetic profile of a P38 inhibitor (PH-797804) in subjects with rheumatoid 
arthritis who are also taking methotrexate. 2008. https:// ClinicalTrials.gov/show/NCT00620685.

370. Wang C, Hockerman S, Jacobsen EJ, et al. Selective inhibition of the $38 \alpha$ MAPK-MK2 axis inhibits inflammatory cues including inflammasome priming signals. J Exp Med 2018;215: 1315-1325. https://doi.org/10.1084/jem.20172063.

371. Aclaris Therapeutics I. Study of ATI-450 plus methotrexate (MTX) vs MTX alone in patients with moderate to severe RA. 2020. https://ClinicalTrials.gov/show/NCT04247815.

372. Anand P, Shenoy R, Palmer JE, et al. Clinical trial of the p38 MAP kinase inhibitor dilmapimod in neuropathic pain following nerve injury. Eur J Pain 2011;15: 1040-1048. https://doi.org/10.1016/j. ejpain.2011.04.005.

373. Zhang Y, Song N, Liu F, et al. Activation of mitogen-activated protein kinases in satellite glial cells of the trigeminal ganglion contributes to substance P-mediated inflammatory pain. Int $\mathrm{J}$ Oral Sci 2019;11: 24. https://doi.org/10.1038/s41368-019-0055-0.

374. Thomas SM, Brugge JS. Cellular functions regulated by Src family kinases. Annu Rev Cell Dev Biol 1997;13: 513-609. https:// doi.org/10.1146/annurev.cellbio.13.1.513.

375. Zhang X, Huang J, McNaughton PA. NGF rapidly increases membrane expression of TRPV1 heat-gated ion channels. EMBO J 2005;24: 4211-4223. https://doi.org/10.1038/sj.emboj. 7600893.

376. Manolache A, Selescu T, Maier GL, et al. Regulation of TRPM8 channel activity by Src-mediated tyrosine phosphorylation. J Cell Physiol 2020;235: 5192-5203. https://doi.org/10.1002/jcp.29397.

377. Liu XJ, Gingrich JR, Vargas-Caballero M, et al. Treatment of inflammatory and neuropathic pain by uncoupling Src from the NMDA receptor complex. Nat Med 2008;14: 1325-1332. https:// doi.org/10.1038/nm.1883.

378. Appel CK, Gallego-Pedersen S, Andersen L, et al. The Src family kinase inhibitor dasatinib delays pain-related behaviour and conserves bone in a rat model of cancer-induced bone pain. Sci Rep 2017;7: 4792. https://doi.org/10.1038/s41598-017-05029-1.

379. Hung AL, Lim M, Doshi TL. Targeting cytokines for treatment of neuropathic pain. Scand J Pain 2017;17: 287-293. https://doi.org/ 10.1016/j.sjpain.2017.08.002.

380. Miller RJ, Jung H, Bhangoo SK, White FA. Cytokine and chemokine regulation of sensory neuron function. Handb Exp Pharmacol 2009; 417-449. https://doi.org/10.1007/978-3-540-79090-7_12.

381. Li M, Shi J, Tang J-R, et al. Effects of complete Freund's adjuvant on immunohistochemical distribution of IL-1beta and IL-1R I in neurons and glia cells of dorsal root ganglion. Acta Pharmacol Sin 2005;26: 192-198. https://doi.org/10.1111/j.1745-7254.2005. 00522.x.

382. Song A, Zhu L, Gorantla G, et al. Salient type 1 interleukin 1 receptor expression in peripheral non-immune cells. Sci Rep 2018;8: 723. https://doi.org/10.1038/s41598-018-19248-7.

383. Binshtok AM, Wang H, Zimmermann K, et al. Nociceptors are interleukin-1beta sensors. J Neurosci 2008;28: 14062-14073. https://doi.org/10.1523/JNEUROSCI.3795-08.2008.

384. Kaneko N, Kurata M, Yamamoto T, Morikawa S, Masumoto J. The role of interleukin-1 in general pathology. Inflamm Regen 2019;39. https://doi.org/10.1186/s41232-019-0101-5.

385. Werman A, Werman-Venkert R, White R, et al. The precursor form of IL-1alpha is an intracrine proinflammatory activator of transcription. Proc Natl Acad Sci U S A 2004;101: 2434-2439. https://doi.org/10.1073/pnas.0308705101.

386. Ferreira SH, Lorenzetti BB, Bristow AF, Poole S. Interleukin-1 beta as a potent hyperalgesic agent antagonized by a tripeptide analogue. Nature. 1988;334: 698-700. https://doi.org/10.1038/ $334698 \mathrm{a} 0$.

387. Allen KD, Adams SB, Mata BA, et al. Gait and behavior in an IL1 $\beta$-mediated model of rat knee arthritis and effects of an IL1 antagonist. J Orthop Res 2011;29: 694-703. https://doi.org/10. 1002/jor.21309.

388. Ren K, Torres R. Role of interleukin- $1 \beta$ during pain and inflammation. Brain Res Rev 2009;60: 57-64. https://doi.org/10.1016/j. brainresrev.2008.12.020.

389. Nemunaitis J, Ross M, Meisenberg B, et al. Phase I study of recombinant human interleukin-1 beta (rhIL-1 beta) in patients with bone marrow failure. Bone Marrow Transplant 1994;14: 583-588

390. Vadhan-Raj S, Kudelka AP, Garrison L, et al. Effects of interleukin-1 alpha on carboplatin-induced thrombocytopenia in patients with recurrent ovarian cancer. J Clin Oncol 1994;12: 707-714. https://doi.org/10.1200/JCO.1994.12.4.707.

391. Dinarello CA, Simon A, van der Meer JWM. Treating inflammation by blocking interleukin-1 in a broad spectrum of diseases. Nat Rev Drug Discov 2012;11: 633-652. https://doi.org/10.1038/ $\operatorname{nrd} 3800$.

392. Lai Y, Dong C. Therapeutic antibodies that target inflammatory cytokines in autoimmune diseases. Int Immunol 2016;28: 181188. https://doi.org/10.1093/intimm/dxv063.

393. Rider P, Carmi Y, Cohen I. Biologics for targeting inflammatory cytokines, clinical uses, and limitations, Int J Cell Biol 2016;2016: 9259646. https://doi.org/10.1155/2016/9259646.

394. Hong DS, Hui D, Bruera E, et al. MABp1, a first-in-class true human antibody targeting interleukin- $1 \alpha$ in refractory cancers: an open-label, phase 1 dose-escalation and expansion study. Lancet Oncol 2014;15: 656-666. https://doi.org/10.1016/S14702045(14)70155-X.

395. Dubois EA, Rissmann R, Cohen AF. Rilonacept and canakinumab. Br J Clin Pharmacol 2011;71: 639-641. https:// doi.org/10.1111/j.1365-2125.2011.03958.x.

396. Rider P, Carmi Y, Yossef R, et al. IL-1 receptor antagonist chimeric protein: context-specific and inflammation-restricted activation. J Immunol 2015;195: 1705-1712. https://doi.org/10.4049/ jimmunol.1501168.

397. Cohen SB, Proudman S, Kivitz AJ, et al. A randomized, doubleblind study of AMG 108 (a fully human monoclonal antibody to IL-1R1) in patients with osteoarthritis of the knee. Arthritis Res Ther 2011;13: R125. https://doi.org/10.1186/ar3430.

398. Gadient RA, Otten U. Postnatal expression of interleukin-6 (IL-6) and IL-6 receptor (IL-6R) mRNAs in rat sympathetic and sensory ganglia. Brain Res 1996;724: 41-46. https://doi.org/10.1016/ 0006-8993(96)00264-8.

399. von Banchet GS, Kiehl M, Schaible H-G. Acute and long-term effects of IL-6 on cultured dorsal root ganglion neurones from adult rat. J Neurochem 2005;94: 238-248. https://doi.org/10. 1111/j.1471-4159.2005.03185.x.

400. Tak PP, Firestein GS. NF-kappaB: a key role in inflammatory diseases. J Clin Invest 2001;107: 7-11. https://doi.org/10.1172/ JCI11830.

401. Ma W, Quirion R. Up-regulation of interleukin-6 induced by prostaglandin $\mathrm{E}$ from invading macrophages following nerve injury: an in vivo and in vitro study. J Neurochem 2005;93: 664-673. https://doi.org/10.1111/j.1471-4159.2005.03050.x.

402. St-Jacques B, Ma W. Role of prostaglandin E2 in the synthesis of the pro-inflammatory cytokine interleukin- 6 in primary sensory neurons: an in vivo and in vitro study. J Neurochem 2011;118: 841-854. https://doi.org/10.1111/j.1471-4159.2011.07230.x.

403. Narazaki M, Kishimoto T. The two-faced cytokine IL-6 in host defense and diseases. Int J Mol Sci 2018;19. https://doi.org/10. 3390/ijms19113528.

404. Scheller J, Garbers C, Rose-John S. Interleukin-6: from basic biology to selective blockade of pro-inflammatory activities. Semin Immunol 2014;26: 2-12. https://doi.org/10.1016/j.smim.2013.11. 002. 
405. Tanaka T, Kishimoto T. The biology and medical implications of interleukin-6. Cancer Immunol Res 2014;2: 288-294. https://doi. org/10.1158/2326-6066.CIR-14-0022.

406. Andratsch M, Mair N, Constantin CE, et al. A key role for gp130 expressed on peripheral sensory nerves in pathological pain. $\mathrm{J}$ Neurosci 2009;29: 13473-13483. https://doi.org/10.1523/ JNEUROSCI.1822-09.2009.

407. Jones SA, Novick D, Horiuchi S, Yamamoto N, Szalai AJ, Fuller GM. C-reactive protein: a physiological activator of interleukin 6 receptor shedding. J Exp Med 1999;189: 599-604.

408. Hashizume M, Hayakawa N, Mihara M. IL-6 trans-signalling directly induces RANKL on fibroblast-like synovial cells and is involved in RANKL induction by TNF-alpha and IL-17. Rheumatology (Oxford) 2008;47: 1635-1640. https://doi.org/10. 1093/rheumatology/ken363.

409. DeLeo JA, Colburn RW, Nichols M, Malhotra A. Interleukin-6mediated hyperalgesia/allodynia and increased spinal IL-6 expression in a rat mononeuropathy model. J Interferon Cytokine Res 1996;16: 695-700. https://doi.org/10.1089/jir.1996.16.695.

410. Arruda JL, Colburn RW, Rickman AJ, Rutkowski MD, DeLeo JA. Increase of interleukin- 6 mRNA in the spinal cord following peripheral nerve injury in the rat: potential role of IL-6 in neuropathic pain. Brain Res Mol Brain Res 1998;62: 228-235. https:// doi.org/10.1016/s0169-328x(98)00257-5.

411. Zhou Y-Q, Liu Z, Liu Z-H, et al. Interleukin-6: an emerging regulator of pathological pain. J Neuroinflammation 2016;13. https:// doi.org/10.1186/s12974-016-0607-6.

412. Arruda JL, Sweitzer S, Rutkowski MD, DeLeo JA. Intrathecal anti-IL-6 antibody and IgG attenuates peripheral nerve injuryinduced mechanical allodynia in the rat: possible immune modulation in neuropathic pain. Brain Res 2000;879: 216-225. https:// doi.org/10.1016/s0006-8993(00)02807-9.

413. Dubový P, Klusáková I, Svízenská I, Brázda V. Satellite glial cells express IL-6 and corresponding signal-transducing receptors in the dorsal root ganglia of rat neuropathic pain model. Neuron Glia Biol 2010;6: 73-83. https://doi.org/10.1017/ S1740925X10000074.

414. Choy EHS, Calabrese LH. Neuroendocrine and neurophysiological effects of interleukin 6 in rheumatoid arthritis. Rheumatology (Oxford) 2018;57: 1885-1895. https://doi.org/10.1093/ rheumatology/kex391.

415. van Rhee F, Rothman M, Ho KF, et al. Patient-reported outcomes for multicentric Castleman's disease in a randomized, placebocontrolled study of siltuximab. Patient. 2015;8: 207-216. https:// doi.org/10.1007/s40271-015-0120-5.

416. Rossi J-F, Lu Z-Y, Jourdan M, Klein B. Interleukin-6 as a therapeutic target. Clin Cancer Res 2015;21: 1248-1257. https://doi. org/10.1158/1078-0432.CCR-14-2291.

417. Kim GW, Lee NR, Pi RH, et al. IL-6 inhibitors for treatment of rheumatoid arthritis: past, present, and future. Arch Pharm Res 2015;38: 575-584. https://doi.org/10.1007/s12272-015-0569-8.

418. Sainoh T, Orita S, Miyagi M, et al. Single intradiscal injection of the interleukin- 6 receptor antibody tocilizumab provides shortterm relief of discogenic low back pain; prospective comparative cohort study. J Orthop Sci 2016;21: 2-6. https://doi.org/10.1016/j. jos.2015.10.005.

419. Ogata A, Kato Y, Higa S, Yoshizaki K. IL-6 inhibitor for the treatment of rheumatoid arthritis: a comprehensive review. Mod Rheumatol 2019;29: 258-267. https://doi.org/10.1080/14397595. 2018.1546357.

420. Davis SM, Pennypacker KR. The role of the leukemia inhibitory factor receptor in neuroprotective signaling. Pharmacol Ther 2018;183: 50-57. https://doi.org/10.1016/j.pharmthera.2017.08. 008 .

421. Gadient RA, Patterson PH. Leukemia inhibitory factor, Interleukin 6 , and other cytokines using the GP130 transducing receptor: roles in inflammation and injury. Stem Cells 1999;17: 127-137. https:// doi.org/10.1002/stem.170127.

422. Scott RL, Gurusinghe AD, Rudvosky AA, et al. Expression of leukemia inhibitory factor receptor mRNA in sensory dorsal root ganglion and spinal motor neurons of the neonatal rat. Neurosci Lett 2000;295: 49-53. https://doi.org/10.1016/s0304-3940(00) 01578-0.

423. Gardiner NJ, Cafferty WBJ, Slack SE, Thompson SWN. Expression of gp130 and leukaemia inhibitory factor receptor subunits in adult rat sensory neurones: regulation by nerve injury. J Neurochem 2002;83: 100-109. https://doi.org/10.1046/j.14714159.2002.01101.x

424. Merck KGaA D. A multicentre, randomised, double-blind, placebo-controlled proof of concept study to compare the efficacy and safety of r-hLIF (Emfilermin) for improving embryo implantation following in vitro fertilization (IVF) and embryo transfer (ET) in women with recurrent implantation failure. 2003. https:// ClinicalTrials.gov/show/NCT00504608.

425. Davis ID, Kiers L, MacGregor L, et al. A randomized, doubleblinded, placebo-controlled phase II trial of recombinant human leukemia inhibitory factor (rhuLIF, emfilermin, AM424) to prevent chemotherapy-induced peripheral neuropathy. Clin Cancer Res 2005;11: 1890-1898. https://doi.org/10.1158/1078-0432. CCR-04-1655.

426. Wang M-T, Fer N, Galeas J, et al. Blockade of leukemia inhibitory factor as a therapeutic approach to KRAS driven pancreatic cancer. Nat Commun 2019;10: 3055. https://doi.org/10.1038/s41467019-11044-9.

427. Tamura S, Morikawa Y, Miyajima A, Senba E. Expression of oncostatin $\mathrm{M}$ receptor beta in a specific subset of nociceptive sensory neurons. Eur J Neurosci 2003;17: 2287-2298. https:// doi.org/10.1046/j.1460-9568.2003.02681.x.

428. Morikawa Y, Tamura S, Minehata K, Donovan PJ, Miyajima A, Senba E. Essential function of oncostatin $\mathrm{m}$ in nociceptive neurons of dorsal root ganglia. J Neurosci 2004;24: 1941-1947. https://doi. org/10.1523/JNEUROSCI.4975-03.2004.

429. Langeslag M, Constantin CE, Andratsch M, Quarta S, Mair N, Kress M. Oncostatin M induces heat hypersensitivity by gp130dependent sensitization of TRPV1 in sensory neurons. Mol Pain 2011;7: 102. https://doi.org/10.1186/1744-8069-7-102.

430. Pöling J, Gajawada P, Richter M, et al. Therapeutic targeting of the oncostatin $\mathrm{M}$ receptor- $\beta$ prevents inflammatory heart failure. Basic Res Cardiol 2014;109: 396. https://doi.org/10.1007/s00395013-0396-3.

431. Reid J, Zamuner S, Edwards K, et al. In vivo affinity and target engagement in skin and blood in a first-time-in-human study of an anti-oncostatin $\mathrm{M}$ monoclonal antibody. Br J Clin Pharmacol 2018;84: 2280-2291. https://doi.org/10.1111/bcp.13669.

432. Oetjen LK, Mack MR, Feng J, et al. Sensory neurons Co-opt classical immune signaling pathways to mediate chronic itch. Cell. 2017;171: 217-228.e13. https://doi.org/10.1016/j.cell.2017. 08.006 .

433. van Helvoort EM, Popov-Celeketic J, Eijkelkamp N, et al. Canine IL4-10 fusion protein provides disease modifying activity in a canine model of OA; an exploratory study. PLoS One 2019;14: e0219587. https://doi.org/10.1371/journal.pone.0219587.

434. Eijkelkamp N, Steen-Louws C, Hartgring SAY, et al. IL4-10 fusion protein is a novel drug to treat persistent inflammatory pain. J Neurosci 2016;36: 7353-7363. https://doi.org/10.1523/ JNEUROSCI.0092-16.2016.

435. Kiguchi N, Sakaguchi H, Kadowaki Y, et al. Peripheral administration of interleukin-13 reverses inflammatory macrophage and tactile allodynia in mice with partial sciatic nerve ligation. J Pharmacol Sci 2017;133: 53-56. https://doi.org/10.1016/j.jphs. 2016.11.005. 
436. Beck LA, Thaçi D, Hamilton JD, et al. Dupilumab treatment in adults with moderate-to-severe atopic dermatitis. N Engl J Med 2014;371: 130-139. https://doi.org/10.1056/NEJMoa1314768.

437. Simpson EL, Bieber T, Guttman-Yassky E, et al. Two phase 3 trials of dupilumab versus placebo in atopic dermatitis. N Engl $\mathrm{J}$ Med 2016;375: 2335-2348. https://doi.org/10.1056/ NEJMoa1610020.

438. Hoy SM. Dupilumab: a review in chronic rhinosinusitis with nasal polyps. Drugs. 2020;80: 711-717. https://doi.org/10.1007/ s40265-020-01298-9.

439. Matsunaga MC, Yamauchi PS. IL-4 and IL-13 inhibition in atopic dermatitis. J Drugs Dermatol 2016;15: 925-929.

440. Dhillon S. Delgocitinib: first approval. Drugs. 2020;80: 609-615. https://doi.org/10.1007/s40265-020-01291-2.

441. Segond von Banchet G, Boettger MK, König C, Iwakura Y, Bräuer R, Schaible H-G. Neuronal IL-17 receptor upregulates TRPV4 but not TRPV1 receptors in DRG neurons and mediates mechanical but not thermal hyperalgesia. Mol Cell Neurosci 2013;52: 152-160. https://doi.org/10.1016/j.mcn.2012.11.006.

442. Richter F, Natura G, Ebbinghaus M, et al. Interleukin-17 sensitizes joint nociceptors to mechanical stimuli and contributes to arthritic pain through neuronal interleukin-17 receptors in rodents. Arthritis Rheum 2012;64: 4125-4134. https://doi.org/10.1002/ art.37695.

443. Yao Z, Fanslow WC, Seldin MF, et al. Herpesvirus Saimiri encodes a new cytokine, IL-17, which binds to a novel cytokine receptor. Immunity. 1995;3: 811-821. https://doi.org/10.1016/ 1074-7613(95)90070-5.

444. Ruddy MJ, Wong GC, Liu XK, et al. Functional cooperation between interleukin-17 and tumor necrosis factor-alpha is mediated by CCAAT/enhancer-binding protein family members. J Biol Chem 2004;279: 2559-2567. https://doi.org/10.1074/jbc. M308809200.

445. Langley RG, Elewski BE, Lebwohl M, et al. Secukinumab in plaque psoriasis-results of two phase 3 trials. N Engl J Med 2014;371: 326-338. https://doi.org/10.1056/NEJMoa1314258.

446. Durham LE, Kirkham BW, Taams LS. Contribution of the IL-17 pathway to psoriasis and psoriatic arthritis. Curr Rheumatol Rep 2015;17: 55. https://doi.org/10.1007/s11926-015-0529-9.

447. Sanford M, McKeage K. Secukinumab: first global approval. Drugs. 2015;75: 329-338. https://doi.org/10.1007/s40265-0150359-0.

448. Leonardi C, Matheson R, Zachariae C, et al. Anti-interleukin-17 monoclonal antibody ixekizumab in chronic plaque psoriasis. $\mathrm{N}$ Engl J Med 2012;366: 1190-1199. https://doi.org/10.1056/ NEJMoa1109997.

449. Kampylafka E, Simon D, d'Oliveira I, et al. Disease interception with interleukin-17 inhibition in high-risk psoriasis patients with subclinical joint inflammation-data from the prospective IVEPSA study. Arthritis Res Ther 2019;21: 178. https://doi.org/10.1186/ s13075-019-1957-0.

450. Liu B, Tai Y, Achanta S, et al. IL-33/ST2 signaling excites sensory neurons and mediates itch response in a mouse model of poison ivy contact allergy. Proc Natl Acad Sci U S A 2016;113: E7572E7579. https://doi.org/10.1073/pnas.1606608113.

451. Meng J, Moriyama M, Feld M, et al. New mechanism underlying IL-31-induced atopic dermatitis. J Allergy Clin Immunol 2018;141: 1677-1689.e8. https://doi.org/10.1016/j.jaci.2017.12. 1002.

452. Tsuji M, Arai I, Miyagawa K, et al. Involvement of interleukin-31 receptor $\mathrm{A}$ in morphine-induced itching and antinociception in mice. Eur J Pain 2019;23: 378-388. https://doi.org/10.1002/ejp. 1312.

453. Choi Y-H, Kim K-M, Kim H-O, Jang Y-C, Kwak I-S. Clinical and histological correlation in post-burn hypertrophic scar for pain and itching sensation. Ann Dermatol 2013;25: 428-433. https://doi. org/10.5021/ad.2013.25.4.428.

454. Lee MY, Shin E, Kim H, Kwak IS, Choi Y. Interleukin-31, interleukin-31RA, and OSMR expression levels in post-burn hypertrophic scars. J Pathol Transl Med 2018;52: 307-313. https://doi.org/ 10.4132/jptm.2018.08.03.

455. Ruzicka T, Hanifin JM, Furue M, et al. Anti-interleukin-31 receptor A antibody for atopic dermatitis. N Engl J Med 2017;376: 826835. https://doi.org/10.1056/NEJMoa1606490.

456. Patruno $\mathrm{C}$, Napolitano $\mathrm{M}$, Balato $\mathrm{N}$, et al. Psoriasis and skin pain: instrumental and biological evaluations. Acta Derm Venereol 2015;95: 432-438. https://doi.org/10.2340/ 00015555-1965.

457. Chen W-Y, Tsai T-H, Yang J-L, Li L-C. Therapeutic strategies for targeting IL-33/ST2 signalling for the treatment of inflammatory diseases. Cell Physiol Biochem 2018;49: 349-358. https://doi.org/ $10.1159 / 000492885$

458. Chinthrajah $\mathrm{S}, \mathrm{Cao} \mathrm{S}$, Liu $\mathrm{C}$, et al. Phase 2a randomized, placebocontrolled study of anti-IL-33 in peanut allergy. JCI Insight 2019;4. https://doi.org/10.1172/jci.insight.131347.

459. Chen Y-L, Gutowska-Owsiak D, Hardman CS, et al. Proof-ofconcept clinical trial of etokimab shows a key role for IL-33 in atopic dermatitis pathogenesis. Sci Transl Med 2019;11. https:// doi.org/10.1126/scitranslmed.aax2945.

460. Gabryelska A, Kuna P, Antczak A, Białasiewicz P, Panek M. IL33 mediated inflammation in chronic respiratory diseasesunderstanding the role of the member of IL-1 superfamily. Front Immunol 2019;10. https://doi.org/10.3389/fimmu.2019.00692.

461. Song P, Zhao ZQ, Liu XY. Expression of IL-2 receptor in dorsal root ganglion neurons and peripheral antinociception. Neuroreport. 2000;11: 1433-1436. https://doi.org/10.1097/ 00001756-200005150-00016

462. Minnone G, De Benedetti F, Bracci-Laudiero L. NGF and its receptors in the regulation of inflammatory response. Int $\mathrm{J}$ Mol Sci 2017;18. https://doi.org/10.3390/ijms 18051028.

463. Thibault K, Lin WK, Rancillac A, et al. BDNF-dependent plasticity induced by peripheral inflammation in the primary sensory and the cingulate cortex triggers cold allodynia and reveals a major role for endogenous BDNF as a tuner of the affective aspect of pain. J Neurosci 2014;34: 14739-14751. https://doi.org/10.1523/ JNEUROSCI.0860-14.2014.

464. Mendell LM, Albers KM, Davis BM. Neurotrophins, nociceptors, and pain. Microsc Res Tech 1999;45: 252-261. https://doi.org/10. 1002/(SICI)1097-0029(19990515/01)45:4/5<252::AIDJEMT9>3.0.CO;2-N.

465. Wyatt S, Shooter EM, Davies AM. Expression of the NGF receptor gene in sensory neurons and their cutaneous targets prior to and during innervation. Neuron. 1990;4: 421-427. https://doi.org/10. 1016/0896-6273(90)90054-j.

466. Richner M, Ulrichsen M, Elmegaard SL, Dieu R, Pallesen LT, Vaegter CB. Peripheral nerve injury modulates neurotrophin signaling in the peripheral and central nervous system. Mol Neurobiol 2014;50: 945-970. https://doi.org/10.1007/s12035014-8706-9.

467. Bonnington JK, McNaughton PA. Signalling pathways involved in the sensitisation of mouse nociceptive neurones by nerve growth factor. J Physiol (Lond) 2003;551: 433-446. https://doi. org/10.1113/jphysiol.2003.039990.

468. Cho KO, Skarnes WC, Minsk B, Palmieri S, Jackson-Grusby L, Wagner JA. Nerve growth factor regulates gene expression by several distinct mechanisms. Mol Cell Biol 1989;9: 135-143. https://doi.org/10.1128/mcb.9.1.135.

469. Delcroix J-D, Valletta JS, Wu C, Hunt SJ, Kowal AS, Mobley WC. NGF signaling in sensory neurons: evidence that early endosomes carry NGF retrograde signals. Neuron. 2003;39: 6984. https://doi.org/10.1016/s0896-6273(03)00397-0. 
470. Santos D, Gonzalez-Perez F, Navarro X, Del Valle J. Dosedependent differential effect of neurotrophic factors on in vitro and in vivo regeneration of motor and sensory neurons. Neural Plast 2016;2016: 4969523. https://doi.org/10.1155/2016/ 4969523.

471. Price TJ, Louria MD, Candelario-Soto D, et al. Treatment of trigeminal ganglion neurons in vitro with NGF, GDNF or BDNF: effects on neuronal survival, neurochemical properties and TRPV1-mediated neuropeptide secretion. BMC Neurosci 2005;6: 4. https://doi.org/10.1186/1471-2202-6-4.

472. Mamet J, Lazdunski M, Voilley N. How nerve growth factor drives physiological and inflammatory expressions of acidsensing ion channel 3 in sensory neurons. J Biol Chem 2003;278: 48907-48913. https://doi.org/10.1074/jbc. M309468200.

473. Ji R-R, Samad TA, Jin S-X, Schmoll R, Woolf CJ. p38 MAPK activation by NGF in primary sensory neurons after inflammation increases TRPV1 levels and maintains heat hyperalgesia. Neuron. 2002;36: 57-68. https://doi.org/10.1016/s0896-6273(02)00908-x.

474. Xu P, Hall AK. Activin acts with nerve growth factor to regulate calcitonin gene-related peptide mRNA in sensory neurons. Neuroscience. 2007;150: 665-674. https://doi.org/10.1016/j. neuroscience.2007.09.041

475. Lee Y-J, Zachrisson O, Tonge DA, McNaughton PA. Upregulation of bradykinin B2 receptor expression by neurotrophic factors and nerve injury in mouse sensory neurons. Mol Cell Neurosci 2002;19: 186-200. https://doi.org/10.1006/mcne. 2001.1073 .

476. Owolabi JB, Rizkalla G, Tehim A, et al. Characterization of antiallodynic actions of ALE-0540, a novel nerve growth factor receptor antagonist, in the rat, J Pharmacol Exp Ther 1999;289: 1271-1276.

477. Chang DS, Hsu E, Hottinger DG, Cohen SP. Anti-nerve growth factor in pain management: current evidence. J Pain Res 2016;9: 373-383. https://doi.org/10.2147/JPR.S89061.

478. Hefti F. Pharmacology of nerve growth factor and discovery of tanezumab, an anti-nerve growth factor antibody and pain therapeutic. Pharmacol Res 2020;154: 104240. https://doi.org/10.1016/ j.phrs.2019.04.024.

479. Schmelz M, Mantyh P, Malfait A-M, et al. Nerve growth factor antibody for the treatment of osteoarthritis pain and chronic lowback pain: mechanism of action in the context of efficacy and safety. Pain. 2019;160: 2210-2220. https://doi.org/10.1097/j. pain.0000000000001625.

480. Huang Y. Expression of BDNF in dorsal root ganglion of rats with bone cancer pain and its effect on pain behavior. J Musculoskelet Neuronal Interact 2018;18: 42-46.

481. Malfait A-M, Miller RE, Block JA. Targeting neurotrophic factors: novel approaches to musculoskeletal pain. Pharmacol Ther 2020; 107553. https://doi.org/10.1016/j.pharmthera.2020.107553.

482. Liu T, Gao Y-J, Ji R-R. Emerging role of Toll-like receptors in the control of pain and itch. Neurosci Bull 2012;28: 131-144. https:// doi.org/10.1007/s12264-012-1219-5.

483. Jack CS, Arbour N, Manusow J, et al. TLR signaling tailors innate immune responses in human microglia and astrocytes. J Immunol 2005;175: 4320-4330. https://doi.org/10.4049/jimmunol.175.7. 4320.

484. Goethals S, Ydens E, Timmerman V, Janssens S. Toll-like receptor expression in the peripheral nerve. Glia. 2010;58: 1701-1709. https://doi.org/10.1002/glia.21041.

485. Bsibsi M, Ravid R, Gveric D, van Noort JM. Broad expression of Toll-like receptors in the human central nervous system. J Neuropathol Exp Neurol 2002;61: 1013-1021. https://doi.org/ 10.1093/jnen/61.11.1013.
486. Qi J, Buzas K, Fan H, et al. Painful pathways induced by TLR stimulation of dorsal root ganglion neurons. J Immunol 2011;186: 6417-6426. https://doi.org/10.4049/jimmunol.1001241.

487. Lacagnina MJ, Watkins LR, Grace PM. Toll-like receptors and their role in persistent pain. Pharmacol Ther 2018;184: 145-158. https://doi.org/10.1016/j.pharmthera.2017.10.006.

488. Bruno K, Woller SA, Miller YI, et al. Targeting toll-like receptor4 (TLR4)-an emerging therapeutic target for persistent pain states. Pain. 2018;159: 1908-1915. https://doi.org/10.1097/j.pain. 0000000000001306.

489. Nicotra L, Loram LC, Watkins LR, Hutchinson MR. Toll-like receptors in chronic pain. Exp Neurol 2012;234: 316-329. https://doi.org/10.1016/j.expneurol.2011.09.038.

490. Tanga FY, Nutile-McMenemy N, DeLeo JA. The CNS role of Toll-like receptor 4 in innate neuroimmunity and painful neuropathy. Proc Natl Acad Sci U S A 2005;102: 5856-5861. https://doi. org/10.1073/pnas.0501634102.

491. Li J, Csakai A, Jin J, Zhang F, Yin H. Therapeutic Developments Targeting Toll-like Receptor-4-Mediated Neuroinflammation. ChemMedChem. 2016;11: 154-165. https://doi.org/10.1002/ cmdc. 201500188.

492. NovImmune SA. Study of an anti-TLR4 mAb in rheumatoid arthritis. 2017. https://ClinicalTrials.gov/show/NCT03241108.

493. Krock E, Millecamps M, Currie JB, Stone LS, Haglund L. Low back pain and disc degeneration are decreased following chronic toll-like receptor 4 inhibition in a mouse model. Osteoarthr Cartil 2018;26: 1236-1246. https://doi.org/10.1016/j.joca.2018.06.002.

494. Zhao Y, Xin Y, Gao J, Teng R-Y, Chu H-C. Analgesic effect of TAK-242 on neuropathic pain in rats. Int J Clin Exp Med 2015;8: 11202-11207.

495. Pan L-F, Yu L, Wang L-M, et al. The Toll-like receptor 4 antagonist TAK-242 protects against chronic pancreatitis in rats. Mol Med Rep 2017;16: 3863-3868. https://doi.org/10.3892/mmr. 2017.7105 .

496. Li X-Q, Zhang Z-L, Tan W-F, Sun X-J, Ma H. Down-regulation of CXCL12/CXCR4 expression alleviates ischemia-reperfusioninduced inflammatory pain via inhibiting glial TLR4 activation in the spinal cord. PLoS One 2016;11: e0163807. https://doi.org/10. 1371/journal.pone.0163807.

497. Fan Y-X, Qian C, Liu B, et al. Induction of suppressor of cytokine signaling 3 via HSF-1-HSP70-TLR4 axis attenuates neuroinflammation and ameliorates postoperative pain. Brain Behav Immun 2018;68: 111-122. https://doi.org/10.1016/j.bbi.2017.10.006.

498. Yin N, Gao Q, Tao W, et al. Paeoniflorin relieves LPS-induced inflammatory pain in mice by inhibiting NLRP3 inflammasome activation via transient receptor potential vanilloid 1 . J Leukoc Biol. 2020. https://doi.org/10.1002/JLB.3MA0220-355R.

499. Freeman ME, Kanyicska B, Lerant A, Nagy G. Prolactin: structure, function, and regulation of secretion. Physiol Rev 2000;80: 1523-1631. https://doi.org/10.1152/physrev.2000.80.4.1523.

500. Wu H, Devi R, Malarkey WB. Expression and localization of prolactin messenger ribonucleic acid in the human immune system. Endocrinology. 1996;137: 349-353. https://doi.org/10.1210/ endo.137.1.8536634.

501. Aoki M, Wartenberg P, Grünewald R, et al. Widespread cellspecific prolactin receptor expression in multiple murine organs. Endocrinology. 2019;160: 2587-2599. https://doi.org/10.1210/ en.2019-00234.

502. Radhakrishnan A, Raju R, Tuladhar N, et al. A pathway map of prolactin signaling. J Cell Commun Signal 2012;6: 169-173. https://doi.org/10.1007/s12079-012-0168-0.

503. Belugin S, Diogenes AR, Patil MJ, Ginsburg E, Henry MA, Akopian AN. Mechanisms of transient signaling via short and long prolactin receptor isoforms in female and male sensory neurons. J Biol Chem 2013;288: 34943-34955. https://doi.org/10. 1074/jbc.M113.486571. 
504. Patil M, Belugin S, Mecklenburg J, et al. Prolactin regulates pain responses via a female-selective nociceptor-specific mechanism. iScience. 2019;20: 449-465. https://doi.org/10.1016/j.isci.2019. 09.039 .

505. Patil MJ, Ruparel SB, Henry MA, Akopian AN. Prolactin regulates TRPV1, TRPA1, and TRPM8 in sensory neurons in a sexdependent manner: contribution of prolactin receptor to inflammatory pain. Am J Physiol Endocrinol Metab 2013;305: E1154E1164. https://doi.org/10.1152/ajpendo.00187.2013.

506. Chen Y, Moutal A, Navratilova E, et al. The prolactin receptor long isoform regulates nociceptor sensitization and opioidinduced hyperalgesia selectively in females. Sci Transl Med 2020;12. https://doi.org/10.1126/scitranslmed.aay7550.

507. Rouet V, Bogorad RL, Kayser C, et al. Local prolactin is a target to prevent expansion of basal/stem cells in prostate tumors. Proc Natl Acad Sci U S A 2010;107: 15199-15204. https://doi.org/10. 1073/pnas.0911651107.

508. Agarwal N, Machiels J-P, Suárez C, et al. Phase I study of the prolactin receptor antagonist LFA102 in metastatic breast and castration-resistant prostate cancer. Oncologist. 2016;21: 535536. https://doi.org/10.1634/theoncologist.2015-0502.

509. Damiano JS, Rendahl KG, Karim C, et al. Neutralization of prolactin receptor function by monoclonal antibody LFA102, a novel potential therapeutic for the treatment of breast cancer. Mol Cancer Ther 2013;12: 295-305. https://doi.org/10.1158/15357163.MCT-12-0886.

510. Liu T-T, Qu Z-W, Ren C, Gan X, Qiu C-Y, Hu W-P. Prolactin potentiates the activity of acid-sensing ion channels in female rat primary sensory neurons. Neuropharmacology 2016;103: 174 182. https://doi.org/10.1016/j.neuropharm.2015.07.016.

511. Ferraris J, Bernichtein S, Pisera D, Goffin V. Use of prolactin receptor antagonist to better understand prolactin regulation of pituitary homeostasis. Neuroendocrinology 2013;98: 171-179. https://doi.org/10.1159/000354701.

512. Poët M, Kornak U, Schweizer M, et al. Lysosomal storage disease upon disruption of the neuronal chloride transport protein ClC-6. Proc Natl Acad Sci U S A 2006;103: 13854-13859. https://doi. org/10.1073/pnas.0606137103.

513. Agata Y, Kawasaki A, Nishimura H, et al. Expression of the PD-1 antigen on the surface of stimulated mouse $\mathrm{T}$ and $\mathrm{B}$ lymphocytes. Int Immunol 1996;8: 765-772. https://doi.org/10.1093/intimm/8. 5.765 .

514. Sharma P, Allison JP. The future of immune checkpoint therapy. Science 2015;348: 56-61. https://doi.org/10.1126/science. aaa8172.

515. Chen G, Kim YH, Li H, et al. PD-L1 inhibits acute and chronic pain by suppressing nociceptive neuron activity via PD-1. Nat Neurosci 2017;20: 917-926. https://doi.org/10.1038/nn.4571.

516. Wang Z, Jiang C, He Q, et al. Anti-PD-1 treatment impairs opioid antinociception in rodents and nonhuman primates. Sci Transl Med 2020;12. https://doi.org/10.1126/scitranslmed.aaw6471.

517. Zhang J, Zhang H, Luo Y. Association between activation of the programmed cell death-1 (PD-1)/programmed death-ligand 1 (PD-L1) pathway and pain in patients with cancer. Med Sci Monit 2019;25: 1275-1282. https://doi.org/10.12659/MSM. 912632.

518. Jaafar J, Fernandez E, Alwan H, Philippe J. Programmed cell death-1 and programmed cell death ligand-1 antibodies-induced dysthyroidism. Endocr Connect 2018;7: R196-R211. https://doi. org/10.1530/EC-18-0079.

519. Johansen A, Christensen SJ, Scheie D, Højgaard JLS, Kondziella D. Neuromuscular adverse events associated with anti-PD-1 monoclonal antibodies: Systematic review. Neurology 2019;92: 663-674. https://doi.org/10.1212/WNL.0000000000007235.

520. Mazaleuskaya LL, Lawson JA, Li X, et al. A broad-spectrum lipidomics screen of antiinflammatory drug combinations in human blood. JCI Insight 2016;1. https://doi.org/10.1172/jci. insight.87031.

521. Shimizu T. Lipid mediators in health and disease: enzymes and receptors as therapeutic targets for the regulation of immunity and inflammation. Annu Rev Pharmacol Toxicol 2009;49: 123-150. https://doi.org/10.1146/annurev.pharmtox.011008.145616.

522. Nomura DK, Morrison BE, Blankman JL, et al. Endocannabinoid hydrolysis generates brain prostaglandins that promote neuroinflammation. Science. 2011;334: 809-813. https://doi.org/10. 1126/science. 1209200.

523. Simmons DL, Botting RM, Hla T. Cyclooxygenase isozymes: the biology of prostaglandin synthesis and inhibition. Pharmacol Rev 2004;56: 387-437. https://doi.org/10.1124/pr.56.3.3.

524. Ricciotti E, FitzGerald GA. Prostaglandins and inflammation. Arterioscler Thromb Vasc Biol 2011;31: 986-1000. https://doi. org/10.1161/ATVBAHA.110.207449.

525. Fuentes AV, Pineda MD, Venkata KCN. Comprehension of top 200 prescribed drugs in the US as a resource for pharmacy teaching, training and practice. Pharmacy (Basel) 2018;6. https://doi. org/10.3390/pharmacy6020043.

526. Akgul O, Di Cesare Mannelli L, Vullo D, et al. Discovery of novel nonsteroidal anti-inflammatory drugs and carbonic anhydrase inhibitors hybrids (NSAIDs-CAIs) for the management of rheumatoid arthritis. J Med Chem 2018;61: 4961-4977. https://doi.org/ 10.1021/acs.jmedchem.8b00420.

527. Gerstmeier J, Newcomer ME, Dennhardt S, et al. 5-Lipoxygenaseactivating protein rescues activity of 5-lipoxygenase mutations that delay nuclear membrane association and disrupt product formation. FASEB J. 2016;30: 1892-1900. https://doi.org/10.1096/ fj.201500210R.

528. Sampson AP. FLAP inhibitors for the treatment of inflammatory diseases. Curr Opin Investig Drugs 2009;10: 1163-1172.

529. Boileau C, Martel-Pelletier J, Jouzeau J-Y, et al. Licofelone (ML3000), a dual inhibitor of 5-lipoxygenase and cyclooxygenase, reduces the level of cartilage chondrocyte death in vivo in experimental dog osteoarthritis: inhibition of pro-apoptotic factors. J Rheumatol 2002;29: 1446-1453.

530. deCODE genetics, Henry Ford Health System, Duke University. Veliflapon (DG-031) to prevent heart attacks or stroke in patients with a history of heart attack or unstable angina. 2006. https:// ClinicalTrials.gov/show/NCT00353067.

531. Diamant Z, Timmers MC, van der Veen H, et al. The effect of MK-0591, a novel 5-lipoxygenase activating protein inhibitor, on leukotriene biosynthesis and allergen-induced airway responses in asthmatic subjects in vivo. J Allergy Clin Immunol 1995;95: 4251. https://doi.org/10.1016/s0091-6749(95)70151-6.

532. Chaudhuri R, Norris V, Kelly K, et al. Effects of a FLAP inhibitor, GSK2190915, in asthmatics with high sputum neutrophils. Pulm Pharmacol Ther 2014;27: 62-69. https://doi.org/10.1016/j.pupt. 2013.11.007.

533. Levy RM, Khokhlov A, Kopenkin S, et al. Efficacy and safety of flavocoxid, a novel therapeutic, compared with naproxen: a randomized multicenter controlled trial in subjects with osteoarthritis of the knee. Adv Ther 2010;27: 731-742. https://doi.org/10.1007/ s12325-010-0064-z.

534. Matsumoto S, Ibrahim R, Grégoire JC, et al. Effect of treatment with 5-lipoxygenase inhibitor VIA-2291 (atreleuton) on coronary plaque progression: a serial CT angiography study. Clin Cardiol 2017;40: 210-215. https://doi.org/10.1002/clc.22646.

535. Garscha U, Romp E, Pace S, et al. Pharmacological profile and efficiency in vivo of diflapolin, the first dual inhibitor of 5lipoxygenase-activating protein and soluble epoxide hydrolase. Sci Rep 2017;7: 9398. https://doi.org/10.1038/s41598-01709795-w. 
536. Yokomizo T. Leukotriene B4 receptors: novel roles in immunological regulations. Adv Enzyme Regul 2011;51: 59-64. https:// doi.org/10.1016/j.advenzreg.2010.08.002.

537. Bisgaard H, Kristensen JK. Leukotriene B4 produces hyperalgesia in humans. Prostaglandins. 1985;30: 791-797. https://doi.org/10. 1016/0090-6980(85)90007-3.

538. Zinn S, Sisignano M, Kern K, et al. The leukotriene B4 receptors BLT1 and BLT2 form an antagonistic sensitizing system in peripheral sensory neurons. J Biol Chem 2017;292: 6123-6134. https://doi.org/10.1074/jbc.M116.769125.

539. Kihara Y, Mizuno H, Chun J. Lysophospholipid receptors in drug discovery. Exp Cell Res 2015;333: 171-177. https://doi.org/10. 1016/j.yexcr.2014.11.020.

540. Juárez-Contreras R, Rosenbaum T, Morales-Lázaro SL. Lysophosphatidic acid and ion channels as molecular mediators of pain. Front Mol Neurosci 2018;11: 462. https://doi.org/10. 3389/fnmol.2018.00462.

541. Makide K, Uwamizu A, Shinjo Y, et al. Novel lysophosphoplipid receptors: their structure and function. J Lipid Res 2014;55: 19861995. https://doi.org/10.1194/jlr.R046920.

542. Inoue M, Rashid MH, Fujita R, Contos JJA, Chun J, Ueda H. Initiation of neuropathic pain requires lysophosphatidic acid receptor signaling. Nat Med 2004;10: 712-718. https://doi.org/10. 1038/nm1060.

543. Kuwajima K, Sumitani M, Kurano M, et al. Lysophosphatidic acid is associated with neuropathic pain intensity in humans: an exploratory study. PLoS One 2018;13. https://doi.org/10.1371/ journal.pone.0207310.

544. Kremer AE, Martens JJWW, Kulik W, et al. Lysophosphatidic acid is a potential mediator of cholestatic pruritus. Gastroenterology. 2010;139: 1008-1018, 1018.e1. https://doi. org/10.1053/j.gastro.2010.05.009.

545. Kittaka H, Uchida K, Fukuta N, Tominaga M. Lysophosphatidic acid-induced itch is mediated by signalling of LPA5 receptor, phospholipase D and TRPA1/TRPV1. J Physiol (Lond). 2017;595: 2681-2698. https://doi.org/10.1113/JP273961.

546. Robering JW, Gebhardt L, Wolf K, Kühn H, Kremer AE, Fischer MJM. Lysophosphatidic acid activates satellite glia cells and Schwann cells. Glia. 2019;67: 999-1012. https://doi.org/10. 1002/glia.23585.

547. Allanore Y, Distler O, Jagerschmidt A, et al. lysophosphatidic acid receptor 1 antagonist SAR100842 for patients with diffuse cutaneous systemic sclerosis: a double-blind, randomized, eight-week placebo-controlled study followed by a sixteen-week open-label extension study, Arthritis Rheumatol (Hoboken, NJ) 2018;70: 1634-1643. https://doi.org/10.1002/art.40547.

548. Palmer SM, Snyder L, Todd JL, et al. Randomized, double-blind, placebo-controlled, phase 2 trial of BMS-986020, a lysophosphatidic acid receptor antagonist for the treatment of idiopathic pulmonary fibrosis. Chest. 2018;154: 1061-1069. https:// doi.org/10.1016/j.chest.2018.08.1058.

549. Aggarwal BB, Gupta SC, Kim JH. Historical perspectives on tumor necrosis factor and its superfamily: 25 years later, a golden journey. Blood. 2012;119: 651-665. https://doi.org/10.1182/ blood-2011-04-325225.

550. Li Y, Ji A, Weihe E, Schäfer MK-H. Cell-specific expression and lipopolysaccharide-induced regulation of tumor necrosis factor $\alpha$ $(\mathrm{TNF} \alpha)$ and TNF receptors in rat dorsal root ganglion. J Neurosci 2004;24: 9623-9631. https://doi.org/10.1523/JNEUROSCI.239204.2004.

551. Russell FA, Fernandes ES, Courade J-P, Keeble JE, Brain SD. Tumour necrosis factor alpha mediates transient receptor potential vanilloid 1-dependent bilateral thermal hyperalgesia with distinct peripheral roles of interleukin-1beta, protein kinase $\mathrm{C}$ and cyclooxygenase-2 signalling. Pain. 2009;142: 264-274. https:// doi.org/10.1016/j.pain.2009.01.021.
552. Ferreira J, Trichês KM, Medeiros R, Calixto JB. Mechanisms involved in the nociception produced by peripheral protein kinase c activation in mice. Pain. 2005;117: 171-181. https://doi.org/10. 1016/j.pain.2005.06.001.

553. Olszewski MB, Groot AJ, Dastych J, Knol EF. TNF trafficking to human mast cell granules: mature chain-dependent endocytosis. J Immunol 2007;178: 5701-5709. https://doi.org/10.4049/ jimmunol.178.9.5701.

554. Gahring LC, Carlson NG, Kulmar RA, Rogers SW. Neuronal expression of tumor necrosis factor alpha in the murine brain. Neuroimmunomodulation. 1996;3: 289-303. https://doi.org/10. 1159/000097283.

555. Yang S, Xie C, Chen Y, et al. Differential roles of TNF $\alpha$-TNFR1 and TNF $\alpha$-TNFR2 in the differentiation and function of CD4+ Foxp3+ induced Treg cells in vitro and in vivo periphery in autoimmune diseases. Cell Death Dis 2019;10: 27. https://doi.org/10. 1038/s41419-018-1266-6.

556. Parada CA, Yeh JJ, Joseph EK, Levine JD. Tumor necrosis factor receptor type-1 in sensory neurons contributes to induction of chronic enhancement of inflammatory hyperalgesia in rat. Eur J Neurosci 2003;17: 1847-1852. https://doi.org/10.1046/j.14609568.2003.02626.x.

557. Melsheimer R, Geldhof A, Apaolaza I, Schaible T. Remicade ${ }^{\circledR}$ (infliximab): 20 years of contributions to science and medicine. Biologics. 2019;13: 139-178. https://doi.org/10.2147/BTT. S207246.

558. Tracey D, Klareskog L, Sasso EH, Salfeld JG, Tak PP. Tumor necrosis factor antagonist mechanisms of action: a comprehensive review. Pharmacol Ther 2008;117: 244-279. https://doi.org/10. 1016/j.pharmthera.2007.10.001.

559. Lis K, Kuzawińska O, Bałkowiec-Iskra E. Tumor necrosis factor inhibitors - state of knowledge. Arch Med Sci 2014;10: 11751185. https://doi.org/10.5114/aoms.2014.47827.

560. Cohen SP, Bogduk N, Dragovich A, et al. Randomized, doubleblind, placebo-controlled, dose-response, and preclinical safety study of transforaminal epidural etanercept for the treatment of sciatica. Anesthesiology. 2009;110: 1116-1126. https://doi.org/ 10.1097/ALN.0b013e3181a05aa0.

561. Korhonen T, Karppinen J, Paimela L, et al. The treatment of discherniation-induced sciatica with infliximab: one-year follow-up results of FIRST II, a randomized controlled trial. Spine. 2006;31: 2759-2766. https://doi.org/10.1097/01.brs. 0000245873.23876.1e.

562. Cohen SP, White RL, Kurihara C, et al. Epidural steroids, etanercept, or saline in subacute sciatica: a multicenter, randomized trial, Ann Intern Med 2012;156: 551-559. https://doi.org/10. 7326/0003-4819-156-8-201204170-00002.

563. Pimentel DC, El Abd O, Benyamin RM, et al. Anti-tumor necrosis factor antagonists in the treatment of low back pain and radiculopathy: a systematic review and meta-analysis. Pain Physician 2014;17: E27-44.

564. Ma Z, Liu X, Xu X, et al. Safety of tumor necrosis factor-alpha inhibitors for treatment of ankylosing spondylitis: a meta-analysis. Medicine (Baltimore) 2017;96: e7145. https://doi.org/10.1097/ MD.0000000000007145.

565. Ceppa EP, Lyo V, Grady EF, et al. Serine proteases mediate inflammatory pain in acute pancreatitis. Am J Physiol Gastrointest Liver Physiol 2011;300: G1033-1042. https://doi.org/10.1152/ ajpgi.00305.2010.

566. Hoogerwerf WA, Shenoy M, Winston JH, Xiao S-Y, He Z, Pasricha PJ. Trypsin mediates nociception via the proteinaseactivated receptor 2: a potentially novel role in pancreatic pain. Gastroenterology. 2004;127: 883-891. https://doi.org/10.1053/j. gastro.2004.07.002.

567. Zhu J, Miao X-R, Tao K-M, et al. Trypsin-protease activated receptor-2 signaling contributes to pancreatic cancer pain. 
Oncotarget. 2017;8: 61810-61823. https://doi.org/10.18632/ oncotarget.18696.

568. Lam DK, Schmidt BL. Serine proteases and protease-activated receptor 2-dependent allodynia: a novel cancer pain pathway. Pain. 2010;149: 263-272. https://doi.org/10.1016/j.pain.2010.02. 010.

569. Poole DP, Amadesi S, Veldhuis NA, et al. Protease-activated receptor 2 (PAR2) protein and transient receptor potential vanilloid 4 (TRPV4) protein coupling is required for sustained inflammatory signaling. J Biol Chem 2013;288: 5790-5802. https://doi.org/ 10.1074/jbc.M112.438184.

570. Hassler SN, Kume M, Mwirigi J, et al. The cellular basis of protease activated receptor type 2 (PAR2) evoked mechanical and affective pain. JCI Insight 2020. https://doi.org/10.1172/jci. insight.137393.

571. Kwong K, Nassenstein C, de Garavilla L, Meeker S, Undem BJ. Thrombin and trypsin directly activate vagal $\mathrm{C}$-fibres in mouse lung via protease-activated receptor-1. J Physiol (Lond) 2010;588: 1171-1177. https://doi.org/10.1113/jphysiol.2009. 181669.

572. Bali KK, Kuner R. Therapeutic potential for leukocyte elastase in chronic pain states harboring a neuropathic component. Pain. 2017;158: 2243-2258. https://doi.org/10.1097/j.pain. 0000000000001032 .

573. Euler USV, Gaddum JH. An unidentified depressor substance in certain tissue extracts. J Physiol 1931;72: 74-87. https://doi.org/ 10.1113/jphysiol.1931.sp002763.

574. Chang MM, Leeman SE, Niall HD. Amino-acid sequence of substance P. Nat New Biol 1971;232: 86-87. https://doi.org/10.1038/ newbio232086a0.

575. Iversen L. Substance P equals pain substance? Nature. 1998;392: 334-335. https://doi.org/10.1038/32776.

576. Mantyh PW. Substance P and the inflammatory and immune response. Ann N Y Acad Sci. 1991;632: 263-271. https://doi.org/ 10.1111/j.1749-6632.1991.tb33114.x.

577. O'Connor TM, O'Connell J, O’Brien DI, Goode T, Bredin CP, Shanahan $\mathrm{F}$. The role of substance $\mathrm{P}$ in inflammatory disease. $\mathrm{J}$ Cell Physiol 2004;201: 167-180. https://doi.org/10.1002/jcp. 20061.

578. Purkiss J, Welch M, Doward S, Foster K. Capsaicin-stimulated release of substance $\mathrm{P}$ from cultured dorsal root ganglion neurons: involvement of two distinct mechanisms. Biochem Pharmacol 2000;59: 1403-1406. https://doi.org/10.1016/S0006-2952(00) 00260-4.

579. Sahbaie P, Shi X, Guo T-Z, et al. Role of substance P signaling in enhanced nociceptive sensitization and local cytokine production after incision. Pain. 2009;145: 341-349. https://doi.org/10.1016/j. pain.2009.06.037.

580. Suvas S. Role of substance P neuropeptide in inflammation, wound healing and tissue homeostasis. J Immunol 2017;199: 1543-1552. https://doi.org/10.4049/jimmunol.1601751.

581. Zhang H, Cang C-L, Kawasaki Y, et al. Neurokinin-1 receptor enhances TRPV1 activity in primary sensory neurons via PKC : a novel pathway for heat hyperalgesia. J Neurosci 2007;27: 12067-12077. https://doi.org/10.1523/JNEUROSCI.0496-07. 2007.

582. dos Santos LV, Souza FH, Brunetto AT, Sasse AD, da Silveira Nogueira Lima JP. Neurokinin-1 receptor antagonists for chemotherapy-induced nausea and vomiting: a systematic review. J Natl Cancer Inst 2012;104: 1280-1292. https://doi.org/10.1093/ jnci/djs335.

583. Duffy RA. Potential therapeutic targets for neurokinin-1 receptor antagonists. Expert Opin Emerg Drugs 2004;9: 9-21. https://doi. org/10.1517/eoed.9.1.9.32956.
584. Goldstein DJ, Offen WW, Klein EG, et al. Lanepitant, an NK-1 antagonist, in migraine prevention. Cephalalgia. 2001;21: 102106. https://doi.org/10.1046/j.1468-2982.2001.00161.x.

585. Goldstein DJ, Wang O, Saper JR, Stoltz R, Silberstein SD, Mathew NT. Ineffectiveness of neurokinin-1 antagonist in acute migraine: a crossover study. Cephalalgia. 1997;17: 785-790. https://doi.org/10.1046/j.1468-2982.1997.1707785.x.

586. Hill R. NK1 (substance P) receptor antagonists - why are they not analgesic in humans? Trends Pharmacol Sci 2000;21: 244-246. https://doi.org/10.1016/S0165-6147(00)01502-9.

587. Wimalawansa SJ. Amylin, calcitonin gene-related peptide, calcitonin, and adrenomedullin: a peptide superfamily. Crit Rev Neurobiol 1997;11: 167-239. https://doi.org/10.1615/ critrevneurobiol.v11.i2-3.40.

588. Charles A, Pozo-Rosich P. Targeting calcitonin gene-related peptide: a new era in migraine therapy. Lancet. 2019;394: 1765-1774. https://doi.org/10.1016/S0140-6736(19)32504-8.

589. Storer RJ, Akerman S, Goadsby PJ. Calcitonin gene-related peptide (CGRP) modulates nociceptive trigeminovascular transmission in the cat. Br J Pharmacol 2004;142: 1171-1181. https:// doi.org/10.1038/sj.bjp.0705807.

590. Fischer MJM, Koulchitsky S, Messlinger K. The nonpeptide calcitonin gene-related peptide receptor antagonist BIBN4096BS lowers the activity of neurons with meningeal input in the rat spinal trigeminal nucleus. J Neurosci 2005;25: 5877-5883. https://doi.org/10.1523/JNEUROSCI.0869-05.2005.

591. Avona A, Burgos-Vega C, Burton MD, Akopian AN, Price TJ, Dussor G. Dural calcitonin gene-related peptide produces femalespecific responses in rodent migraine models. J Neurosci 2019;39: 4323-4331. https://doi.org/10.1523/JNEUROSCI.0364-19.2019.

592. Kroeger I, Erhardt A, Abt D, et al. The neuropeptide calcitonin gene-related peptide (CGRP) prevents inflammatory liver injury in mice. J Hepatol 2009;51: 342-353. https://doi.org/10.1016/j.jhep. 2009.03.022

593. Holland PR, Goadsby PJ. Targeted CGRP small molecule antagonists for acute migraine therapy. Neurotherapeutics. 2018;15: 304-312. https://doi.org/10.1007/s13311-018-0617-4.

594. Levy D, Burstein R, Strassman AM. Calcitonin gene-related peptide does not excite or sensitize meningeal nociceptors: implications for the pathophysiology of migraine. Ann Neurol 2005;58: 698-705. https://doi.org/10.1002/ana.20619.

595. Lennerz JK, Rühle V, Ceppa EP, et al. Calcitonin receptor-like receptor (CLR), receptor activity-modifying protein 1 (RAMP1), and calcitonin gene-related peptide (CGRP) immunoreactivity in the rat trigeminovascular system: differences between peripheral and central CGRP receptor distribution. J Comp Neurol 2008;507: 1277-1299. https://doi.org/10.1002/cne.21607.

596. Sixt M-L, Messlinger K, Fischer MJM. Calcitonin gene-related peptide receptor antagonist olcegepant acts in the spinal trigeminal nucleus. Brain. 2009;132: 3134-3141. https://doi.org/10.1093/ brain/awp168.

597. Menkin V. Biology of inflammation; chemical mediators and cellular injury. Science. 1956;123: 527-534. https://doi.org/10.1126/ science.123.3196.527.

598. van Zwieten R, Wever R, Hamers MN, Weening RS, Roos D. Extracellular proton release by stimulated neutrophils. J Clin Invest 1981;68: 310-313. https://doi.org/10.1172/jci110250.

599. Bellocq A, Suberville S, Philippe C, et al. Low environmental pH is responsible for the induction of nitric-oxide synthase in macrophages. Evidence for involvement of nuclear factor-kappaB activation. J Biol Chem 1998;273: 5086-5092. https://doi.org/10. 1074/jbc.273.9.5086.

600. Rajamäki K, Nordström T, Nurmi K, et al. Extracellular acidosis is a novel danger signal alerting innate immunity via the NLRP3 inflammasome. J Biol Chem 2013;288: 13410-13419. https:// doi.org/10.1074/jbc.M112.426254. 
601. Hellwig N, Plant TD, Janson W, Schäfer M, Schultz G, Schaefer M. TRPV1 acts as proton channel to induce acidification in nociceptive neurons. J Biol Chem 2020. https://doi.org/10.1074/jbc. M402966200.

602. Dhaka A, Uzzell V, Dubin AE, et al. TRPV1 is activated by both acidic and basic pH. J Neurosci 2009;29: 153-158. https://doi.org/ 10.1523/JNEUROSCI.4901-08.2009.

603. Pattison LA, Callejo G, St John Smith E. Evolution of acid nociception: ion channels and receptors for detecting acid. Philos Trans R Soc B Biol Sci 2019;374: 20190291. https://doi. org/10.1098/rstb.2019.0291.

604. Diochot S, Baron A, Salinas M, et al. Black mamba venom peptides target acid-sensing ion channels to abolish pain. Nature. 2012;490: 552-555. https://doi.org/10.1038/nature11494.

605. Brzezicki MA, Zakowicz PT. Mambalgins, the venom-origin peptides as a potentially novel group of analgesics: mini review. CNS Neurol Disord Drug Targets 2018;17: 87-97. https://doi.org/10. 2174/1871527317666171221110419.

606. Tang BL. ADAMTS: a novel family of extracellular matrix proteases. Int J Biochem Cell Biol 2001;33: 33-44. https://doi.org/10. 1016/s1357-2725(00)00061-3.

607. Porter S, Clark IM, Kevorkian L, Edwards DR. The ADAMTS metalloproteinases. Biochem J 2005;386: 15-27. https://doi.org/ 10.1042/BJ20040424.

608. Dancevic CM, McCulloch DR. Current and emerging therapeutic strategies for preventing inflammation and aggrecanase-mediated cartilage destruction in arthritis. Arthritis Res Ther 2014;16. https://doi.org/10.1186/s13075-014-0429-9.

609. Little CB, Meeker CT, Golub SB, et al. Blocking aggrecanase cleavage in the aggrecan interglobular domain abrogates cartilage erosion and promotes cartilage repair. J Clin Invest 2007;117: 1627-1636. https://doi.org/10.1172/JCI30765.

610. Mead TJ, Apte SS. ADAMTS proteins in human disorders. Matrix Biol 2018;71-72: 225-239. https://doi.org/10.1016/j.matbio. 2018.06.002

611. Kashiwagi M, Tortorella M, Nagase H, Brew K. TIMP-3 is a potent inhibitor of aggrecanase 1 (ADAM-TS4) and aggrecanase 2 (ADAM-TS5). J Biol Chem 2001;276: 12501-12504. https:// doi.org/10.1074/jbc.C000848200.

612. He M, Pang J, Sun H, Zheng G, Lin Y, Ge W. Overexpression of TIMP3 inhibits discogenic pain by suppressing angiogenesis and the expression of substance $\mathrm{P}$ in nucleus pulposus. Mol Med Rep 2020;21: 1163-1171. https://doi.org/10.3892/mmr.2020.10922.

613. Wozniak KM, Rojas C, Wu Y, Slusher BS. The role of glutamate signaling in pain processes and its regulation by GCP II inhibition. Curr Med Chem 2012;19: 1323-1334. https://doi.org/10.2174/ 092986712799462630

614. Bacich DJ, Wozniak KM, Lu X-CM, et al. Mice lacking glutamate carboxypeptidase II are protected from peripheral neuropathy and ischemic brain injury. J Neurochem 2005;95: 314-323. https:// doi.org/10.1111/j.1471-4159.2005.03361.x.

615. Rais R, Vávra J, Tichý T, et al. Discovery of a para-acetoxybenzyl ester prodrug of a hydroxamate-based glutamate carboxypeptidase ii inhibitor as oral therapy for neuropathic pain. J Med Chem 2017;60: 7799-7809. https://doi.org/10.1021/acs. jmedchem. 7b00825.

616. Lieu EL, Nguyen T, Rhyne S, Kim J. Amino acids in cancer. Exp Mol Med 2020;52: 15-30. https://doi.org/10.1038/s12276-0200375-3.

617. Vazquez A, Kamphorst JJ, Markert EK, Schug ZT, Tardito S, Gottlieb E. Cancer metabolism at a glance. J Cell Sci 2016;129: 3367-3373. https://doi.org/10.1242/jcs.181016.

618. Coccurello R, Nazio F, Rossi C, et al. Effects of caloric restriction on neuropathic pain, peripheral nerve degeneration and inflammation in normometabolic and autophagy defective prediabetic
Ambra1 mice. PLoS One 2018;13: e0208596. https://doi.org/10. 1371/journal.pone.0208596.

619. Liu Y, Ni Y, Zhang W, Sun Y-E, Ma Z, Gu X. Antinociceptive effects of caloric restriction on post-incisional pain in nonobese rats. Sci Rep 2017;7: 1805. https://doi.org/10.1038/s41598-01701909-8.

620. Shell WE, Pavlik S, Roth B, et al. Reduction in pain and inflammation associated with chronic low back pain with the use of the medical food theramine. Am J Ther 2016;23: e1353-e1362. https://doi.org/10.1097/MJT.0000000000000068.

621. Kawaguchi Y, Lin J-C, Kawashima Y, et al. Relationship between pain and plasma amino acid levels in chronic pancreatitis. JOP. 2015;16: 53-57. https://doi.org/10.6092/1590-8577/2897.

622. Fazzari J, Singh G. Effect of glutaminase inhibition on cancerinduced bone pain. Breast Cancer (Dove Med Press) 2019;11: 273-282. https://doi.org/10.2147/BCTT.S215655.

623. Boutet M-A, Nerviani A, Pitzalis C. IL-36, IL-37, and IL-38 cytokines in skin and joint inflammation: a comprehensive review of their therapeutic potential. Int J Mol Sci 2019;20. https://doi.org/ 10.3390/ijms20061257.

624. Marrakchi S, Guigue P, Renshaw BR, et al. Interleukin-36receptor antagonist deficiency and generalized pustular psoriasis. N Engl J Med 2011;365: 620-628. https://doi.org/10.1056/ NEJMoa1013068.

625. Su Z, Paulsboe S, Wetter J, et al. IL-36 receptor antagonistic antibodies inhibit inflammatory responses in preclinical models of psoriasiform dermatitis. Exp Dermatol 2019;28: 113-120. https://doi.org/10.1111/exd.13841.

626. van de Veerdonk FL, Stoeckman AK, Wu G, et al. IL-38 binds to the IL-36 receptor and has biological effects on immune cells similar to IL-36 receptor antagonist. Proc Natl Acad Sci U S A 2012;109: 3001-3005. https://doi.org/10.1073/pnas.1121534109.

627. Rudloff I, Godsell J, Nold-Petry CA, et al. Brief report: interleukin-38 exerts antiinflammatory functions and is associated with disease activity in systemic lupus erythematosus, Arthritis Rheumatol (Hoboken, NJ) 2015;67: 3219-3225. https://doi.org/ 10.1002/art.39328.

628. Mora J, Schlemmer A, Wittig I, et al. Interleukin-38 is released from apoptotic cells to limit inflammatory macrophage responses. J Mol Cell Biol 2016;8: 426-438. https://doi.org/10.1093/jmcb/ mjw006.

629. Kopf M, Bachmann MF, Marsland BJ. Averting inflammation by targeting the cytokine environment. Nat Rev Drug Discov 2010;9: 703-718. https://doi.org/10.1038/nrd2805.

630. Lee J-K, Kim S-H, Lewis EC, Azam T, Reznikov LL, Dinarello CA. Differences in signaling pathways by IL-1beta and IL-18. Proc Natl Acad Sci U S A 2004;101: 8815-8820. https://doi.org/ 10.1073/pnas.0402800101.

631. Reznikov LL, Kim S-H, Westcott JY, et al. IL-18 binding protein increases spontaneous and IL-1-induced prostaglandin production via inhibition of IFN- $\gamma$. Proc Natl Acad Sci U S A 2000;97: 2174 2179.

632. Nakamura S, Otani T, Okura R, et al. Expression and responsiveness of human interleukin-18 receptor (IL-18R) on hematopoietic cell lines. Leukemia. 2000;14: 1052-1059. https://doi.org/10. 1038/sj.leu.2401789.

633. Miyoshi K, Obata K, Kondo T, Okamura H, Noguchi K. Interleukin-18-mediated microglia/astrocyte interaction in the spinal cord enhances neuropathic pain processing after nerve injury. J Neurosci 2008;28: 12775-12787. https://doi.org/10.1523/ JNEUROSCI.3512-08.2008.

634. Pilat D, Piotrowska A, Rojewska E, et al. Blockade of IL-18 signaling diminished neuropathic pain and enhanced the efficacy of morphine and buprenorphine. Mol Cell Neurosci 2016;71: 114124. https://doi.org/10.1016/j.mcn.2015.12.013. 
635. Dinarello CA, Novick D, Kim S, Kaplanski G. Interleukin-18 and IL-18 Binding Protein. Front Immunol 2013;4. https://doi.org/10. 3389/fimmu.2013.00289.

636. Kiltz U, Kiefer D, Braun J, Schiffrin EJ, Girard-Guyonvarc'h C, Gabay C. Prolonged treatment with Tadekinig alfa in adult-onset Still's disease. Ann Rheum Dis 2020;79: e10. https://doi.org/10. 1136/annrheumdis-2018-214496.

637. Ding L, Hong X, Sun B, et al. IL-37 is associated with osteoarthritis disease activity and suppresses proinflammatory cytokines production in synovial cells. Sci Rep 2017;7: 1-8. https://doi.org/ 10.1038/s41598-017-11397-5.

638. Bufler P, Azam T, Gamboni-Robertson F, et al. A complex of the IL-1 homologue IL-1F7b and IL-18-binding protein reduces IL-18 activity. Proc Natl Acad Sci U S A 2002;99: 13723-13728. https:// doi.org/10.1073/pnas.212519099.

639. Bai J, Li Y, Li M, Tan S, Wu D. IL-37 as a potential biotherapeutics of inflammatory diseases. Curr Drug Targets 2020. https://doi.org/10.2174/1389450121666200429114926.

640. Fedorak RN, Gangl A, Elson CO, et al. Recombinant human interleukin 10 in the treatment of patients with mild to moderately active Crohn's disease. The Interleukin 10 Inflammatory Bowel Disease Cooperative Study Group. Gastroenterology. 2000;119: 1473-1482. https://doi.org/10.1053/gast.2000.20229.

641. Jia H, Liu J, Han B. Reviews of Interleukin-37: functions, receptors, and roles in diseases, Biomed Res Int 2018;2018: 3058640 . https://doi.org/10.1155/2018/3058640.

642. Schweizerhof M, Stösser S, Kurejova M, et al. Hematopoietic colony-stimulating factors mediate tumor-nerve interactions and bone cancer pain. Nat Med 2009;15: 802-807. https://doi.org/10. 1038/nm.1976.

643. Fukuzono S, Kato T, Fujita H, Watanabe N, Kitagawa S. Granulocyte colony-stimulating factor negatively regulates Tolllike receptor agonist-induced cytokine production in human neutrophils. Arch Biochem Biophys 2010;495: 144-151. https://doi. org/10.1016/j.abb.2010.01.005.

644. Welte K. G-CSF: filgrastim, lenograstim and biosimilars. Expert Opin Biol Ther 2014;14: 983-993. https://doi.org/10.1517/ 14712598.2014 .905537$.

645. Frampton JE, Yarker YE, Goa KL. Lenograstim. A review of its pharmacological properties and therapeutic efficacy in neutropenia and related clinical settings. Drugs. 1995;49: 767-793. https:// doi.org/10.2165/00003495-199549050-00009.

646. Moore DC, Pellegrino AE. Pegfilgrastim-induced bone pain: a review on incidence, risk factors, and evidence-based management. Ann Pharmacother 2017;51: 797-803. https://doi.org/10. $1177 / 1060028017706373$.

647. Basso L, Lapointe TK, Iftinca M, et al. Granulocyte-colony-stimulating factor (G-CSF) signaling in spinal microglia drives visceral sensitization following colitis. Proc Natl Acad Sci U S A 2017;114: 11235-11240. https://doi.org/10.1073/pnas. 1706053114 .

648. CSL Behring. Safety and pharmacokinetics of repeat doses of CSL324 in subjects with hidradenitis suppurativa and palmoplantar pustulosis. 2019. https://ClinicalTrials.gov/show/ NCT03972280.

649. Bhattacharya P, Budnick I, Singh M, et al. Dual role of GM-CSF as a pro-inflammatory and a regulatory cytokine: implications for immune therapy. J Interferon Cytokine Res 2015;35: 585-599. https://doi.org/10.1089/jir.2014.0149.

650. Rosas M, Gordon S, Taylor PR. Characterisation of the expression and function of the GM-CSF receptor alpha-chain in mice. Eur J Immunol 2007;37: 2518-2528. https://doi.org/10.1002/eji. 200636892.

651. Francisco-Cruz A, Aguilar-Santelises M, Ramos-Espinosa O, et al. Granulocyte-macrophage colony-stimulating factor: not just another haematopoietic growth factor. Med Oncol 2014;31: 774. https://doi.org/10.1007/s12032-013-0774-6.

652. Li J, Liu W, Zhang G, Wang D, Lou H, Duang J. Effectiveness of recombinant human granulocyte macrophage colony-stimulating factor for treating deep second-degree burns: a systematic review and meta-analysis. BMJ Mil Health 2020. https://doi.org/10.1136/ bmjmilitary-2019-001395.

653. Cook AD, Pobjoy J, Steidl S, et al. Granulocyte-macrophage colony-stimulating factor is a key mediator in experimental osteoarthritis pain and disease development. Arthritis Res Ther 2012;14: R199. https://doi.org/10.1186/ar4037.

654. Nicol LSC, Thornton P, Hatcher JP, et al. Central inhibition of granulocyte-macrophage colony-stimulating factor is analgesic in experimental neuropathic pain. Pain. 2018;159: 550-559. https:// doi.org/10.1097/j.pain.0000000000001130.

655. Burmester GR, McInnes IB, Kremer J, et al. A randomised phase IIb study of mavrilimumab, a novel GM-CSF receptor alpha monoclonal antibody, in the treatment of rheumatoid arthritis. Ann Rheum Dis 2017;76: 1020-1030. https://doi.org/10.1136/ annrheumdis-2016-210624.

656. Okubo M, Yamanaka H, Kobayashi K, et al. Macrophage-colony stimulating factor derived from injured primary afferent induces proliferation of spinal microglia and neuropathic pain in rats. PLoS One 2016;11. https://doi.org/10.1371/journal.pone. 0153375.

657. Guan Z, Kuhn JA, Wang X, et al. Injured sensory neuron-derived CSF1 induces microglial proliferation and DAP12-dependent pain. Nat Neurosci 2016;19: 94-101. https://doi.org/10.1038/nn. 4189.

658. Trinchieri G. Interleukin-12: a proinflammatory cytokine with immunoregulatory functions that bridge innate resistance and antigen-specific adaptive immunity. Annu Rev Immunol 1995;13: 251-276. https://doi.org/10.1146/annurev.iy.13. 040195.001343.

659. Verri WA, Molina RO, Schivo IRS, et al. Nociceptive effect of subcutaneously injected interleukin-12 is mediated by endothelin (ET) acting on ETB receptors in rats. J Pharmacol Exp Ther 2005;315: 609-615. https://doi.org/10.1124/jpet.105.089409.

660. Mule NK, Singh JN, Shah KU, Gulati A, Sharma SS. Endothelin1 decreases excitability of the dorsal root ganglion neurons via ETB receptor. Mol Neurobiol 2018;55: 4297-4310. https://doi. org/10.1007/s12035-017-0640-1.

661. Hikawa N, Ishikawa Y, Takenaka T. Interleukin-12 p40-homodimer production in sensory dorsal root ganglion neurons. Neuroscience. 2004;129: 75-83. https://doi.org/10.1016/j. neuroscience.2004.07.035.

662. Gollob JA, Mier JW, Veenstra K, et al. Phase I trial of twiceweekly intravenous interleukin 12 in patients with metastatic renal cell cancer or malignant melanoma: ability to maintain IFNgamma induction is associated with clinical response. Clin Cancer Res 2000;6: 1678-1692.

663. Lenzi R, Rosenblum M, Verschraegen C, et al. Phase I study of intraperitoneal recombinant human interleukin 12 in patients with Müllerian carcinoma, gastrointestinal primary malignancies, and mesothelioma. Clin Cancer Res 2002;8: 3686-3695.

664. Fonseca MM, Davoli-Ferreira M, Santa-Cecília F, et al. IL-27 counteracts neuropathic pain development through induction of IL-10. Front Immunol 2019;10: 3059. https://doi.org/10.3389/ fimmu.2019.03059.

665. Sasaguri T, Taguchi T, Murata Y, et al. Interleukin-27 controls basal pain threshold in physiological and pathological conditions. Sci Rep 2018;8: 1-13. https://doi.org/10.1038/s41598-01829398-3.

666. Duffy SS, Keating BA, Perera CJ, et al. Regulatory T cells and their derived cytokine, interleukin-35, reduce pain in experimental 
autoimmune encephalomyelitis. J Neurosci 2019;39: 2326-2346. https://doi.org/10.1523/JNEUROSCI.1815-18.2019.

667. Jiang Y, Wang J, Li H, Xia L. IL-35 alleviates inflammation progression in a rat model of diabetic neuropathic pain via inhibition of JNK signaling. J Inflamm (Lond) 2019;16: 19. https://doi. org/10.1186/s12950-019-0217-z.

668. Jiang Y, Wang J, Li H, Xia L. IL-35 promotes microglial M2 polarization in a rat model of diabetic neuropathic pain. Arch Biochem Biophys 2020;685: 108330. https://doi.org/10.1016/j. abb.2020.108330.

669. Lowes MA, Russell CB, Martin DA, Towne JE, Krueger JG. The IL-23/T17 pathogenic axis in psoriasis is amplified by keratinocyte responses. Trends Immunol 2013;34: 174-181. https://doi.org/10.1016/j.it.2012.11.005.

670. Riol-Blanco L, Ordovas-Montanes J, Perro M, et al. Nociceptive sensory neurons drive interleukin-23-mediated psoriasiform skin inflammation. Nature. 2014;510: 157-161. https://doi.org/10. 1038/nature13199.

671. Barragán-Iglesias P, Franco-Enzástiga Ú, Jeevakumar V, et al. Type I interferons act directly on nociceptors to produce pain sensitization: implications for viral infection-induced pain. $\mathrm{J}$ Neurosci 2020;40: 3517-3532. https://doi.org/10.1523/ JNEUROSCI.3055-19.2020.

672. Neumann H, Schmidt H, Wilharm E, Behrens L, Wekerle H. Interferon gamma gene expression in sensory neurons: evidence for autocrine gene regulation. J Exp Med 1997;186: 2023-2031. https://doi.org/10.1084/jem.186.12.2023.

673. Schroder K, Hertzog PJ, Ravasi T, Hume DA. Interferon-gamma: an overview of signals, mechanisms and functions. J Leukoc Biol 2004;75: 163-189. https://doi.org/10.1189/jlb.0603252.

674. Robertson B, Xu XJ, Hao JX, et al. Interferon-gamma receptors in nociceptive pathways: role in neuropathic pain-related behaviour. Neuroreport. 1997;8: 1311-1316. https://doi.org/10.1097/ 00001756-199703240-00050

675. Racz I, Nadal X, Alferink J, et al. Interferon-gamma is a critical modulator of $\mathrm{CB}(2)$ cannabinoid receptor signaling during neuropathic pain. J Neurosci 2008;28: 12136-12145. https://doi.org/10. 1523/JNEUROSCI.3402-08.2008.

676. Al-Salama ZT. Emapalumab: first global approval. Drugs. 2019;79: 99-103. https://doi.org/10.1007/s40265-018-1046-8.

677. Shouval DS, Ouahed J, Biswas A, et al. Interleukin 10 receptor signaling: master regulator of intestinal mucosal homeostasis in mice and humans: Adv Immunol 2014;122: 177-210. https://doi. org/10.1016/B978-0-12-800267-4.00005-5.

678. Rahimi AAR, Gee K, Mishra S, Lim W, Kumar A. STAT-1 mediates the stimulatory effect of IL-10 on CD14 expression in human monocytic cells. J Immunol 2005;174: 7823-7832. https:// doi.org/10.4049/jimmunol.174.12.7823.

679. Riley JK, Takeda K, Akira S, Schreiber RD. Interleukin-10 receptor signaling through the JAK-STAT pathway. Requirement for two distinct receptor-derived signals for anti-inflammatory action. J Biol Chem 1999;274: 16513-16521. https://doi.org/10.1074/jbc. 274.23.16513.

680. Asadullah K, Sterry W, Volk HD. Interleukin-10 therapy-review of a new approach. Pharmacol Rev 2003;55: 241-269. https://doi. org/10.1124/pr.55.2.4

681. Lauw FN, Pajkrt D, Hack CE, Kurimoto M, van Deventer SJ, van der Poll T. Proinflammatory effects of IL-10 during human endotoxemia. J Immunol 2000;165: 2783-2789. https://doi.org/ 10.4049/jimmunol.165.5.2783.

682. Moore KW, de Waal Malefyt R, Coffman RL, O'Garra A. Interleukin-10 and the interleukin-10 receptor. Annu Rev Immunol 2001;19: 683-765. https://doi.org/10.1146/annurev. immunol.19.1.683.

683. Griffith JW, Sokol CL, Luster AD. Chemokines and chemokine receptors: positioning cells for host defense and immunity. Annu
Rev Immunol 2014;32: 659-702. https://doi.org/10.1146/ annurev-immunol-032713-120145.

684. Zhang Z-J, Jiang B-C, Gao Y-J. Chemokines in neuron-glial cell interaction and pathogenesis of neuropathic pain. Cell Mol Life Sci 2017;74: 3275-3291. https://doi.org/10.1007/s00018-0172513-1.

685. Oh SB, Tran PB, Gillard SE, Hurley RW, Hammond DL, Miller RJ. Chemokines and glycoprotein 120 produce pain hypersensitivity by directly exciting primary nociceptive neurons. J Neurosci 2001;21: 5027-5035. https://doi.org/10.1523/JNEUROSCI.2114-05027.2001.

686. Jones DP, Sies H. The redox code. Antioxid Redox Signal 2015;23: 734-746. https://doi.org/10.1089/ars.2015.6247.

687. Cortese-Krott MM, Koning A, Kuhnle GGC, et al. The reactive species interactome: evolutionary emergence, biological significance, and opportunities for redox metabolomics and personalized medicine. Antioxid Redox Signal 2017;27: 684-712. https://doi. org/10.1089/ars.2017.7083.

688. Kuppusamy P, Zweier JL. Characterization of free radical generation by xanthine oxidase. Evidence for hydroxyl radical generation. J Biol Chem 1989;264: 9880-9884.

689. Phaniendra A, Jestadi DB, Periyasamy L. Free radicals: properties, sources, targets, and their implication in various diseases. Indian J Clin Biochem 2015;30: 11-26. https://doi.org/10.1007/s12291014-0446-0.

690. Panday A, Sahoo MK, Osorio D, Batra S. NADPH oxidases: an overview from structure to innate immunity-associated pathologies. Cell Mol Immunol 2015;12: 5-23. https://doi.org/10.1038/ cmi.2014.89.

691. Clichici S, Filip A, Daicoviciu D, et al. The dynamics of reactive oxygen species in photodynamic therapy with tetra sulfophenylporphyrin. Acta Physiol Hung 2010;97: 41-51. https://doi.org/10. 1556/APhysiol.97.2010.1.5.

692. Hill K, Schaefer M. Ultraviolet light and photosensitising agents activate TRPA1 via generation of oxidative stress. Cell Calcium 2009;45: 155-164. https://doi.org/10.1016/j.ceca.2008.08.001.

693. Loscalzo J. The identification of nitric oxide as endotheliumderived relaxing factor. Circ Res 2013;113: 100-103. https://doi. org/10.1161/CIRCRESAHA.113.301577.

694. Bogdan C. Nitric oxide synthase in innate and adaptive immunity: an update. Trends Immunol 2015;36: 161-178. https://doi.org/10. 1016/j.it.2015.01.003.

695. Opländer C, Suschek CV. The role of photolabile dermal nitric oxide derivates in ultraviolet radiation (UVR)-induced cell death. Int J Mol Sci 2012;14: 191-204. https://doi.org/10.3390/ ijms14010191.

696. Page AJ, O’Donnell TA, Cooper NJ, Young RL, Blackshaw LA. Nitric oxide as an endogenous peripheral modulator of visceral sensory neuronal function. J Neurosci 2009;29: 7246-7255. https://doi.org/10.1523/JNEUROSCI.6099-08.2009.

697. Qian Y, Chao DS, Santillano DR, et al. cGMP-dependent protein kinase in dorsal root ganglion: relationship with nitric oxide synthase and nociceptive neurons. J Neurosci 1996;16: 3130-3138. https://doi.org/10.1523/JNEUROSCI.16-10-03130.1996.

698. Lawand NB, Willis WD, Westlund KN. Blockade of joint inflammation and secondary hyperalgesia by L-NAME, a nitric oxide synthase inhibitor. Neuroreport. 1997;8: 895-899. https://doi.org/ 10.1097/00001756-199703030-00016.

699. Garthwaite J. Concepts of neural nitric oxide-mediated transmission. Eur J Neurosci 2008;27: 2783-2802. https://doi.org/10. 1111/j.1460-9568.2008.06285.x.

700. Meller ST, Gebhart GF. Nitric oxide (NO) and nociceptive processing in the spinal cord. Pain. 1993;52: 127-136. https://doi.org/ 10.1016/0304-3959(93)90124-8. 
701. Holthusen H, Arndt JO. Nitric oxide evokes pain in humans on intracutaneous injection. Neurosci Lett 1994;165: 71-74. https:// doi.org/10.1016/0304-3940(94)90712-9.

702. Miyamoto T, Dubin AE, Petrus MJ, Patapoutian A. TRPV1 and TRPA1 mediate peripheral nitric oxide-induced nociception in mice. PLoS One 2009;4: e7596. https://doi.org/10.1371/journal. pone. 0007596.

703. Wild V, Messlinger K, Fischer MJM. Hydrogen sulfide determines HNO-induced stimulation of trigeminal afferents. Neurosci Lett 2015;602: 104-109. https://doi.org/10.1016/j. neulet.2015.06.056.

704. Eberhardt M, Dux M, Namer B, et al. H2S and NO cooperatively regulate vascular tone by activating a neuroendocrine HNOTRPA1-CGRP signalling pathway. Nat Commun 2014;5: 4381. https://doi.org/10.1038/ncomms5381.

705. Hess DT, Matsumoto A, Kim S-O, Marshall HE, Stamler JS. Protein S-nitrosylation: purview and parameters. Nat Rev Mol Cell Biol 2005;6: 150-166. https://doi.org/10.1038/nrm1569.

706. Franchi L, Eigenbrod T, Muñoz-Planillo R, Nuñez G. The inflammasome: a caspase-1-activation platform that regulates immune responses and disease pathogenesis. Nat Immunol 2009;10: 241-247. https://doi.org/10.1038/ni.1703.

707. Kelley N, Jeltema D, Duan Y, He Y. The NLRP3 inflammasome: an overview of mechanisms of activation and regulation. Int J Mol Sci 2019;20. https://doi.org/10.3390/ijms20133328.

708. He W, Long T, Pan Q, et al. Microglial NLRP3 inflammasome activation mediates IL- $1 \beta$ release and contributes to central sensitization in a recurrent nitroglycerin-induced migraine model. J Neuroinflammation 2019;16: 78. https://doi.org/10.1186/s12974019-1459-7.

709. Zhang H, Li F, Li W-W, et al. The inflammasome as a target for pain therapy. Br J Anaesth 2016;117: 693-707. https://doi.org/10. 1093/bja/aew376.

710. Swanson KV, Deng M, Ting JP-Y. The NLRP3 inflammasome: molecular activation and regulation to therapeutics. Nat Rev
Immunol 2019;19: 477-489. https://doi.org/10.1038/s41577019-0165-0.

711. Huang Y, Jiang H, Chen Y, et al. Tranilast directly targets NLRP3 to treat inflammasome-driven diseases. EMBO Mol Med 2018;10. https://doi.org/10.15252/emmm.201708689.

712. Sugaya K, Nishijima S, Kadekawa K, Ashitomi K, Ueda T, Yamamoto H. Naftopidil improves symptoms in a rat model of tranilast-induced interstitial cystitis. Low Urin Tract Symptoms 2017;9: 107-110. https://doi.org/10.1111/luts.12113.

713. Chandrabalan A, McPhillie MJ, Morice AH, Boa AN, Sadofsky LR. N-Cinnamoylanthranilates as human TRPA1 modulators: Structure-activity relationships and channel binding sites. Eur J Med Chem 2019;170: 141-156. https://doi.org/10.1016/j. ejmech.2019.02.074.

714. Coll RC, Hill JR, Day CJ, et al. MCC950 directly targets the NLRP3 ATP-hydrolysis motif for inflammasome inhibition. Nat Chem Biol 2019;15: 556-559. https://doi.org/10.1038/s41589019-0277-7.

715. Vande Walle L, Stowe IB, Šácha P, et al. MCC950/CRID3 potently targets the NACHT domain of wild-type NLRP3 but not disease-associated mutants for inflammasome inhibition. PLoS Biol 2019;17: e3000354. https://doi.org/10.1371/journal.pbio. 3000354 .

716. Levy M, Thaiss CA, Elinav E. Taming the inflammasome. Nat Med 2015;21: 213-215. https://doi.org/10.1038/nm.3808.

717. Marchetti C, Swartzwelter B, Gamboni F, et al. OLT1177, a $\beta$ sulfonyl nitrile compound, safe in humans, inhibits the NLRP3 inflammasome and reverses the metabolic cost of inflammation. Proc Natl Acad Sci U S A 2018;115: E1530-E1539. https://doi. org/10.1073/pnas.1716095115.

Publisher's Note Springer Nature remains neutral with regard to jurisdictional claims in published maps and institutional affiliations. 